Florida International University FIU Digital Commons

3-5-2014

\title{
Ethnic and American Identity Development: A Developmental Systems Approach
}

Alan Meca

Florida International University, ameca002@fiu.edu

DOI: $10.25148 /$ etd.FI14040806

Follow this and additional works at: https://digitalcommons.fiu.edu/etd

Cart of the Developmental Psychology Commons

\section{Recommended Citation}

Meca, Alan, "Ethnic and American Identity Development: A Developmental Systems Approach" (2014). FIU Electronic Theses and Dissertations. 1123.

https://digitalcommons.fiu.edu/etd/1123

This work is brought to you for free and open access by the University Graduate School at FIU Digital Commons. It has been accepted for inclusion in FIU Electronic Theses and Dissertations by an authorized administrator of FIU Digital Commons. For more information, please contact dcc@fiu.edu. 


\section{FLORIDA INTERNATIONAL UNIVERSITY}

Miami, Florida

\section{ETHNIC AND AMERICAN IDENTITY DEVELOPMENT:}

A DEVELOPMENTAL SYSTEMS APPROACH

A dissertation submitted in partial fulfillment of

the requirements for the degree of

DOCTOR OF PHILOSOPHY

in

PSYCHOLOGY

by

Alan Meca

2014 
To: Dean Kenneth G. Furton

College of Arts and Sciences

This dissertation, written by Alan Meca, and entitled Ethnic and American Identity Development: A Developmental Systems Approach, having been approved in respect to style and intellectual content, is referred to you for judgment.

We have read this dissertation and recommend that it be approved.

$\begin{array}{r}\hline \text { Asia A. Eaton } \\ \hline \text { Mary J. Levitt } \\ \hline \text { Thomas G. Reio } \\ \hline \text { Seth J. Schwartz } \\ \hline \text { Dionne P. Stephens, Major Professor }\end{array}$

Date of Defense: March 5, 2014

The dissertation of Alan Meca is approved.

Dean Kenneth G. Furton College of Arts and Sciences

Dean Lakshmi N. Reddi University Graduate School

Florida International University, 2014 


\section{DEDICATION}

I dedicate this dissertation to both my father, Gaston Meca (1947-2009) and the love of my life, Cynthia Benitez. My father will never have a chance to see my career flourish, however he has been beyond instrumental in sparking it. He forsook his hopes and dreams so that I could live mine. His last wishes will never be forgotten and his memory will forever live imbued in my quest to encourage and promote positive development so others in turn may seek to peer into the depths of the cosmos and the vast vaults of knowledge that awaits humanity. Cynthia, my loving girlfriend, has brought a level of happiness I have never thought possible, rebooting my enthusiasm and love for my research and career. In this sense, this dissertation was written in honor of my past and in the hopes for a better future. 


\section{ACKNOWLEDGMENTS}

This dissertation could not have been possible without the combined and dedicated efforts of Dr. Stephens and Dr. Schwartz. Dr. Stephens has been nothing short of amazing. She adopted me into her lab without hesitation and has guided me through every single step of the way. Dr. Schwartz has dedicated more than enough of his precious time to advancing my career and encouraging me to answer the questions that beckon my curiosity. I would further like to express my sincere gratitude to all the staff at the University of Miami Center for Family Studies who worked towards the collection of the dataset used in this project. Additionally, I have often said that the Ronald E. McNair fellowship showed me the way to the door while the McKnight Fellowship helped me emerge through it.

My sincere gratitude and appreciation extends to both of these programs. To my friends, life would not exist without balance, and in this great adventure, my success would have not been feasible without your assistance in balancing work with leisure - as a reward you are absolved of having to read this 140 page dissertation. To my loving Cynthia and my family, I thank you for putting up with me. Their support, compassion, understanding, and love have been instrumental in allowing me to place education beyond everything else. Finally, I would like to thank my extended family, my two annoying and troublesome cats, Ally Cat and Sir Thomas Vanguard, for distracting and making the completion of this dissertation that much more troublesome (and entertaining). 


\section{ABSTRACT OF THE DISSERTATION \\ ETHNIC AND AMERICAN IDENTITY DEVELOPMENT: A DEVELOPMENTAL SYSTEMS APPROACH}

by

Alan Meca

Florida International University, 2014

Miami, Florida

Professor Dionne P. Stephens, Major Professor

Given the role ethnic identity has as a protective factor against the effects of marginalization and discrimination (Umaña-Taylor, 2011), research longitudinally examining ethnic identity has become of increased importance. However, successful identity development must incorporate elements from both one's ethnic group and from the United States (Berry, 1980). Despite this, relatively few studies have jointly evaluated ethnic and American identity (Schwartz et al., 2012). The current dissertation, guided by three objectives, sought to address this and several other gaps in the literature. First, psychometric properties of the Multigroup Ethnic Identity Measure (MEIM) and the American Identity Measure (AIM) were evaluated. Secondly, the dissertation examined growth trends in recently immigrated Hispanic adolescents' and their caregivers' ethnic and American identity. Lastly, the relationship between adolescents' and caregivers' ethnic and American identity was evaluated. The study used an archival sample consisting of 301 recently immigrated Hispanic families collected from Miami $(\mathrm{N}=151)$ and Los Angeles $(\mathrm{N}=150)$. Consistent with previous research, results in Study 1 indicated a two-factor model reliably provided better fit than a one-factor model and 
established longitudinal invariance for the MEIM and the AIM. Results from Study 2 found significant growth in adolescents' American identity. While some differences were found across site and nationality, evidence suggested recently immigrated Hispanic adolescents were becoming more bicultural. Counterintuitively, results found a significant decline in caregivers' ethnic identity which future studies should further examine. Finally, results from Study 3, found several significant positive relationships between adolescents' and their caregivers' ethnic and American identity. Findings provided preliminary evidence for the importance of examining identity development within a systemic lens. Despite several limitations, these three studies represented a step forward in addressing the current gaps in the cultural identity literature. Implications for future investigation are discussed. 


\section{TABLE OF CONTENTS}

CHAPTER

PAGE

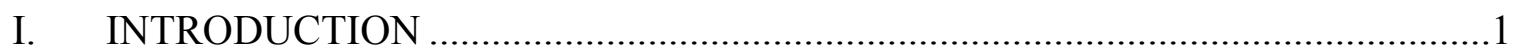

A Developmental Systems Theory ……………….........................................

Adolescence: A Time of Change ……….......................................................

Marginalized and Disempowered Youths........................................................

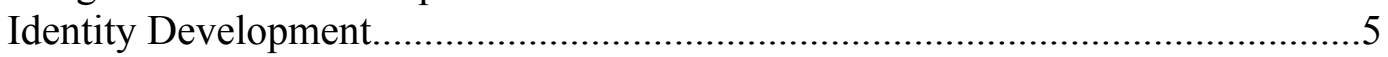

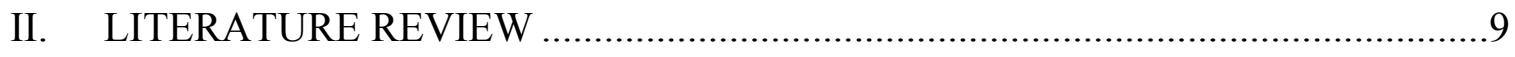

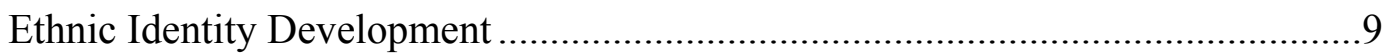

American Identity Development .......................................................................15

Moving Forward - Gaps in the Field of Ethnic Identity .......................................17

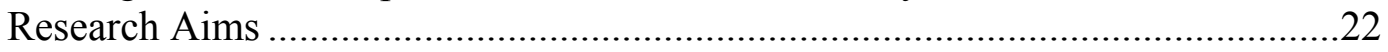

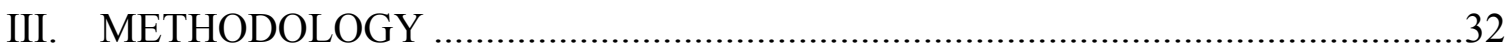

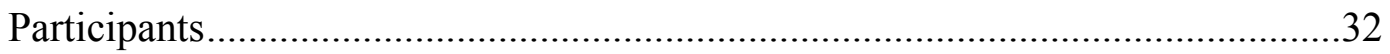

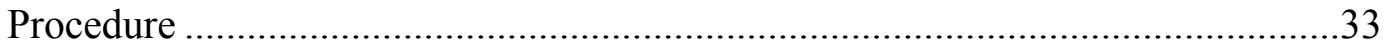

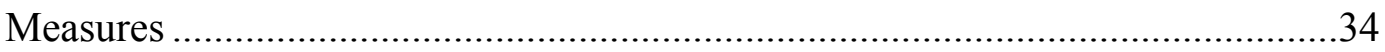

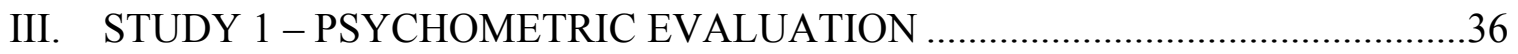

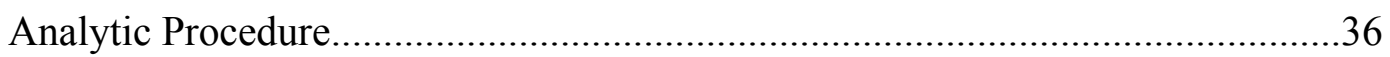

Multigroup Ethnic Identity Measure (MEIM) .....................................................37

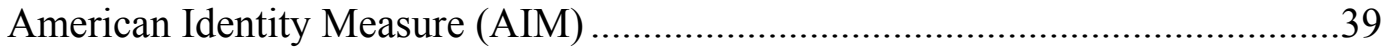

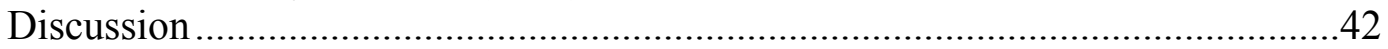

IV. STUDY 2 - EVALUATING GROWTH AND PREDICTORS OF GROWTH......46

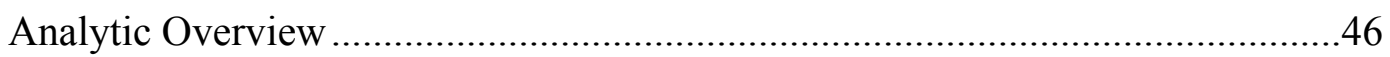

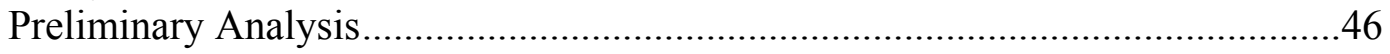

Evaluating Growth in Ethnic and American Identity Affirmation ........................46

Predictors of Growth in Ethnic and American Identity Affirmation .......................53

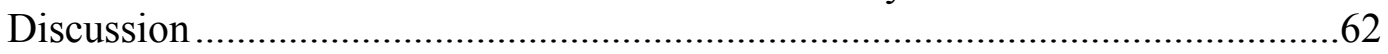

V. STUDY 3 - ADOLESCENTS' AND CAREGIVERS' CULTURAL IDENTITY

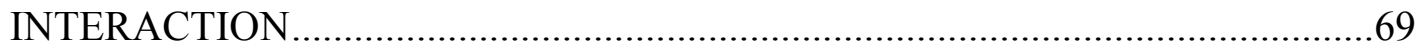

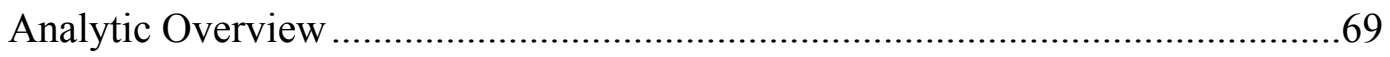

Dyadic Latent Growth Curve Models ...............................................................69

Assessing for Differences Across Site and Nationality ..........................................74

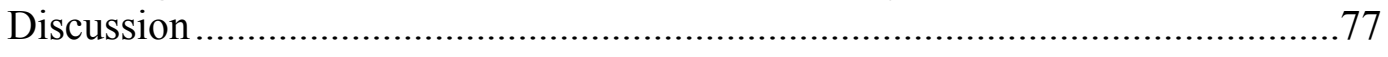

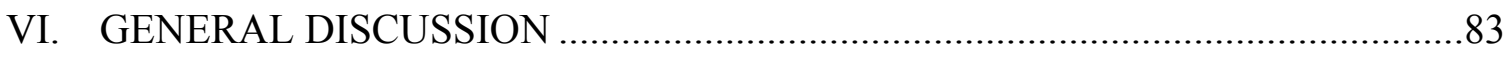

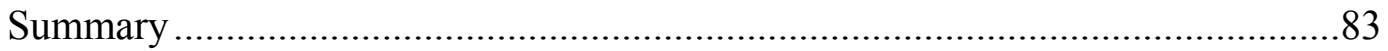

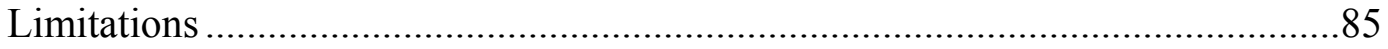

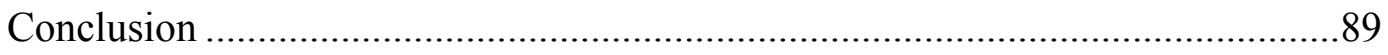




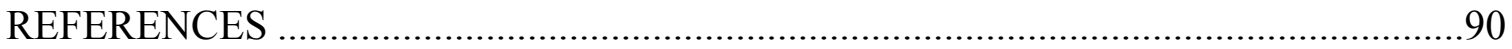

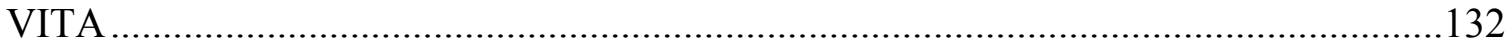




\section{LIST OF TABLES}

TABLE

PAGE

1. Item Description for the Multigroup Ethnic Identity Measure and the American Identity Measure

2. Model Comparison for the Multigroup Ethnic Identity Measure 106

3. Model Comparison for the American Identity Measure 107

4. Longitudinal Invariance for the Multigroup Ethnic Identity Measure. 108

5. Longitudinal Invariance for the American Identity Measure 109

6. Descriptive Statistics for Study Variables

7. Evaluation of Latent Growth Curve Models for Recently Immigrated Hispanic Adolescents' Cultural Identity

8. Evaluation of Latent Growth Curve Models for Recently Immigrated Hispanic Caregivers' Cultural Identity

9. Growth Parameters for Recently Immigrated Hispanic Adolescents' and their Caregivers' Ethnic and American Affirmation Separately....

10. Growth in Recently Immigrated Hispanic Adolescents' American Affirmation with Ethnic Affirmation as a Time Varying Predictor.

11. Relationship among Recently Immigrated Hispanic Adolescents' American and Ethnic Affirmation

12. Growth in Recently Immigrated Hispanic Caregivers' Ethnic and American Affirmation

13. Relationship among Recently Immigrated Hispanic Caregivers' Ethnic and American Affirmation.

14. Evaluation of Latent Growth Curve Models for Recently Immigrated Hispanic Adolescents' Ethnic and American Affirmation by Site

15. Evaluation of Latent Growth Curve Models for Recently Immigrated Hispanic Caregivers' Ethnic and American Affirmation by Site.

16. Evaluation of Latent Growth Curve Models for Recently Immigrated Hispanic Adolescents' Ethnic and American Affirmation by Nationality 
17. Evaluation of Latent Growth Curve Models for Recently Immigrated Hispanic Caregivers' Ethnic and American Affirmation by Nationality

18. General Ethnic and American Affirmation Growth Parameters

19. Model Fit for Concurrent Latent Growth Curve Models of Recently Immigrated Hispanic Adolescents and their Caregivers' Ethnic and American Affirmation...... 123

20. Model 1 - Concurrent Growth Parameters for Recently Immigrated Hispanic Adolescents' and their Caregivers' Ethnic Affirmation

21. Model 1 - Relationship Among Adolescents' and their Caregivers' Ethnic Affirmation Growth Parameter

22. Model 2 - Concurrent Growth Parameters for Recently Immigrated Hispanic Adolescents' and their Caregivers' American Affirmation

23. Model 2 - Relationship Among Adolescents' and their Caregivers' American Affirmation Growth Parameter

24. Model 3 - Concurrent Growth Parameters for Recently Immigrated Hispanic Adolescents' and their Caregivers' American Affirmation

25. Model 3 - Relationship Between Cultural Affirmation Within Caregivers and Adolescents

26. Model 3 - Relationship Between Cultural Affirmation Across Caregivers and Adolescents

27. Model 3 - Invariant Paths Across Site. 


\section{INTRODUCTION}

\section{A Developmental Systems Theory}

Developmental science focuses on describing, explaining, and optimizing individual developmental change and interindividual differences in developmental changes across the life-span (Baltes, Reese, \& Nesselroade, 1977; Lerner, Lerner, Bowers, Lewin-Bizan, Gestsdóttir, \& Urban, 2011). In recent years, developmental science has moved towards recognizing that development involves mutually-influential relations between the organism and multiple levels of his or her changing context (Lerner et al., 2011). Towards this end, contemporary theories have taken on a theoretical framework known as Developmental Systems Theory (DST). Developmental systems theory, by taking a relational metatheory (Overton, 2006), "heals" false dichotomies (i.e., nature versus nurture, quantitative versus qualitative, applied versus basic research) and takes on an integrated systemic perspective which stresses that developmental change emerges from alterations in the dynamic individual-context relationship (Lerner \& Castellino, 2002). Developmental systems theory adopts a developmental contextual and relational framework by incorporating not just multi-linear developmental relationships but bi-directional relationships across multiple levels of organization (biological, psychological, and social and physical ecological levels embedded in history) that are structurally and functionally integrated (Lerner \& Castellino, 2002).

Because temporality is an integrated and embedded level of the system, and moreover, because no level of organization functions as a consequence of its own isolated activity (Lerner \& Castellino, 2002), the potential for systemic change across the life span is always present (Baltes, Lindenberger, \& Staudinger, 2006; Lerner, 1984; Lerner 
\& Castellino, 2002; Lerner et al., 2011) and thereby represents a fundamental strength of human development (Lerner \& Castellino, 2002; Lerner et al., 2011). Thus, change within a DST framework, "is a necessary, inevitable feature of variables from all levels of organization" (Lerner \& Castellino, 2002, p. 125). From this perspective, structural organizational change emerges from mutually influential relations between an individual and his or her context (Gestsdottir \& Lerner, 2007). These bidirectional relations between the individual and his or her context regulate (i.e., govern) the course of development. Thus, these "developmental regulations" become the key process of human development (Lerner, 2004). Brandtstädter (2006) extended the concept of developmental regulation by specifying adaptive developmental regulation as developmental regulations that are mutually beneficial to both individual and context.

With regards to evaluation of developmental regulations, a distinction has been made between the individual's and context's contributions to developmental regulation (Gestsdottir \& Lerner, 2007). The individual's contribution can be further differentiated as organismic or intentional self-regulation. Unlike organismic self-regulations (which are primarily physiological), intentional self-regulations refer to goal-directed actions-incontexts that can be actively selected and controlled (Gestsdottir \& Lerner, 2007; Lerner et al., 2011). Intentional self-regulations are "contextualized actions that are actively aimed toward harmonizing demand and resources in the context with personal goals to attain better functioning and to enhance self-development" (Gestsdottir \& Lerner, 2008, p. 204). 


\section{Adolescence: A Time of Change}

Adolescence is a developmental stage that serves as a time of profound change across various levels of organization (i.e., physical, cognitive, emotional, behavioral, social, and institutional). During childhood, the capacity for self-regulation is limited to attention and inhibition; however, new cognitive, behavioral, and social relational skills during adolescence transform the individual's contributions to developmental regulation (Gestsdottir \& Lerner, 2007; Lerner, 1982; Lerner \& Busch-Rossnagel, 1981; Lerner \&Walls, 1999). More specifically, adolescents' self-regulations are more developmentally advanced in that adolescents can serve as active producers or contributors to their own development. It is for this reason that adolescence serves as an ideal "ontogenetic laboratory" for studying the plasticity of human development and for exploring how individual and contextual contributions to developmental regulation may promote positive development (Lerner, 2004).

As highlighted by Lerner and colleagues (2011), adaptive developmental regulations during this period of the life span increase the likelihood that youth will thrive (that is, manifest healthy, positive developmental changes). A DST perspective emphasizes that all young people have strengths that may be capitalized on to promote thriving across the adolescent years (Lerner et al., 2011). From this perspective, adolescents are viewed as resources to be developed rather than as problems to be managed (Lerner, 2005; Roth \& Brooks-Gunn, 2003). As a result of the potential for change, adolescence becomes a developmental period that offers opportunities (and constraints) for change an individual's life course throughout various interactions in positive or negative directions (Montgomery et al., 2008). 
The development of a sense of self and identity has also been tied to the emergence of developmentally advanced intentional self-regulation. As advanced developmental intentional self-regulation involves actions aimed at changing a part of a developmental system toward a particular goal, a person must have the capacity to form representations of them that inform the person of past experiences, offer self-evaluations, and provide directions for future actions (Gestsdottir \& Lerner, 2007). Thus, a sense of identity and of personal future is fundamental for the development of successful selfregulation (Brandtstädter, 1999). Furthermore, the emergence of the capacity for developmentally advanced intentional self-regulation has been hypothesized to provide the foundation for the formation of an increasingly integrated-and therefore an increasingly complex, coherent, and cohesive-sense of identity (Eichas, Meca, Montgomery, \& Kurtines, in press; Gestsdottir \& Lerner, 2007).

Marginalized and Disempowered Youths. Previous studies have found that adolescence is not universally a time of stress and storm (Arnett, 1999). However, youth from marginalized populations and disadvantaged contexts marked by pervasive violence, crime, and substance abuse (Berman, Kurtines, Silverman, \& Serafini, 1996; Wilson, Rodriguez, \& Taylor, 1997), often find the transition to adulthood a formidable challenge. As these populations develop outside of mainstream social institutions (e.g., schools, family, religion, etc.) and lack the traditional references and support (Côté \& Allathar, 1994), they are sometimes withdrawn from proactive participation in their own personal lives. Thus, these youth tend to search for daily adventure, inclusive of antisocial activities and problem behaviors, rather than taking control and responsibility over their lives (Dahlberg, 1998). 
Hispanic Adolescents. The current dissertation focused on Hispanic families, the largest and fastest growing immigrant group in the United States. According to the U.S. Census Bureau's 2011 American Community Survey (ACS), Hispanics comprised nearly 16.7\% of U.S. residents (Motel \& Pattern, 2013). Hispanic adolescents are more likely than other ethnic groups to drop out of school (Greene \& Forster, 2003), use illicit drugs (Johnston, O'Malley, Bachman, \& Schulenberg, 2006), cigarette and alcohol (Prado et al., 2008) and to engage in unsafe sex (Centers for Disease Control \& Prevention, 2004). Several scholars (e.g., Case \& Robinson, 2003) and the US Surgeon General (Thompson, 2001) have called for more prevention research focused on ethnic minority groups as a result of the increased risk across multiple maladjustive indices ranging from delinquency to physical and mental health problems (Umaña-Taylor, 2011). Consistently, Schwartz, Zamboanga, and Jarvis (2007) have highlighted the need for examining predictors and indices of psychosocial adjustment in Hispanic children and adolescents. The current study focused on one specific predictor and index - identity.

\section{Identity Development}

Identity is a relatively stable self-structure (i.e., the self-constructed, coherent, and dynamic organization of drives, abilities, beliefs, and personal history) that guides individuals' life paths and decisions (Kroger, 2007) and serves as an individual's "steering mechanism" for directing choices and actions within the "constraints and opportunities of history and social circumstances throughout the duration of a life course" (Elder, 1998, p. 961). Erikson (1950) highlighted the formation of a consolidated sense of self and identity as the critical crisis for adolescence. Although identity-related questions 
begin to emerge in childhood, it is during adolescence, as a result of structural organizational changes across multiple levels of organization, that the search for a sense of self and identity turns into a critical developmental task (Erikson, 1950). Erikson viewed identity as a continuum that ranged from identity synthesis (a set of selfdetermined ideals) to confusion (an inability to derive a self-determined set of ideals) with the ideal identity emerging from somewhere in the middle of these two endpoints (Schwartz, 2001).

Despite this conceptualization of the development of a sense of self and identity, Erikson's work was in large part abstract and derived predominately from his clinical work and psychobiographies, leaving the work of operationalizing identity development for others (Schwartz, Zamboanga, Luyckx, Meca, \& Ritchie, 2013). While many took up the challenge, Marcia's (1966) formulation produced one of the first empirical operationalization. It has generated more than 45 years of theoretical and empirical work and nearly 1,000 theoretical and empirical publications (see Kroger \& Marcia, 2011). Marcia's (1966) Identity Status Model proposed two distinct processes- exploration and commitment. Exploration refers to sorting through various potential identity alternatives, whereas commitment represents selecting one or more alternatives to which to adhere.

Adolescents face the challenge of exploring multiple possible alternatives to make decisions about life choices (Grotevant, 1987; Marcia, 1980, 1988; Schwartz, 2001). Identity exploration is the search for an updated and revised sense of self. Adolescence is often characterized by a period of intensified identity exploration (Adams et al., 2001; Waterman, 1999), when youth may try on and discard multiple identifications over a 
relatively brief span of time. The process of choosing one or more alternatives and following through with them has been described as making an identity commitment (Marcia, 1988). An identity commitment is characterized by the adherence to a selfselected specific set of goals, values, and beliefs (Marcia, 1988; Schwartz, 2001). While the conflict between existing identity commitments and the environment has been described as the "starting point" for the identity process (Bosma \& Kunnen, 2001), identity exploration has been described as the "work" of the identity process (Grotevant, 1987).

Identity and Psychosocial Functioning. Several studies have found the development of a coherent sense of self and identity to be associated with higher levels of positive psychosocial functioning and lower levels of negative psychosocial functioning (see Crocetti, Meeus, Ritchie, Meca, \& Schwartz, 2014). As emphasized by Schwartz (2005), the value of identity lies in its ability to promote healthy development, and to prevent individually and socially destructive outcomes. Moreover, Erikson's (e.g., 1950, 1968) asserts that identity provides individuals with a foundation for feeling satisfaction with oneself (self-esteem), meaning and direction (purpose in life), and agency (internal locus of control). Recent studies have consistently established a relationship between identity commitment and positive well-being (Luyckx et al., 2011; Passmore, Fogarty, Bourke, \& Baker-Evans, 2005; Ritchie et al., 2013; Schwartz et al., 2011a; Waterman, 2007). Moreover, the development of a consolidated sense of self and identity has repeatedly been found to serve as a protective barrier against anxiety, depression, and problem behaviors (Adams et al., 2001; Jones \& Hartmann, 1988; Luyckx et al., 2011; 
Ritchie et al., 2013; Schwartz et al., 2011a). Thus, the development of a sense of self and identity serves as a key developmental asset (Scales, Benson, Leffert, \& Blyth, 2000).

Identity Domains. Although identity was first conceptualized as a broad encompassing construct, the identity literature has highlighted various domains of identity (Vignoles, Schwartz, \& Luyckx, 2011). The identity status model proposed by Marcia (1966) operationalized identity to encompass religion and spirituality, occupational goals, values and morality, friendships, dating relationships, and gender roles. Since Marcia's operationalization of identity development, some of these, and other, domains, have inspired separate literatures outside the identity status model. Moreover, research has suggested not only that identity work proceeds unevenly across domains (e.g., Goossens, 2001; Pastorino, Dunham, Kidwell, Bacho, \& Lamborn, 1997), but that different domains are salient for different individuals.

One such domain is informed by an individual's ethnicity and by one's culture of origin and is often associated with specific cultural values, attitudes, and behaviors (Phinney, 1996). It has been suggested that ethnic identity is of particular importance because it directly impacts identity formation (Phinney \& Rosenthal, 1992). Ethnic identity has even greater salience in minority groups within the United States as a result of significant disparities, discrimination, and marginalization (Devos \& Banaji, 2005; Phinney, 1989). Given the role research has shown ethnic identity development has in serving as a protective factor against negative experiences associated with marginalization and discrimination and, its relation to overall adjustment (Umaña-Taylor, 2011) research examining the developmental trajectories of ethnic identity has become of increased importance. While ethnic identity has been considered a critical piece of ones' 
cultural identity, research in the last decade highlighted that the development of an integrated sense of self and identity should incorporate elements from both one's ethnic group and from the United States (Berry, 1980, 1997). Consistently, the current dissertation sought to address multiple gaps in the literature examining the developmental trajectory of cultural identity (i.e., ethnic and American) development in recently immigrated Hispanic adolescents and their caregivers.

\section{LITERATURE REVIEW}

\section{Ethnic Identity Development}

Ethnic identity is not only defined by the specific cultural values, attitudes, and behaviors of ones' culture of origin (Phinney, 1996) but also refers to the subjective experience of retaining ones' cultural heritage (Roberts et al., 1999; Schwartz, Zamboanga, \& Jarvis, 2007). As previously mentioned, ethnicity is a highly salient topic in the United States as a result of the significant social-economic disparities, discrimination, and marginalization that minority ethnic groups face (Devos \& Banaji, 2005; Phinney, 1989). Research has varied in the ways it has conceptualized and operationalized ethnic identity, ranging from simple self-identification to multifaced typologies (Umaña-Taylor, 2011). However, ethnic identity varies not just across groups but within groups as well (Phinney, 1996; Umaña-Taylor, Diversi, \& Fine, 2002). For example, how much someone has explored their ethnic and cultural background may determine whether or not ethnic identity will be a salient component of his or her sense of self and identity (Phinney, 1989; 1992). As a means of addressing the in-group variability across ethnic identity, researchers have turned to the ego identity perspective proposed by Phinney (1989), which provides one of the more comprehensive conceptualizations by 
taking into account group membership, identification, and its developmental nature (Umaña-Taylor, Diversi, \& Fine, 2002).

Theoretical Models. As stated above, ethnic identity has been conceptualized as a component of one's overall sense of self and identity (Umaña-Taylor, 2011). Towards that extension, research on ethnic identity development has drawn upon Erikson's (1968) conceptualization and Marcia's (1980) operationalization of identity development. More specifically, Phinney (1993) proposed a model of ethnic identity composed of three dimensions: exploration, commitment, and affirmation.

Exploration. Drawing on Marcia's (1980) operationalization of identity development, Phinney (1989) highlighted exploration as a key process of the development of an ethnic identity. As described by Phinney (1992), the process of ethnic identity formation involves exploration "of the meaning of one's ethnicity (e.g., its history and traditions) that leads to a secure sense of oneself as a minority group member" (p. 160). The focus on ethnic identity exploration has been on participation in social activities (with other members of one's ethnic group) and cultural traditions (Phinney, 1992), asking questions, reading books, or talking with friends (Phinney, 1993).

Commitment. Once more drawing on Marcia's (1980) identity status model, Phinney (1989) emphasized commitment as a key process in the development of an ethnic identity. Within the ethnic identity literature, ethnic identity commitment specifically "pertains to individuals understanding of what their ethnic group membership means to them and the extent to which it plays an important role in their life" (UmañaTaylor, 2011, p. 793). 
Affirmation. Finally, Phinney (1989) drew from social identity theory (Tajeel, 1981) to highlight affirmation as a key process in ethnic identity development. More specifically, Phinney (1989) drew on the notion that in an effort to maintain a positive self-concept, individuals' strive to achieve a positive social identity by adopting positive attitudes toward the social groups to which they belong, in this case, their ethnic group. Thus, ethnic identity affirmation refers to whether or not an individual feels positively or negatively about their ethnic group membership (Umaña-Taylor et al., 2004).

Ethnic Identity and Psychosocial Functioning. Research within the past decade has consistently found ethnic identity to not only serve as a protective factor against negative experiences of discrimination and marginalization for ethnic group members but also to be associated with several positive psychosocial outcomes (Umaña-Taylor, 2011). With regards to individual dimensions of ethnic identity and with pooled ethnically diverse samples, research has found ethnic identity affirmation to be associated with lower levels of drug use (Marsiglia, Kulis, \& Hect, 2001; Marsiglia, Kulis, Hect, \& Sills, 2004). These results support the assertion that ethnic identity exploration and commitment to be positively associated with self-esteem in pooled ethnically diverse samples (Umaña-Taylor, Yazedjian, \& Bámaca-Gómez 2004, 2009). Using composite scores, research with pooled ethnically diverse samples has found ethnic identity to be associated with higher self-esteem among minority adolescents (Bracey, Bamaca-Gomez, \& Umaña-Taylor, 2004; Martinez \& Dukes, 1995; Phinney, 1992; Phinney, Cantu, \& Kurtz, 1997; Smith, Walker, Fields, Brookins, \& Seay, 1999), higher purpose in life and self-confidence (Martinez \& Dukes, 1995), higher self-efficacy (Smith, Walker, Fields, Brookins, \& Seay, 1999), and higher overall quality of life among adults (Utsey, Chae, 
Brown, \& Kelly, 2002). Ethnic identity has also been related to lower levels of personality characteristics commonly linked to drug use, such as rebelliousness and impulsivity, among young adults (Brook, Duan, Brook, \& Ning, 2007).

Hispanic Samples. While ethnic diverse pooled samples have found ethnic identity development to be associated with positive psychosocial functioning, as reviewed by Umaña-Taylor (2011), studies conducted with Latino/Hispanic only sample have found mixed results. Using total composite scores, Roberts and colleagues (1999) found ethnic identity to be positively associated with several indicators of positive psychosocial functioning: coping, mastery, self-esteem, and optimism. Similarly, Schwartz, Zamboanga, and Jarvis (2007) found ethnic identity to be positively associated with self-esteem among early adolescents, and indirectly (through self-esteem) and negatively associated with externalizing symptoms and positively associated with academic performance. Studies conducted with late Hispanic adolescents have paralleled these findings, detecting a positive relationship between ethnic identity and self-esteem (Bracey, Bamaca-Gomez, \& Umaña-Taylor, 2004; Umaña-Taylor, 2004). In stark contrast, ethnic identity has also been found to be positively associated with heavy alcohol use in Mexican-American College Students (Zamoanga, Raffaelli, \& Horton, 2006), and with alcohol use in early Hispanic adolescents (Marsiglia, Kulis, Hect, \& Sills, 2004). Similarly, Zamboanga, Schwartz, Jarvis, and Van Tyne (2009) found ethnic identity was positively and significantly associated with frequency of cigarette use (among smokers), and marginally significantly associated with frequency of alcohol use (among drinkers) and marijuana use in early Hispanic adolescents. 
With regards to individual components of ethnic identity (i.e., exploration, commitment, and affirmation), studies have found exploration and commitment to be positively associated with self-esteem among Latino adolescents (Umaña-Taylor \& Updegraff, 2007) and college students (Umaña-Taylor \& Shin, 2007). However, French, Kim, and Pillado (2006) found ethnic identity exploration to be positively associated with delinquency. Moreover, while ethnic identity affirmation has been found to serve as a protective factor against discrimination in Mexican Adolescents (Romero \& Roberts, 2003), decreased drug use in Puerto Rican adolescents (Brook, Whiteman, Balka, Win, \& Gursen, 1998), and positive teacher-reported academic performance in Latino youth (Supple, Ghazarian, Frabutt, Plunkett, \& Sands, 2006), Marsigilia and colleagues (2004) also found ethnic identity affirmation to be positively associated with alcohol use in Mexican youth.

The Development of an Ethnic Identity. Although several studies have examined the role of ethnic identity and its relation with psychosocial outcomes using cross-sectional methods, few studies to date have used longitudinal methods in order to evaluate its developmental trajectory (French, Seidman, Allen, \& Aber, 2006; UmañaTaylor, 2011). For example, French and colleagues (2006), using a longitudinal design, found significant growth in ethnic identity affirmation and exploration during middle adolescence for Latino Youth. Similarly, Umaña-Taylor and colleagues (2008) found significant growth in ethnic identity affirmation from middle to late adolescence $(M$ age $=$ $15.31, S D=0.75)$. The same study also observed significant growth in ethnic identity exploration and commitment in Latino girls. Despite these findings, Pahl \& Way (2006) in a pooled sample of Blacks and Latinos, found a decrease in ethnic identity exploration 
between middle and late adolescence while ethnic identity affirmation remained constant. By conducting longitudinal studies, researchers can begin to map the course of ethnic identity development and evaluate antecedents as well as contextual variables that lead to more versus less successful ethnic identity development (Schwartz, 2005).

Measuring Ethnic Identity. Among the measures that have been developed to assess ethnic identity, the Multigroup Ethnic Identity Measure (MEIM; Phinney, 1992) has been among the most widely used, in part, as a result of the fact that the MEIM was explicitly designed for use with various ethnic groups (Phinney, 1992; Phinney \& Ong, 2007). While Phinney (1992) delineating three processes behind ethnic identity previously explained, a number of psychometric evaluations of the MEIM have supported either a one-factor structure (Ponterotto, Gretchen, Utsey, Stracuzzi, \& Saya, 2003; Reese, Vera, \& Paikoff, 1998; Worrell, 2000) or a two-factor structure (Plybon, 2001; Roberts et al., 1999; Spencer et al., 2000). Regarding the two-factor structure, using a large ethnically diverse sample of young adolescents $\left(\bar{x}_{\text {Age }}=12.9\right.$, Range $\left.=12-14\right)$, Roberts and colleagues (1999) found commitment and affirmation loaded on to a single factor (in otherwise specified, henceforth be considered and labeled as Ethnic Identity Affirmatio). Similarly, Spencer et al. (2000), Yancey et al. (2001), and Pegg and Plybon (2005) have found the MEIM was best composed of two discrete yet related factors of ethnic identity in early adolescents. As a result, in recent years, scholars have moved away from using a composite ethnic identity score of ethnic identity to focusing on individual ethnic identity components (Umaña-Taylor, 2011). While psychometric evaluation of the MEIM has been conducted with a variety of samples, to date no study has examined the factor structure of the MEIM in a sample of recently immigrated 
Hispanic adolescents or adults, nor have any studies determined whether the MEIM is longitudinally invariant.

\section{American Identity Development}

As a result of the September 11 attack and the continuing increase in ethnic diversity in the United States, both scholars and the general public have been concerned with what an American identity is and how strongly immigrants identify with being an American (Schildkraut, 2005, 2007; Schwartz et al., 2012a). This concern has been focused not just on citizenship and other demographic indicators, but also with psychological dimensions including thoughtful consideration of what being part of the United States means to individuals, and pride in and attachment to the country and the national group (Schwartz et al., 2012a). Thus, American Identity can be conceptualized like ethnic identity, as both an individual construction and a collective identification (Ashmore, Deaux, \& McLaughlin-Volpe, 2004; Spinner-Halev \& Theiss- Morse, 2003; Theiss-Morse, 2009).

Consistent with Phinney's (1989) conceptualization of ethnic identity, American identity has been divided into two processes - American identity exploration and American identity commitment and affirmation (Schwartz et al., 2012a). While commitment and affirmation is more consistent with the concept of American identity, just as with ethnic identity, individuals must first consider what their identification with the United States signifies to them (exploration) before they can commit to and internalize a specific identification with the nation (Schwartz et al., 2012a). It is critical to note that, as a whole, American identity has been conceptualized not in opposition to ethnic identity. Instead, the development of an integrated sense of self and identity has 
been theorized to incorporate elements from both one's ethnic group and from the United States (Berry, 1980, 1997). Thus, the current dissertation adopted this bicultural model and examined both ethnic and American identity development in recently immigrated Hispanic adolescents and their caregivers.

Measuring American Identity. In terms of measurement, while some studies have used single-item scales asking participants how American they consider themselves (Gong, 2007), other studies have measured American identity via related constructs such as prototypical American beliefs (e.g., universal rights, civic participation, and valuing of diversity; Devos \& Banaji, 2005; Schildkraut, 2003), engagement in American Civic behaviors (e.g., voting, serving on juries; Stepick et al., 2008), nationalism (Kosterman \& Feshbach, 1989), patriotism (Schatz, Staub, \& Lavine, 2003), and national glorification (Roccas, Klar, \& Liviatan, 2006). As a result, Schwartz and colleagues (2012a) sought to develop a psychometrically valid, multiple-item questionnaire, modeled after the MEIM, to quantify the extent to which individuals have explored and commitment to/affirmed their 'American Identity'. The American Identity Measure (AIM) was found not only to be psychometrically sound and structurally equivalent to the MEIM, but psychometrically equivalent across ethnicity and immigrant generation (Schwartz et al., 2012a). Moreover, the AIM was found to be strongly associated with American cultural behaviors (i.e., speaking English, eating American foods, associating with American friends and romantic partners, and accessing American media) providing evidence for convergent validity (Schwartz et al., 2012a). However, and as noted by Schwartz and colleagues (2012a), it is important for future studies to examine the psychometric properties of the AIM in samples of noncollege individuals. 


\section{Moving Forward - Gaps in the Field of Ethnic Identity}

Despite the recent increase in research examining ethnic identity development in the last decade, there still remain several gaps in the field. More specifically, over and above the need for psychometric evaluations of current measures and longitudinal studies examining change in cultural identity (i.e., ethnic and American) over time, there has been a call in the field to examine cultural identity development in adults, employ multisite studies in order to take into examine differences across receiving contexts (UmañaTaylor, 2011), to examine within-group differences (e.g., Mexican versus Cuban), and finally, to take on a more systemic approach towards the emergence individuals' sense of self and identity (Koepke \& Denissen, 2012).

Lack of focus on adult populations. As highlighted by Umaña-Taylor (2011), the vast majority of ethnic identity research has focused on adolescents and emerging adults. While identity formation is the primary developmental challenge for both of these age groups, identity and ethnic identity development have been conceptualized as processes that are revisited throughout the lifespan (Phinney, 1996; Syed et al., 2007). In examining ethnic identity development of the parent-child system, the current study would add to the body of literature by investigative how ethnic identity develops in adults (the adolescents' caregivers) who have recently immigrated and thereby are likely to be revisiting (if not for the first time) their sense of ethnic identity. Similarly, American identity has mainly been evaluated in college students and to date, the American Identity Measure has yet to be evaluated psychometrically with an adult sample (Schwartz et al., 2012a). 
Receiving Context and the Need for Multisite Studies. As highlighted by Schwartz and colleagues (2010) in their work on acculturation, the context of reception may also exert important effects that may not necessarily be reducible to differences in the Hispanic subgroups settling in each context (Schwartz et al., 2013c). Context of reception, as defined by sociologist Portes and Rumbaut (2001), refers to the individual's perception of the overall valence that the receiving society directs toward an immigrant group and the opportunity structure available to that group. While immigrants in a negative context of reception are likely to feel isolated, have difficulty finding jobs, and experience discrimination or perceive hostility, those in positive context of reception are able to aspire to succeed and achieve the "American Dream" (Schwartz et al., 2013c). Thus, and consistent with a DST framework (Lerner \& Castellino, 2002), immigration and acculturation can be conceptualized as the interaction between a specific immigrant group and the context in which they are received (Schwartz, Unger, Zamboanga, \& Szapocznik, 2010; Schwartz, Vignoles, Brown, \& Zagefka, in press).

Given the high level of variability in the opportunity structure, degree of openness, hostility, and acceptance across receiving contexts, it is important for research to evaluate and take into account the effect different communities have on immigrants. As stated by Schwartz and colleagues (2013c), "not all receiving communities are equally friendly or unfriendly" (p. 2). While this research has mainly been conducted within the area of acculturation, identity theorist view identity as emerging within the opportunities, parameters, and constraints provided by historical and social circumstances (Côté \& Levine, 2002; Eihcas et al., in press; Vignoles, Schwartz, and Luyckx, 2011). As such, inconsistent findings between ethnic identity and psychosocial functioning is likely a 
result of unexamined differences across receiving context of the study (Umana-Tayler, 2011). In light of this limitation, the current dissertation examined ethnic and American identity development across two sites - Miami and Los Angeles.

Miami is not only a thriving metropolis as a result of the influx of Cubans migration (Portes \& Stepick, 1994) aided by the "wet foot, dry foot" law that allows them to stay legally in the United States (Stepick \& Stepick, 2002), but it is also a highly bicultural context where Hispanics account for the majority of the population in Miami (65\%; U.S. Census Bureau, 2011) and hold the majority of political and economic power positions (Stepick, Grenier, Castro, \& Dunn, 2003). While the majority of Miami's Hispanic population is composed of Cubans (52.7\%; U.S. Census Bureau, 2011), since 1980, the Hispanic population of Miami has diversified to include Central and South Americans (Fernández-Kelly \& Curran, 2001; Sabogal, 2005). Los Angeles on the other hand, is home to a sizable Mexican community since being annexed by the United States in the $19^{\text {th }}$ century from Mexico. Although the majority of Hispanics in Los Angeles are of Mexican origin (68.2\%; U.S. Census Bureau, 2011), there was an influx in the 1990s of immigrants from Central America (e.g., Nicaragua, El Salvador, Guatemala). While Mexican Americans in Los Angeles have enjoyed increasing political and economic power in recent years, Los Angeles still favors non-Hispanics and is defined by an ambivalence toward Hispanic immigrants (Hayes-Bautista, 2004). Consistently, Schwartz and colleagues (2013c) found caregivers' from Los Angeles reported higher perceived negative context of reception and discrimination than those in Miami.

Within-Group Diversity. One aspect that has been over looked when it comes to examining ethnic identity is the high level of within-group diversity (Umaña-Taylor, 
Diversi, \& Fine, 2002). This is especially true for Hispanics who vary not just in terms of national origin but in socioeconomic status, colonization, culture, dialect, history with the US, and other factors (Ennis et al., 2011). As previously noted, there have been inconsistent findings in regards to the relationship between ethnic identity and psychosocial functioning. As proposed by Umaña-Taylor (2011), one potential explanation for these inconsistencies may be the lack of consideration of within-group differences. When studying Latino populations, the specific nationality of group members is important for many reasons. To begin with, there are vast differences in histories concerning immigration into the United States as well as demographic differences that exist across nationalities. Moreover, and as outlined by Schwartz, Zamboanga, and Jarvis (2007), "there is a great deal of variability among individuals of Spanish-speaking descent in terms of skin tone, national origin, socioeconomic status, and ability to fit into mainstream U.S. society" (p. 371). As a result, a call has been placed for the need to focus on and examine differences across national origin groups rather than an assumed homogenous pan-ethnic population (Umaña-Taylor, 2011).

Identity Development as a Developmental System. Erikson (1969) postulated that development of an individual's sense of self and identity occurs at the intersection between the individual and the society/culture. In light of more systemic theories of human development (i.e., developmental systems theory), there has been a growing recognition for the need to examine identity development from a more systemic perspective (Crocetti et al., 2014; Koepke \& Denissen, 2012). Drawing on Erikson's (1968) writings and developmental systems theory (Lerner \& Castellino, 2002), identity development should be conceptualized to emerge as a result of multi-linear bi-directional 
relationships across multiple levels of organization that are structurally and functionally integrated. Consistently, Bosma and Kunnen (2001) have defined identity as "rooted in emotion, emerging in relationships, [and] developing as a dynamic, self-organizing system"' (p. 5).

As a starting point, Koepke and Denissen (2012) have emphasized the need to incorporate the caregiver-child system as the most basic level of analysis. As specified by Koepke and Denissen (2012), children are dependent on parents' feedback to assess the appropriateness of their behaviour. During childhood, caregivers may react to their behavior by either adjusting their expectations, which may likely require a re-adjustment of their own identity standard, or by changing the child's behavior (Bosma \& Kunnen, 2001; Grotevant, 1987; Kerpelman et al., 1997). These parents' reactions are in part determined by the way in which their own identity system depends on the identity system of the child (Stierlin, 1974). Thus, caregivers and their children can be conceptualized as two inter-related identity systems that directly (and indirectly) affect each other (Koepke \& Denissen, 2012).

Consistently, sociological research has highlighted the role parents have in encouraging their children to gravitate towards specific aspects of their cultural heritage and to avoid specific aspects of the receiving cultural context (Portes \& Rumbaut, 2006). Moreover, Portes and Rumbaut (2006) have highlighted how parent-child differences in acculturation can affect family processes, acculturative stress, and mental health outcomes. Specifically, Portes and Rumbaut proposed children of immigrants acculturate or resist acculturation in consonance or in dissonance with their parents. Umaña-Taylor, Bhanot, and Shin (2006) referred to this phenomenon as familial ethnic socialization. 
Similarly, recent research on acculturation has found the presence of heritage culture in the home increases the likelihood that children and adolescents will retain or adopt their heritage culture (Schwartz, Zamboanga, Rodriguez, \& Wang, 2007; Umaña-Taylor, Bhanot, \& Shin, 2006). Regarding acquisition/rejection of American culture though, evidence has found caregivers' socialization attempts are less effective in shaping youths' American identrity (Schwartz, Zamboanga, Rodriguez, \& Wang, 2007). However, it is important to note these studies have focused on caregivers' socialization and not their own ethnic/American identity. It is likely caregivers' ethnic and American identity will guide what specific aspects caregivers encouraging their children to gravitate towards (or away) their cultural heritage and receiving cultural context. Out of this recognition and consistent with a systemic conceptualization of identity development, the current study examined how ethnic and American identity within this parent-child system by examining the interaction between adolescent/parent ethnic identity.

\section{Research Aims}

As outlined below, the current dissertation seeking to address these gaps in the literature (i.e., need for psychometric evaluation, longitudinal studies, a more systemic approach, to examine cultural identity development in adults, evaluate differences across receiving context, and examine within-group differences) was guided by three objectives. First, the current dissertation sought to examine the psychometric properties of the MEIM and AIM with recently immigrated Hispanic adolescents and their caregivers (Study 1). Next, analysis proceeded to evaluate longitudinal change in adolescents' and their caregivers' ethnic and American identity and determine whether differences might arise across site (receiving context) and participants' nationality (Study 2). Lastly, the current 
dissertation sought to examine the relationship between adolescents' and their caregivers' ethnic and American affirmation (Study 3). Additionally, the third study sought to examine whether the relationship between adolescents' and their caregivers' ethnic and American affirmation vary by site and/or nationality.

Study 1 - Psychometric Evaluation. Before longitudinal analysis can be conducted, it is critical to assess the adequacy of the expected relations between the measured indicators and the underlying latent constructs and ensure that observed longitudinal change in a construct is a result of true change (Brown, 2006; Little, 2013). Given the fact that no study to date has evaluated factor structure of the MEIM or the AIM in a sample of recently immigrated Hispanic adolescents or adults, the aim of Study 1 was first to evaluate the proposed two-factor structure (i.e., exploration and affirmation) against a one-factor model at each time point. Moreover, Study 1 sought to evaluate whether the factor structures of the MEIM and AIM was longitudinally/temporally invariant for both recently immigrated Hispanic adolescents and their caregivers. As stated by Brown (2006), "in the absence of such evaluation, it cannot be determined whether temporal change observe in a construct is due to true change or to changes in the structure of measurement of the construct over time" (p. 252).

Study 2 - Evaluating Growth and Predictors of Growth. Having established the two-factor structure and longitudinal invariance for the MEIM and AIM, the second study used Latent Growth Curve Modeling to (a) examine change in recently immigrated Hispanic adolescents' and their caregivers' ethnic and American identity affirmation and (b) evaluate whether this change varied across receiving context and nationality. In doing so, the second study was able to address three out of the four previously highlighted gaps 
in the cultural identity literature. More specifically, in evaluating growth of ethnic and American identity in recently immigrated Hispanic adolescents and their caregivers, Study 2 added to the few studies that have used longitudinal methods, examined cultural identity development in adults, and evaluated the effects of receiving context and withingroup differences on cultural identity development.

\section{Hypothesis 2A - General Growth in Adolescents' and Their Caregivers' Ethnic}

and American Identity Affirmation. Building on previous longitudinal research (French et al., 2011; Umaña-Taylor et al., 2008), Study 2 predicted an average increase in adolescents' ethnic identity affirmation. Regarding American affirmation, no study has yet to evaluate change in American affirmation over time. However, Schwartz and colleagues (2013a) found significant and positive change in a large number (64\%) of recently immigrated Hispanic adolescents' sense of Americanism (the level to which they are comfortable engaging in American cultural practices). Moreover, given the fact adolescents are exposed and socialized to American culture through participation in the school system (Padilla, 2006), Study 2 predicted an average positive change in adolescents' American identity affirmation.

Similarly, research examining change in caregivers' ethnic and American identity affirmation has been remarkably scant. In the same acculturation study, Schwartz and colleagues (2013a) extracted three classes for caregivers' acculturation using levels of Americanism and Hispanicism (i.e., highly Hispanic, moderate bicultural, and moderately Hispanic). However, none of these acculturation classes were associated with significant change over time. It is important to note that although Americanism and Hispanicism serve as behavioral indicators of acculturation, research has found different components 
of acculturation to be differentially associated with various outcomes (Schwartz et al., 2013b; Schwartz et al., 2011b). Thus lack of change in caregivers' behavioral acculturation does not imply a lack of change in caregivers' ethnic or American identification. Given the high levels of Hispanicism among recent immigrants, and given that ethnic identity serves a protective function in offsetting the negative effects of discrimination (Gee et al., 2007; Mossakowski, 2003), Study 2 predicted an average positive change in caregivers' ethnic affirmation. Regarding caregivers' American affirmation, for individuals who migrate as adults it may be especially difficult to identify with the receiving society (Portes \& Rumbaut, 2006; Schwartz, Pantin, Sullivan, Prado, \& Szapocznik, 2006; Schwartz, Unger, Zamboanga, \& Szapocznik, 2010). Moreover, it is important to note the current study was conducted in two large ethnic enclaves (i.e., Miami and Los Angeles). In these large Hispanic communities, recently arrived immigrants can settle in areas where they can largely interact with one another (Portes \& Rumbaut, 2006) and avoid ever having to learn how to speak English (Schwartz et al., $2011 b$ ) or adapt to the US culture. Thus, Study 2 predicted there would be no change in caregivers' American identity.

\section{Hypothesis $2 B$ - Predictors of Growth in Adolescents' and Their Caregivers'}

Ethnic and American Identity Affirmation. Additionally, Study 2 sought to evaluate whether growth parameters (i.e., intercept and slope) varied across participants' context (i.e., Miami versus Los Angeles) and/or nationality (i.e., Cuban, Mexican, all Other nationalities).

Previous evaluation of the COPAL dataset revealed significant differences across context. More specifically, Schwartz and colleagues (2012c) found recently immigrated 
Hispanic adolescents in Miami scored significantly higher than their Los Angeles counterparts on both ethnic and American identity. However, research examining perceived negative context of reception has found no significant differences across site, suggesting that the school context predominately composed of Hispanics may insulate adolescents from negative aspects of their local context (Schwartz et al., 2013c). Observed differences in adolescents' ethnic and American identity may therefore be more reflective of the large variability across nationality. For example, while Cubans are economically and politically empowered relative to other Hispanic groups, Mexican immigrants who are more likely to be undocumented (Massey et al., 2010) and nonWhite than Cubans (Smart \& Smart, 1995), are faced with lack of access to jobs, education, and economic benefits, and the constant fear of deportation. Although few studies have examined differences across sub-groups, Cislo (2008) found Cubans young adults reported higher levels of ethnic identity than Nicaraguans (Cislo, 2008). As such, Study 2 predicted significant differences across site and nationality in recently immigrated Hispanic adolescents' ethnic and American identity affirmation baseline (Time 1) scores, with participants from Miami and Cubans scoring higher than their counterparts. As a result of the insulation provided by school, no significant differences where predicted to emerge in adolescents' ethnic and American identity growth parameters across site and nationality.

With regards to recently immigrated Hispanic caregivers, findings by Schwartz and colleagues (2013c) highlight that differences across context are more likely to emerge as caregivers "may encounter hostility from other ethnic groups while seeking housing, employment, health care, or social services" (p. 11). As previously stated, 
relative to Miami, Hispanic immigrants in Los Angeles are often met with ambivalence (Hayes-Bautista, 2004). Consistently, studies conducted with the COPAL dataset have found participants in Miami reported a higher American identity at baseline (Schwartz et al., 2012b) and lower levels of perceived negative context of reception (Schwartz et al., 2013c) than those Los Angeles. While the favorable social position held by Hispanics in Miami (in particular, Cubans) may allow them to selectively identify with the United States (Stepick et al., 2011), results indicate for participants in Los Angeles, identifying with the United States makes them a target for discrimination and feeling rejected (Schwartz et al., 2013c). Thus, Study 2 predicted that change in American identity affirmation for participants from Miami would be higher than their Los Angeles counterparts. Moreover, given the majority of political and economic power position in Miami are held by Cubans (Stepick, Grenier, Castro, \& Dunn, 2003), Study 2 predicted Cuban caregivers would report higher baseline scores and growth in their American identity than their counterparts.

Study 3 - Caregiver-Child Developmental Systems Models. The aim of the third study was to examine the reciprocal and dynamic nature of ethnic and American affirmation respectively. In doing so, Study 3 addresses the last gap in the literature by placing adolescents' cultural identity development within the dyadic context it emerges out of. To achieve this goal, Study 3 conducted three additional latent growth curve models. While Model 1 would examined change and the relationship of that change in adolescents' and their caregivers' ethnic affirmation and Model 2 the same American affirmation, Model 3 would examine whether significant relationships emerged across ethnic and American affirmation in both adolescents and their caregivers. 


\section{Hypothesis 3A - General Relationship in the Change of Adolescents' and Their}

Caregivers' Ethnic and American Identity Affirmation. Although an in depth review found no study to date has examined the relationship between adolescents and their caregivers' ethnic and American identity development, as previously outlined, several studies have examined the role parents play in socializing adolescents' towards cultural identity. In particular, research from both the sociological (Portes \& Rumbaut, 2006) and psychological fields (Schwartz, Zamboanga, Rodriguez, \& Wang, 2007; Umaña-Taylor, Bhanot, \& Shin, 2006; Umaña-Taylor, Zeiders, Updegraff, \& Kimberly, 2013) has highlighted the role caregivers' have in promoting the retention of adolescents' ethnic affirmation. Given this extensive literature within the field of acculturation, Study 3 predicted positive relationships between change in adolescents' and their caregivers' ethnic affirmation over time.

While adolescents are exposed to American culture through participation in the school system (Padilla, 2006), as previously stated, adults settling in ethnically enclaves may not be inclined to adopt to the United States culture and/or identify as an American (Schwartz et al., 2006). That being said, research has emphasized the role adolescents, particularly immigrated adolescents, have in transmitting American values and culture (Padilla, 2006). As such, adolescents are likely encourage their caregivers' to explore the meaning of what being an American means to them. Moreover, one cannot ignore the potential contribution caregivers' might have in encouraging their children to develop a sense of belonging to the United States. As specified earlier, identity is a dynamic interaction and parents' reactions to adolescents' are in part determined by the way in which their own identity system is organized (Stierlin, 1974). Thus caregivers' who are 
developing or have a sense of belonging and identification with the Untied States, are more likely to encourage their children to explore what being an American means to them. While previous studies have found a positive but weak relationship between parents' socialization attempts and youths' acquisition/rejection of an American identity, caregivers' American identity has not been evaluated (Schwartz, Zamboanga, Rodriguez, \& Wang, 2007). Taken together, the current study predicted a positive relationships between change in adolescents' and their caregivers' American affirmation over time.

Additionally, adolescents' with higher ethnic affirmation, which in turn have a stronger family orientation (Sabogal, Marin, Otero-Sabogal, Marin, \& Perez-Stable, 1987) and parent-child relationship (Schwartz et al., 2013a), will likely be better suited towards assisting in the emergence of caregivers' American affirmation. With regards to caregivers' contribution, studies within the field of acculturation has delineating parentchild gap in acculturation as potentially detrimental towards family functioning (Schwartz et al., 2012b; Szapocznik \& Kurtines, 1993; Telzer, 2010). In these cases, parents may perceive certain individualistic behaviors and/or attitudes their children have adopted from the United States as disrespectful (Portes \& Rumbaut, 2001). Consistently, Schwartz and colleagues (2012b) found acculturation gap in American practices were associated with decreases in caregivers' account of parent/adolescent communication. For parents who have high sense of belonging to the United States though, these behaviors and attitudes may be perceived in a better light or even deemed acceptable. As such, Study 3 hypothesized a positive relationship between change in adolescents' ethnic and caregivers' American affirmation. Finally, regarding the relationship between adolescents' American affirmation and caregivers' ethnic affirmation, a negative 
relationship was specified between caregivers' Ethnic affirmation and adolescents' American affirmation. More specifically, caregivers' with higher ethnic affirmation might be more restrictive and exert more parental control (Halgunseth et al., 2006), thereby limiting adolescents' exposure towards the United States culture (e.g., limitations on peer-friendships).

\section{Hypothesis 3B - Relationship in the Change of Adolescents' and Their} Caregivers' Ethnic and American Identity Affirmation Across Site and Nationality. As was done in Study 2, Study 3 also sought to evaluate whether differences emerged in the relationship between adolescents' and their caregivers' growth parameters varied across participants' context and/or nationality.

As previous stated, given the fact recently immigrated Hispanic caregivers are met with greater ambivalence (Hayes-Bautista, 2004) and noted higher perceived discrimination and negative context of reception in Los Angeles relative to Miami (Schwartz et al., 2013c), caregivers in Los Angeles are likely to make greater efforts to encourage their children to retain their heritage culture. As such, Study 3 hypothesized the relationship between change in adolescents' and caregivers' ethnic affirmation would be higher for participants in Los Angeles than in Miami. Similarly, given the fact Cubans, which were predominately in Miami in this sample, are economically and politically empowered relative to other Hispanic groups while Mexican immigrants are more likely to be undocumented (Massey et al., 2010) and non-White than Cubans (Smart \& Smart, 1995), Study 3 hypothesized the relationship between change in adolescents' and their caregivers' ethnic affirmation would be higher for Mexican and those from all Other nationalities than for Cubans. 
On the other hand, the exact opposite pattern was hypothesized for the relationship between both adolescents' and their caregivers' American affirmation and between adolescents' ethnic and their caregivers' American affirmation. More specifically, given the favorable social position held by Hispanics in Miami and Cubans as a whole, which may allow them to selective identify with aspects of the Untied States culture (Stepick et al., 2011), these caregivers' are likely to be more receptive towards acquiring an American identity. On the other hand, given identification with the United States in Los Angeles (and for non-Cubans) may lead caregivers to become a greater target for discrimination and rejection (Schwartz et al., 2013c), caregivers may be less willing to adopt an American identification independent of the efforts made by their adolescents to transmit American values and culture. As such, stronger relationships were predicted for participants in Miami than in Los Angeles. Similarly, Study 3 predicted the relationship between both adolescents' and their caregivers' American affirmation and between adolescents' ethnic and their caregivers' American affirmation would be stronger for Cubans than Mexicans and participants from all Other nationalities. 


\section{METHODOLOGY}

\section{Participants}

The current study used four waves of data collected as part of the Construyendo Oportunidades Para Adolescentes Latinos (COPAL), a longitudinal study of acculturation among recently arrived Hispanic immigrant families (Schwartz et al., 2013c). The sample consisted of 301 adolescents from Miami $(N=151)$ and Los Angeles $(N=150)$. Data were collected at six month intervals. Miami participants were primarily from Cuba (61\%), the Dominican Republic (8\%), Nicaragua (7\%), Honduras (6\%), and Colombia (6\%). Los Angeles participants were primarily from Mexico (70\%), El Salvador (9\%), and Guatemala (6\%). At Time 1, only $7.8 \%$ of the families in Miami and $25 \%$ in Los Angeles reported household incomes greater than $\$ 30,000$ per year. Adolescents' mean age at baseline was 14.51 years $(S D=0.88$ years, range 14 to 17$)$. A slight majority $(53 \%)$ of the adolescent sample were boys. As per inclusion criteria, all adolescents had arrived in the US within five years of the time of data collection and were either finishing or going into the ninth grade.

While the data consisted of 301 caregivers, there were 34 cases in which the assessed caregiver changed over time (i.e., Father at time 1, Mother at time 2, Uncle at time 3 and 4). As a result, these 34 cases were not included in the analysis. Of the remaining cases, caregivers were predominately the mother $(67.5 \%)$ or father $(18.2 \%)$ of the adolescent. Caregivers' mean age at baseline was 41.09 years $(\mathrm{SD}=7.13$ years, range 22 to 64). In terms of Caregivers' education, in Miami, 14\% of caregivers reported less than nine years of education, $17 \%$ reported attending high school but not graduating, $41 \%$ reported receiving a high school degree, 15\% reported attending college, and 13\% 
reported having a bachelor's degree or greater. In Los Angeles, $40 \%$ of caregivers reported less than nine years of education, 19\% reported attending high school but not graduating, $25 \%$ reported receiving a high school degree, $9 \%$ reported attending college, and $7 \%$ reported having a bachelor's degree or greater.

\section{Procedure}

Recruitment Procedures. As part of the COPAL data collection procedure, families were recruited from randomly selected schools (in the case of Miami-Dade County, which has only one school district) or school districts (in Los Angeles County, which has several). In total, 23 schools took part in the study (10 in Miami and 13 in Los Angeles). The study was approved by the Institutional Review Boards at the University of Miami and the University of Southern California, and by the Research Review Committees for each of the school districts that participated in the study.

Presentations about the study were given in English for Speakers of Other Languages (ESOL) classes in both Miami and Los Angeles. In Los Angeles though, because students are transferred out of ESOL after one year, participants were also recruited from the student body at large. Interested students provided their parent's or guardian's phone number. Staff at each site followed up with these families, ensuring they had been in the US for less than five years. Of the 632 families who met the study's inclusion criteria, 197 were unreachable, primarily because of incorrect or non-working telephone numbers. Of the remaining 435 families who were contacted $31 \%(n=133)$ did not participate $(65 \%$ were unable to participate as a result of work or scheduling conflicts, $13 \%$ missed at least three scheduled assessment appointments, $1 \%$ was planning to move, $2 \%$ were experiencing serious health problems, and $14 \%$ declined but 
did not provide a reason). Each caregiver received $\$ 40$, and each adolescent received a voucher for a movie ticket, for their participation.

Informed Consent/Assent Procedures. Prior to beginning the assessments, the caregiver within each family was asked to provide informed consent for her/himself and the adolescent to participate. In addition, adolescents were asked to provide informed assent. Both consent and assent procedures were made available in English or in Spanish. Moreover, assessment specialists were fluent in both English and Spanish to answer any questions. Within each family, parents and adolescents were taken to separate rooms so that the consent/assent process could be conducted privately. In cases where adolescents declined to provide assent, parents were told that the family did not meet inclusion criteria, as a way of protecting the adolescent's privacy and confidentiality.

Assessment Procedures. Both adolescents and the caregivers' completed assessments on laptop computers. Each participant completed the assessment battery in English or Spanish, according to her/his preference, using an audio computer-assisted interviewing (A-CASI) system (Turner et al., 1998).

\section{Measures}

Multigroup Identity Measure. Ethnic identity exploration and commitment/affirmation was assessed using the Multigroup Ethnic Identity Measure (MEIM; Roberts et al., 1999), one of the most commonly used ethnic identity instruments (Phinney \& Ong, 2007). The MEIM is a 12-item scale measured on a 5-point Likert scale, ranging from 1 (strongly disagree) to5 (strongly agree). As shown in Table 1, the MEIM is composed of 5 items worded to tap into identity exploration (Sample Item: "I think a lot about how my life will be affected by being a member of my ethnic group") 
and 7 to assess identity affirmation (Sample Item: "I have a lot of pride in my ethnic group"').

American Identity Measure. American identity was measured using the US identity Measure (AIM; Schwartz et al., 2012a). The US identity Measure was adapted from the MEIM, with "the United States" inserted in place of "my ethnic group" (see Table 1). Like the MEIM, the AIM is a 12-item rated on a 5-point Likert Scale with 5 items worded to assess American identity exploration (Sample Item: " I think a lot about how my life will be affected by being an American) and 7 devoted to assess identity affirmation (Sample Item: "I have a lot of pride in the United States"). 


\section{STUDY 1 - PSYCHOMETRIC EVALUATION}

\section{Analytic Procedure}

As specified in the Research Aims, Study 1, using Confirmatory Factor Analysis (CFA), sought to test a two-factor versus a one-factor model for the Multigroup Ethnic Identity Measure (MEIM) and the American Identity Measure (AIM) for both recently immigrated Hispanic adolescents and their caregivers respectively. Analysis was conducted Mplus 5.0 using a sandwich estimator (Kauermann \& Carroll, 2001) to adjust the standard errors and account for nesting of participants within data collection sites (specific schools). As outlined by Bollen and Long (1993), indices of absolute fit, relative fit, and indices of fit with a penalty function for lack of parsimony were used in order to examine goodness of model fit. These include the $\chi^{2}$ test of model fit (which should be statistically non-significant, $p<.05)$, the Root Mean Square Error of Approximation (RMSEA), the Comparative Fit Index (CFI); and the standardized root mean square residual (SRMR). According to values suggested by Little (2013), good model fit is represented as $\mathrm{CFI} \geq .95, \mathrm{RMSEA} \leq .05$, and $\mathrm{SRMR} \leq .05$, acceptable fit is represented as CFI $=.90-.95$, and RMSEA $=.08-.05$, and $\mathrm{SRMR}=.08-.05$, and mediocre fit is represented as CFI $=.85-.90$, and RMSEA $=.10-.08$, and SRMR $=.10-$ .08. Although reported throughout the dissertation, given the $\chi^{2}$ value tests a null hypothesis of perfect fit, which is rarely plausible in large samples or complex models (Davey \& Savla, 2010), it was not used to evaluate model fit.

After determining good fit, longitudinal invariance was evaluated next across both measures separately for adolescents and parents using a single sample to take into account the lagged relationship between indicators (e.g., MEIM1 at Time 1 with MEIM1 
at Time 4) as well as the within-time covariances (Brown, 2006). For simplicity, latent variables for exploration and affirmation (respectively for MEIM and AIM) were constrained to be structurally the same solely across Time 1 and Time 4 . As outlined by Brown (2006) and Little (2013), all aspects necessary for determining measurement invariance including configural invariance (pattern invariance), weak factorial invariance (metric/loading invariance), and strong factorial invariance (intercept/scalar invariance) were evaluated. In doing so, it is possible to ensure the same constructs are captured across time (configural invariance) and whether that items function similarly (weak and strong factorial invariance). All analysis began with the least restricted solution and progress towards increasingly restrictive constraints. While the $\Delta \chi^{2}$ difference test is reported, because studies have highlighted its poor performance (Cheung \& Rensvold, 2002; Meade, Johnson, \& Braddy, 2008), the $\Delta$ CFI (>.010), and the $\triangle$ RMSEA $(>.010)$ criteria were primarily used in order evaluate significant differences across models (Little, 2013).

\section{Multigroup Ethnic Identity Measure (MEIM)}

Psychometric Evaluation of the MEIM with Adolescents. Prior to evaluating longitudinal invariance, a one-factor and two-factor model were tested and compared separately at four time points $\left(\mathrm{T}_{1}-\mathrm{T}_{4}\right)$. As seen in Table 2 , with the exception of Time 4 $\left[\chi^{2}(53)=145.334, p<.001 ; \mathrm{CFI}=.875 ; \mathrm{RMSEA}=.084(90 \%\right.$ C.I. $=.068-.100) ; \mathrm{SRMR}$ $=.063]$, all models were indicative of acceptable fit according to the CFI, RMSEA, and the SRMR criterion. Moreover, at every time point, the two-factor model was found to provide significantly better fit compared to the one-factor model. Retaining the twofactor model, longitudinal measurement invariance was assessed next. The estimated 
solution for configural invariance was not associated with acceptable fit [see Table 4, $\chi^{2}(234)=482.22, p<.001 ;$ CFI $=.895 ;$ RMSEA $=.059(90 \%$ C.I. $=.052-.067) ;$ SRMR $=.059]$. As a result of similar wording and suggested modification indices from both the Time 4 and the configural invariance model, error terms for items 9 ('I have a lot of pride in my ethnic group.') and 12 ('I feel good about my cultural or ethnic background.') were allowed to covary at both time point and constrained to be equal. The final model was indicative of acceptable fit $\left[\chi^{2}(233)=463.470, p<.001 ; \mathrm{CFI}=.902 ; \mathrm{RMSEA}=.057\right.$ $(90 \%$ C.I. $=.050-.065) ;$ SRMR $=.059]$.

Given evidence for configural invariance, analysis proceeded to examine weak factorial invariance by constraining repeated indicators to be equal. The difference between the configural and the weak factorial invariance models was found to be nonsignificant $\left[\Delta \chi^{2}(10)=13.741, p=.186 ; \Delta \mathrm{CFI}=.001 ; \Delta \mathrm{RMSEA}<.001\right]$. Finally, with the exception of MEIM01 and MEIM03 which were fixed at 1 to set the scale respectively for Ethnic Identity Exploration and Ethnic Identity Affirmation at Time 1 and Time 4, the indicator intercepts were constrained to be equal across time. There was no significant difference in model fit associated with this additional constraint relative to the weak factorial model $\left[\Delta \chi^{2}(10)=13.186, p=.213 ; \Delta \mathrm{CFI}=.001 ; \Delta \mathrm{RMSEA}=.001\right]$.

Psychometric Evaluation of the MEIM with Caregivers. As before, one-factor and two-factor models were tested separately at each time point and compared. At each time point, the two-factor model provided significantly better fit than the one factor model. However, as seen in Table 2, the two factor model was not indicative of acceptable or mediocre fit at Time $1\left[\chi^{2}(53)=216.487, p<.001 ; \mathrm{CFI}=.846\right.$; RMSEA $=$ $.101(90 \%$ C.I. $=.088-.116) ; \mathrm{SRMR}=.060]$ and Time $2\left[\chi^{2}(53)=225.391, p<.001\right.$; 
$\mathrm{CFI}=.843 ; \mathrm{RMSEA}=.108(90 \%$ C.I. $=.094-.123) ; \mathrm{SRMR}=.057]$ and indicative

mediocre fit at Time $3\left[\chi^{2}(53)=167.783, p<.001 ; \mathrm{CFI}=.893 ; \mathrm{RMSEA}=.092(90 \%\right.$ C.I. $=.076-.108) ; \mathrm{SRMR}=.057]$. Following modification indices, residual correlations were added between items 10 ("I participate in cultural practices of my own group, such as special food, music, or customs”) and 11 (“I feel a strong attachment towards my own ethnic group”) and items 9 ('I have a lot of pride in my ethnic group.') and 12 ('I feel good about my cultural or ethnic background.'). As displayed in Table 2, the fit for the two factor model improved and was indicative of acceptable to mediocre fit at Time 1 $\left[\chi^{2}(51)=160.889, p<.001 ; \mathrm{CFI}=.896 ; \mathrm{RMSEA}=.085(90 \%\right.$ C.I. $=.070-.100) ; \mathrm{SRMR}$ $=.053]$, Time $2\left[\chi^{2}(51)=169.271, p<.001 ; \mathrm{CFI}=.892 ; \mathrm{RMSEA}=.091(90 \%\right.$ C.I. $=$ $.076-.107) ; \mathrm{SRMR}=.062]$, or Time $3\left[\chi^{2}(51)=144.472, p<.001 ; \mathrm{CFI}=.913\right.$; RMSEA $=.084(90 \%$ C.I. $=.068-.101) ;$ SRMR $=.057]$.

Retaining the two-factor model, and building on suggested modification, the configural invariance model was evaluated for Time 1 and Time 4. As shown in Table 4, model fit estimates for the configural invariance model was associated with adequate fit $\left[\chi^{2}(232)=.414, p<.001 ; \mathrm{CFI}=.931 ; \mathrm{RMSEA}=.051(90 \%\right.$ C.I. $=.043-.059) ; \mathrm{SRMR}=$ .053]. Extending this model, there were no significant decreases in model fit when the additional constraints associated with weak $\left[\Delta \chi^{2}(10)=15.590, p=.112 ; \Delta \mathrm{CFI}=.002\right.$; $\Delta \mathrm{RMSEA}<.001]$ and strong factorial invariance $\left[\Delta \chi^{2}(29)=15.981, p=.100 ; \Delta \mathrm{CFI}=\right.$ $.003 ; \triangle \mathrm{RMSEA}<.001]$ were included.

\section{American Identity Measure (AIM)}

Psychometric Evaluation of the AIM with Adolescents. As highlighted in Table 3, while the two factor model was associated with significantly better fit than the 
one factor model, the two factor model was not indicative of acceptable fit at Time 1 $\left[\chi^{2}(53)=194.496, p<.001 ; \mathrm{CFI}=.896 ; \mathrm{RMSEA}=.094(90 \%\right.$ C.I. $=.080-.109) ; \mathrm{SRMR}$ $=.051]$ and Time $2\left[\chi^{2}(53)=161.9537, p<.001 ; \mathrm{CFI}=.918 ; \mathrm{RMSEA}=.086(90 \%\right.$ C.I. $=.071-.101) ; \mathrm{SRMR}=.058]$. Modification indices at both time points suggested a residual correlation between item 3 ("I have a clear sense of the United States and what it means to me") and 7 ("I understand pretty well what being American means to me") and at all four time points a residual correlation between item 5 ('I am happy that I am an American.') and 12 ('I feel good about being American'). Building on these suggested modifications, the two factor model was indicative of acceptable to mediocre fit at Time $1\left[\chi^{2}(51)=194.496, p<.001 ; \mathrm{CFI}=.931 ; \mathrm{RMSEA}=.078(90 \%\right.$ C.I. $=.063-.093) ;$ $\operatorname{SRMR}=.045]$ and Time $2\left[\chi^{2}(51)=148.733, p<.001 ; \mathrm{CFI}=.927 ; \mathrm{RMSEA}=.083(90 \%\right.$ C.I. $=.068-.099) ; \mathrm{SRMR}=.056]$.

Despite this improvement, as shown in Table 5, the configural invariance model without any modifications provided acceptable fit to the data $\left[\chi^{2}(234)=434.861, p<\right.$ $.001 ; \mathrm{CFI}=.913 ; \mathrm{RMSEA}=.053(90 \%$ C.I. $=.046-.061) ; \mathrm{SRMR}=.051]$. As before, analysis proceeded to examine weak and strong factorial invariance. While results provided evidence for weak factorial invariance $\left[\Delta \chi^{2}(10)=15.500, p=.115 ; \Delta \mathrm{CFI}=\right.$ $.003 ; \triangle \mathrm{RMSEA}<.001]$ there was significant decrease in fit statistics for the strong factorial invariance model $\left[\Delta \chi^{2}(10)=44.011, p<.001 ; \Delta \mathrm{CFI}=.015 ; \Delta \mathrm{RMSEA}=.003\right]$. Moving forward, analysis sought to identify offending indicators that violated the assumption of strong invariance. Following recommendations by Cheung and Rensvold (1999), analysis began with the least restrictive model and proceeded by constraining one intercept at a time, examining the change in the chi-square, CFI, and RMSEA indices. 
While results indicated none of the individual item intercepts were considered nonequivalent, two items approached the criteria for significances, item $8\left[\Delta \chi^{2}(1)=\right.$ $12.897, p<.001 ; \Delta \mathrm{CFI}=.006 ; \Delta \mathrm{RMSEA}=.002]$ and item $11\left[\Delta \chi^{2}(1)=16.226, p<.001 ;\right.$ $\Delta \mathrm{CFI}=.006 ; \Delta \mathrm{RMSEA}=.002]$. Thus, evidence indicated partial strong factorial invariance.

Psychometric Evaluation of the AIM with Caregivers. Finally, although the two factor model was consistently associated with significantly better fit than the one factor model, the two factor models were indicative of even mediocre fit. Following theoretically meaningful modifications indices, residual correlations where added between items 3 ("I have a clear sense of the United States and what it means to me") and 7 ("I understand pretty well what being an American means to me"), and between items 5 ("I am happy that I am an American") and 12 ("I feel good about being an American"). The modified the two factor model was indicative of acceptable to mediocre fit at Time 1 $\left[\chi^{2}(51)=142.884, p<.001 ; \mathrm{CFI}=.936 ; \mathrm{RMSEA}=.077(90 \%\right.$ C.I. $=.062-.092)$ SRMR $=.050]$, Time $2\left[\chi^{2}(51)=161.980, p<.001 ; \mathrm{CFI}=.907 ; \mathrm{RMSEA}=.089(90 \%\right.$ C.I. $=.076-.107) ; \mathrm{SRMR}=.055]$, Time $3\left[\chi^{2}(51)=136.221, p<.001 ; \mathrm{CFI}=.908 ;\right.$ $\mathrm{RMSEA}=.080(90 \%$ C.I. $=.064-.097) ; \mathrm{SRMR}=.058]$, and Time $4\left[\chi^{2}(51)=157.288, p\right.$ $<.001 ; \mathrm{CFI}=.901 ; \mathrm{RMSEA}=.091(90 \%$ C.I. $=.075-.108) ; \mathrm{SRMR}=.050]$. Despite the suggested model modifications, in evaluating longitudinal invariance at Time 1 and Time 4, analysis found the configural invariance model without any modifications was indicative of acceptable fit $\left[\chi^{2}(235)=482.216, p<.001 ; \mathrm{CFI}=.909 ; \mathrm{RMSEA}=.050\right.$ $(90 \%$ C.I. $=.050-.065) ; \mathrm{SRMR}=.053]$. Moreover, and building upon the configural invariance model, results provided evidence for weak $\left[\Delta \chi^{2}(10)=4.856, p=.900 ; \Delta \mathrm{CFI}=\right.$ 
$.001 ; \Delta \mathrm{RMSEA}=.007]$ and strong $\left[\Delta \chi^{2}(10)=25.572, p<.001 ; \Delta \mathrm{CFI}=.005 ; \Delta \mathrm{RMSEA}\right.$ $=.001]$ factorial invariance (see Table 5).

\section{Discussion}

Drawing on Erikson's (1968) conceptualization and Marcia's (1980) operationalization of identity development and social identity theory (Tajfel \& Turner, 1986), Phinney (1992) developed a measure explicitly designed for use with various ethnic groups (Phinney, 1992; Phinney \& Ong, 2007). However, as previously stated, before longitudinal analysis can be conducted, it is critical to assess the adequacy of the expected relations between the measured indicators and the underlying latent constructs and ensure that observed longitudinal change in a construct is the result of true change (Brown, 2006; Little, 2013). Given no study to date has evaluated the psychometric properties of the Multigroup Ethnic Identity Measure (MEIM) and the American Identity Measure (AIM) with recently immigrated Hispanic adolescents or adults, Study 1 sought to examine the factor structure of the MEIM and AIM in recently immigrated Hispanic adolescents and their caregivers at each time point. Moreover, given how critical longitudinal factorial invariance is towards evaluating longitudinal change (Little, 2013), the current study sought to ensure both measures are longitudinally/temporally invariant for adolescents and their caregivers' respectively.

Dimensional Analysis. Previous psychometric evaluations of the MEIM using various samples have found conflicting and differing factor structures. More specifically, as reviewed by Phinney and Ong (2007), psychometric studies have proposed either a one-factor or two-factor model as the best fitting factor structure (Phinney \& Ong, 2007). As a whole, despite the various psychometric evaluations suggesting a one-factor solution 
(e.g., Ponterotto, Gretchen, Utsey, Stracuzzi, \& Saya, 2003; Worrell, 2000), Study 1 provided further support for the two-factor structure (i.e., ethnic identity exploration and affirmation) derived by Roberts and colleagues (1999). More specifically, at every time point, examination of the theoretical model for the MEIM consistently indicated a twofactor model provided better fit than a one-factor ethnic identity resolution for recently immigrated Hispanic adolescents and their caregivers.

As reviewed earlier, consistent with Roberts and colleagues' (1999) proposed factor structure, Schwartz and colleagues (2012a) developed the AIM to assess for American identity exploration and affirmation. However, psychometric evaluation of the AIM has been solely conducted in a sample of college students. Study 1, addressing this limitation, provided support for the validity and generalizability of the AIM. More specifically, not only was the proposed two-factor structure derived by Schwartz and colleagues (2012a) consistently indicative of acceptable fit in a sample of recently immigrated Hispanic adolescents and their caregivers, but at each time point, the twofactor structure provide better fit than an overall one-factor model of American identity resolution. These findings clearly support the assertion that ethnic and American identity development may both be structurally characterized by exploration and affirmation.

It should be noted however, that acceptable fit for the two-factor model both the MEIM and AIM for adolescents and their caregivers was not achieved without additional residual correlations between measurement indicators. As stated by Brown (2006), the inclusion of a residual correlation implies that some of the covariance in the indicators are not fully explained by the underlying latent constructs. The shared variance between indicators not accounted by latent constructs maybe a result of the similarity in the 
wording of items or a result of an outside or third variable (Brown, 2006). While including residual correlations to account for the effects of a third variable are problematic, that it is not the case for including residual correlations that account for similarity in wording between indicators (Landis, Edwards, \& Cortina, 2009).

Regarding the MEIM, as suggested by modification indices and consistent with Schwartz and colleagues' (2012a) psychometric evaluation of the AIM, residual correlations between items 9 ('I have a lot of pride in my ethnic group.') and 12 ('I feel good about my cultural or ethnic background.') were included in order to account for extremely similar item wording. Additionally, for caregivers, residual correlations were also drawn between item 10, which assess individuals' level of participation in cultural practices, and item 11 which assess the level of individuals' attachment towards their ethnic group. It likely that for adults, who have spent the better part of their life in their country of origin, attachment towards their heritage culture and engagement in cultural practices may be inextricably tied. Future studies should further examine the relation between these two items through the use of cognitive interviews, which are able to ensure participants understand the question in the way intended by the researcher (Collins, 2003) and identify and analyze sources of response error by tapping into the thought processes respondents use to answer questions on a survey (Beatty and Willis 2007; Willis, 2005). Although the configural invariance model for the AIM did not include any residual correlations, paralleling Schwartz and colleagues' (2012a) psychometric assessment, at nearly all time points acceptable fit for the two-factor model was only achieved by including residual correlations between extremely similarly worded items: items 3 ("I have a clear sense of the United States and what it means to me") and 7 ("I understand 
pretty well what being an American means to me"), and between items 5 ("I am happy that I am an American") and 12 ("I feel good about being an American").

Longitudinal Invariance. In many respects, longitudinal factorial invariance is one of the most important empirical questions to address (Little, 2013). Before longitudinal analysis can be conducted, is important to ensure observed longitudinal change is a result of true change (Brown, 2006). To date however, no study has sought to examine whether observe longitudinal change in the MEIM and AIM is solely a result of true change and not change on the structure of the measure. Building on the Confirmatory Factor Analysis (CFA) models conducted at each time point, Study 1 examined all aspects necessary for determining measurement invariance. In particular, psychometric evaluation of the MEIM and AIM with recently immigrated Hispanic adolescents examined configural invariance, weak factorial invariance, and strong factorial invariance. Results of Study 1 found the MEIM for both adolescents and their caregivers and the AIM for caregivers to be completely longitudinally invariant. Regarding adolescents' response to the AIM, analysis for longitudinal invariance failed to meet the $\Delta$ CFI criteria for strong factorial invariance. However, given item intercept level analysis determined no one item was longitudinally invariant, the AIM for recently immigrated Hispanic adolescents was found to be indicative of partial longitudinal invariance. Thus, as a whole, findings suggest that mean change over time can be attributed to change in the true score of the construct and not due to temporally unstable relationships or inequality in indicator's location parameters over time (Brown, 2006). 


\section{STUDY 2 - EVALUATING GROWTH AND PREDICTORS OF GROWTH}

\section{Analytic Overview}

To evaluate growth in adolescents' and their caregivers' ethnic and American identity affirmation, latent growth curve modeling was utilized in Mplus 5.0 using a sandwich estimator (Kauermann \& Carroll, 2001) to adjust the standard errors and account for nesting of participants within data collection sites (specific schools). Because statistical tests of model fit in Mplus for latent growth curve models apply the incorrect null model (Widaman \& Thompson, 2003), analysis began with an intercept-only model. From there, the model moved to a linear growth curve model and finally to a quadratic growth curve model. Models were compared against each other using the likelihood ratio test to evaluate for significant differences.

\section{Preliminary Analysis}

Prior to conducting the primary analyses, descriptive statistics for all variables were calculated (see Table 6). Data were examined for normality and outliers. With regard to normality, skewness and kurtosis were used as indicators of univariate normality, with absolute values greater than 2.3 indicating non-normality problematic for maximum likelihood estimation (Lei \& Lomax, 2005). Kurtosis and skewness for all variables were within acceptable ranges. Data were also evaluated for non-model based outliers by examining leverage indices for each individual and defining an outlier as a leverage score four times greater than the mean leverage. No outliers were found.

\section{Evaluating Growth in Ethnic and American Identity Affirmation}

\section{Adolescents' Ethnic and American Identity Affirmation. Regarding}

adolescents' ethnic and American identity affirmation, three models were evaluated: 
growth in ethnic affirmation (Model 1), growth in American identity affirmation (Model 2), and growth in both ethnic and American identity affirmation (Model 3).

Model 1 - Adolescents' Change in Ethnic Identity Affirmation. As seen in Table 7, there was a significant difference between the linear growth curve model and the intercept model $[\Delta-2 \operatorname{LL}(3)=9.294, p=.026]$. Prior to interpreting paths within this model, the corrected CFI (Widaman \& Thompson, 2003) was calculated using the intercept-only model as the null model. While all standard fit indices were found to be indicative of acceptable fit $\left[\chi^{2}(5)=9.828, p=.080 ;\right.$ CFI $=.929 ;$ RMSEA $<.001 ;$ SRMR $=.032]$, the corrected CFI indicated poor fit $\left[\mathrm{CFI}_{\text {cor. }}=.247\right]$. In addition, analysis revealed a non-significant average linear slope $\left[\bar{x}_{\text {Slope }}=.010, p=.931\right.$, see Table 9]. Results did however find significant variability around this slope $[S D=1.127, p=.033]$. The average level of ethnic identity affirmation at Time 1 was $19.757(p<.001)$ with about $95 \%$ of the participants scoring between 12.975 and 26.539 [SD $=3.391, p<.001]$.

Model 2-Adolescents' Change in American Identity Affirmation. With regard to American identity affirmation, analysis indicated that the linear growth curve model provided better fit than the intercept-only model $[\Delta-2 \operatorname{LL}(3)=29.292, p<.001$; see Table 7]. Next, a quadratic model was evaluated against the linear growth curve model with freely estimated residuals. The difference between the two models was not significant $[\Delta$ $2 \mathrm{LL}(4)=4.306, p=.366]$, nor was the quadratic slope coefficient $\left[\bar{x}_{\text {Quad }}=-.033, p=\right.$ .739]. Thus, the linear growth curve model was retained. The corrected CFI along with all other fit indices, were indicative of good model fit $\left[\chi^{2}(5)=4.718, p=.451 ; \mathrm{CFI}=1.000\right.$; $\left.\mathrm{CFI}_{\text {cor }}=1.015 ; \mathrm{RMSEA}<.001 ; \mathrm{SRMR}=.025\right]$. 
Results indicated (see Table 9) that, at Time 1, the average level of American identity affirmation was $16.499(p<.001)$ with about $95 \%$ of the participants scoring between 7.482 and $25.516[S D=4.51, p<.001]$. Moreover, the linear slope was significant, such that with every assessment period, on average, there was a .480 ( $p=$ .001) increase in American identity affirmation. In addition, there was significant variation around this slope $[S D=1.32, p=.001]$, with $95 \%$ of the sample having a slope between -.2.15 and 3.11. Finally, there was a significant relationship between adolescents' American identity affirmation at Time 1 and their growth across time, such that higher levels of American affirmation was associated with decreased growth $[\psi(r)=$ $2.533(-.427), p=.004]$.

Model 3 - Ethnic and American Identity Affirmation. Next, Study 2 sought to examine the relationship between ethnic and American identity affirmation. Given that Schwartz and colleagues (2012a) found a significant positive relationship between adolescents' ethnic and American identity affirmation, not accounting for adolescents' American identity affirmation may have masked significant growth in adolescents' ethnic identity affirmation. As such, analysis began with an intercept model for both ethnic and American identity affirmation. Not surprisingly, this model was not indicative of good fit $\left[\chi^{2}(38)=108.594, p=.535 ; \mathrm{CFI}=1.000 ; \mathrm{RMSEA}<.001 ; \mathrm{SRMR}=.032\right]$. Building upon this model, analysis proceeded first by specifying linear growth for adolescents' American identity affirmation and then for adolescents' ethnic identity affirmation. While fit significantly improved in both cases, the final dual process model was indicative of mediocre fit $\left[\chi^{2}(22)=74.769, p<.001 ; \mathrm{CFI}=.861 ; \mathrm{RMSEA}=.089 ; \mathrm{SRMR}=.089\right]$. Moreover, growth curve parameter for adolescents' ethnic identity affirmation was still 
found to be non-significant. As such, analysis proceeded by including ethnic identity affirmation as a time-varying predictor of adolescents' American identity affirmation. This model was indicative of good fit $\left[\chi^{2}(17)=15.838, p=.535\right.$; CFI $=1.000$; RMSEA $<$ $.001 ; \mathrm{SRMR}=.032]$. For purposes of interpretation, American identity was centered at the grand mean.

As seen in Table 10, at Time 1 the average level of American identity affirmation for adolescents' with an average ethnic identity affirmation, was $16.50(p<.001)$ with about $95 \%$ of the participants scoring between 7.644 and $25.356[S D=4.43, p<.001]$. Once more, the model detected a significant linear slope such that on average, after controlling for ethnic identity affirmation, there was a .492 increase in American identity affirmation. Analysis revealed significant variation around this slope $[S D=1.297, p<$ .001 ] with $95 \%$ of the sample having a slope between -2.102 and 3.086. Moreover, there was a significant and negative relationship between adolescents' American identity affirmation at Time 1 and growth $[\psi(r)=-2.603(-.431), p=.005]$. With regards to the relationship between American and ethnic identity affirmation, analysis found significant relationships at Time 2, Time 3, and Time 4 (see Table 11). More specifically, at Time 2, for a 1 unit increase in ethnic identity affirmation there was a .251 increase in adolescents' American identity affirmation $(p=.003)$. Similarly, at Time 3 and Time 4 respectively, there was a .386 and .371 in American identity affirmation at corresponding time points $(p<.001)$.

Caregivers' Ethnic and American Identity Affirmation. Just as we did with adolescents, three models were evaluated: growth in Caregivers' Ethnic affirmation 
(Model 4), American affirmation (Model 5), and finally both ethnic and American affirmation (Model 6).

Model 4 - Change in Ethnic Identity Development Affirmation. As seen in Table 8 , analysis found the growth curve model indicative of better fit than the intercept-only model $[\Delta-2 \operatorname{LL}(3)=29.40, p<.001]$. As before, the linear growth curve model was compared to a quadratic growth curve model. Analysis revealed no significant difference between the two models $[\Delta-2 \operatorname{LL}(4)=3,234, p=.519]$. Given the quadratic growth parameter was not found to be significant $\left[\bar{x}_{\text {Quad }}=-0.027, p=.737\right]$, the linear growth curve model was put forth championed model $\left[\chi^{2}(5)=3.944, p=.557 ; \mathrm{CFI}=1.000\right.$, $\left.\mathrm{CFI}_{\text {cor. }}=1.063, \mathrm{RMSEA}<.001, \mathrm{SRMR}=.068\right]$. Growth parameters are displayed in Table 9. At Time 1 the average level of caregivers' ethnic identity affirmation was 20.954 $(p<.001)$ with about $95 \%$ of the participants scoring between 17.292 and $24.616[S D=$ $1.831, p<.001]$. Moreover, the model detected a significant linear slope such that on average, there was a $.250(p=.050)$ decrease in caregivers' ethnic identity affirmation. Analysis revealed no significant variation around this slope $[S D=.594, p=.147]$. Finally, although moderate to high in strength, a marginally significant relationship was found between caregivers' ethnic identity affirmation at Time 1 and their growth across time $[\psi(r)=.580(.532), p=.093]$.

Model 5 - Change in American Identity Affirmation. With regards to caregivers' American identity, analysis found the linear growth curve model to be indicative of better fit than the intercept-only model $[\Delta-2 \operatorname{LL}(3)=14.710, p=.002]$. Moreover, the linear growth curve model was indicative of good model fit $\left[\chi^{2}(5)=4.736, p=.449, \mathrm{CFI}=\right.$ $\left.1.000, \mathrm{CFI}_{\text {cor. }}=1.019, \mathrm{RMSEA}<.001, \mathrm{SRMR}=.056\right]$. However, despite the fact that the 
linear growth curve model provided better fit, the average growth was not found to be statistically different from zero $\left[\bar{x}_{\text {Slope }}=-.002, p=.985\right.$; see Table 8]. Results did however find significant variance around the slope $[S D=1.227, p=.005]$. The average level of American identity affirmation at Time 1 was $17.668(p<.001)$ with about 95\% of the participants scoring between 9.331 and $26.004[S D=4.168, p<.001]$.

Model 6 - Ethnic and American Identity Affirmation. As was done with adolescents, analysis began with an intercept model for both ethnic and American identity affirmation. Not surprisingly, this model was not indicative of good fit $[\Delta-2 \mathrm{LL}$ $(38)=108.594, p=.535 ; \mathrm{CFI}=1.0 ; \mathrm{RMSEA}<.001 ; \mathrm{SRMR}=.032]$. As before, and consistent with Model 4, analysis proceeded by including a growth parameter for caregivers' ethnic identity affirmation. This model was found to be statistically significant $[\Delta-2 \operatorname{LL}(4)=30.706, p<.001]$, however indicative of mediocre fit $\left[\chi^{2}(27)=\right.$ 97.007, $p<.001 ; \mathrm{CFI}=.894 ;$ RMSEA $<.001 ;$ SRMR $=.069]$. Finally, a growth parameter was included for caregivers' America identity affirmation. While the dual process model was associated with acceptable fit, a linear dependency emerged between variables resulting in a correlation greater than 1 between change in ethnic affirmation and baseline scores $[\psi(r)=.683(1.035), p<.001]$ and between change in caregivers' American identity affirmation $[\psi(r)=.679(1.338), p<.001]$. Although Model 3 found a significant negative slope, no significant variance was detected around this slope. Similarly, the dual process revealed no significant variance around this slope. Given the positive correlation between caregivers' ethnic and American affirmation, the inclusion of caregivers' American was likely to result in the emergence of a linear dependency and multicollinearity between variables. As such, in order to evaluate the relationship 
between caregivers' ethnic and American affirmation, the covariance between caregivers' ethnic intercept and slope parameter was constrained to zero. The final model was still a significant improvement upon the ethnic affirmation growth only model $[\Delta-2 \operatorname{LL}(4)=$ $44.592, p<.001]$ and associated with acceptable fit $\left[\chi^{2}(23)=62.558, p<.001 ; \mathrm{CFI}=\right.$ $.940 ;$ RMSEA $=.080 ;$ SRMR $=.067]$.

As see in Table 12 at Time 1 the average level of ethnic identity affirmation was $20.964(p<.001)$ with about $95 \%$ of the participants scoring between 16.680 and 24.375 $[S D=2.142, p<.001]$. Additionally, and consistent with Model 4, there was a negative linear slope for caregivers' ethnic identity affirmation $\left[\bar{x}_{\text {Slope }}=-.259, p=.038\right]$ with significant variation around this slope $[S D=.541, p=.018]$, likely a result of removing the variance accounted for by baseline scores. With regards to American identity affirmation, results once again detected no significant change over time $\left[\bar{x}_{\text {Slope }}=-.004, p\right.$ $=.965]$ with a significant amount of variation around this slope $[S D=1.194, p=.007]$. As previously stated, several significant relationships emerged between ethnic and American identity (see Table 13). In addition to the high correlation between slope parameters specified earlier $[\psi(r)=.671(.820), p=.001]$, a significant positive relation emerged between ethnic and American baseline scores $[\psi(r)=4.122(.468), p<.001]$. Finally, analysis revealed a significant negative relationship between American affirmation at Time 1 and change in caregivers' ethnic identity $[\psi(r)=-0.997(-.440), p$ $=.050]$ and a significant and negative relationship between ethnic affirmation at Time 1 and change in American affirmation [ $\psi(r)=-0.881(-.344), p=.044]$. 


\section{Predictors of Growth in Ethnic and American Identity Affirmation}

Given the fact that preceding analyses found significant inter-individual differences around linear rates of change (significant variance around growth parameters for all but caregivers' ethnic identity affirmation), it was important to determining if there were significant differences across key contextual factors that may account for this variation. As previously highlighted, the literature has recognized the role receiving contexts may exert on ethnic and American identity development (Schwartz et al., 2013c). Additionally, as a result of the large amount of variability among people of Latino and Hispanic descent (Schwartz et al., 2007), there is a growing recognition that studies must evaluate whether differences across national origin exists rather than assume Hispanics are a homogenous pan-ethnic population (Umaña-Taylor, 2011). Thus, analysis continued by evaluating if there were significant differences across receiving context and national subgroups.

Differences across Receiving Contexts. Paralleling the process above, receiving context or site location was included in all growth models as a time-invariant predictor.

Model 1a - Adolescents' Ethnic Identity Affirmation. Once again, the linear growth curve model with site as a time-invariant predictor was found to be significantly better than the intercept model $[\Delta-2 \operatorname{LL}(4)=14.050, p=.007$, see Table 14]. In addition, results did reveal a significant difference across site in change in ethnic identity affirmation over time $\left[\bar{x}_{d i f}=.429, p=.043\right]$. More specifically, as shown in Table 18, while neither growth parameters were significant, participants from Miami had a negative trajectory $\left[\bar{x}_{\text {Slope }}=-.234, p=.274\right]$ while those from Los Angeles had a positive trajectory 
$\left[\bar{x}_{\text {Slope }}=.267, p=.110\right]$. Analysis also revealed significant differences in adolescents' ethnic affirmation at baseline $\left[\bar{x}_{d i f}=-1.201, p=.002\right]$ such that participants in Miami scored $1.201(p=.003)$ units higher than participants from Los Angeles at Time 1.

Model 2a-Adolescents' American Identity Affirmation. Moving forward, growth in adolescents' American identity with site as a time-invariant predictor was examined. With site as a time-invariant predictor, the linear growth curve model was once again an improvement upon an intercept-only model $[\Delta-2 \operatorname{LL}(4)=28.900, p<.001$, see Table 14 $]$ and associated with good fit $\left[\chi^{2}(7)=6.399, p=.494 ;\right.$ CFI $=1.000 ;$ RMSEA $<.001 ; \mathrm{SRMR}=.025]$, but with an improvement over an intercept-only model. At baseline, there was a significant difference in the average level of American identity affirmation across site $\left[\bar{x}_{d i f}=2.382, p=.024\right]$ with adolescents in Miami $\left[\bar{x}_{\text {Intercept }}=\right.$ $17.676, p<.001]$ scoring higher than participants in Los Angeles $\left[\bar{x}_{\text {Intercept }}=15.294, p<\right.$ $.001]$. With regards to average change over time, there were no significant differences between Miami and Los Angeles $\left[\bar{x}_{d i f}=-.184, p=.486\right]$.

Model 3a-Adolescents' Ethnic and American Identity Affirmation. As was done before, site was added as a time-invariant predictor on an intercept-only model of adolescents' American and ethnic identity affirmation. As shown in Table 14, while including growth parameters for American and ethnic identity affirmation improved fit, the final dual process model was once again associated with mediocre fit $\left[\chi^{2}(26)=\right.$ 78.482, $p<.001 ; \mathrm{CFI}=.880 ; \mathrm{RMSEA}=.082 ; \mathrm{SRMR}=.060]$. As was done in Model 3 previously, analysis proceeded by including ethnic identity affirmation as at time-varying predictor of American identity affirmation. This model was indicative of goodness-of-fit 
$\left[\chi^{2}(19)=16.314, p=.636 ; \mathrm{CFI}=1.000 ; \mathrm{RMSEA}<.001 ; \mathrm{SRMR}=.027\right]$. Parameter estimates are presented in Table 18.

After controlling for adolescents' ethnic identity, there was still a significant difference in the average level of American identity affirmation at Time 1 between adolescents' in Miami and Los Angeles $\left[\bar{x}_{d i f}=-2.215, p=.032\right]$ with those in Miami scoring higher. Moreover, even after controlling for adolescents' ethnic identity, there was still no significant differences in the average level of change in participants' American identity between adolescents from Miami and Los Angeles in $\left[\bar{x}_{d i f}=.092, p=\right.$ .719]. However, after controlling for ethnic identity, analysis revealed a significant change in American identity for adolescents from Miami $\left[\bar{x}_{\text {Slope }}=.4404, p=.026\right]$. Similar to Model 3a, the relationship between American and ethnic identity affirmation, analysis once more found significant relationships at Time 2, Time 3, and Time 4 that parallel the effects found in Model 3.

Model 4a-Caregivers' Ethnic Identity Affirmation. Although Model 4 found no significant variation around change in caregivers' ethnic identity affirmation, as stated by Muthen (2002) on October 30 in the Mplus Discussion forum, "even if the slope growth factor variance is not statistically significant without covariates, inclusion of covariates often shows that they have significant influence on the slope so that the slope does vary (as a function of the covariates)". As such, analysis proceeded to include site as a timeinvariant predictor of caregivers"' ethnic identity affirmation. This model was not only associated with good fit $\left[\chi^{2}(7)=10.474, p=.163 ; \mathrm{CFI}=.980 ; \mathrm{RMSEA}=.043 ; \mathrm{SRMR}=\right.$ $.060]$ but better than an intercept-only model $[\Delta-2 \operatorname{LL}(4)=32.944, p<.001]$. While the 
average level of caregivers' ethnic identity affirmation at baseline was not significantly different across site, difference in the average change over time approached significance $\left[\bar{x}_{d i f}=.335, p=.088\right]$. More specifically, as seen in Table 18, on average caregivers' ethnic identity affirmation for participants in Los Angeles decreased $\left[\bar{x}_{\text {Slope }}=-.424, p<\right.$ $.001]$ while the average change over time for participants from Miami was not found to be statistically different from zero $\left[\bar{x}_{\text {Slope }}=-.088, p=.611\right]$.

Model 5a-Caregivers' American Identity Affirmation. Next, analysis proceeded to examine site differences across caregivers' American identity affirmation. As shown in Table 15, the linear growth model with site as a time-invariant predictor was a significant improvement of an intercept-only $[\Delta-2 \mathrm{LL}(4)=26.466, p<.001]$ model and met all criteria for good fit $\left[\chi^{2}(7)=5.703, p=.575 ; \mathrm{CFI}=1.000 ; \mathrm{RMSEA}<.001 ; \mathrm{SRMR}\right.$ $=.042]$. At baseline, there was a significant difference in the average level of American identity affirmation across site $\left[\bar{x}_{d i f}=3.114, p<.001\right]$ with caregivers in Miami $\left[\bar{x}_{\text {Intercept }}\right.$ $=19.247, p<.001]$ scoring higher than participants Los Angeles $\left[\bar{x}_{\text {Intercept }}=16.247, p<\right.$ $.001]$. There was no significant difference across site in the average change of American identity affirmation overtime $\left[\bar{x}_{d i f}=.305, p=.119\right]$.

Model 6a-Caregivers' Ethnic and American Identity Affirmation. Finally, paralleling the process conducted in Model 3a, analysis began with an intercept-only model of caregivers' ethnic and American identity affirmation with site as a timeinvariant predictor. This model was not indicative of good fit $\left[\chi^{2}(37)=123.034, p<.001\right.$; $\mathrm{CFI}=.910 ; \mathrm{RMSEA}=.088 ; \mathrm{SRMR}=.119]$. Building on this model, linear growth was specified for caregivers' ethnic identity affirmation. As shown in Table 15, model fit 
improved $[\Delta-2 \operatorname{LL}(5)=42.356, p<.001]$. While this model was indicative of acceptable fit, analysis proceeded to evaluate a dual-process model. Once more however, a linear dependency emerged upon the inclusion of the slope parameter for caregivers' American identity. As before, analysis proceeded by constraining the covariance between slope and intercept for caregivers' Ethnic identity affirmation to zero. The final model was found to be a significant improvement upon the ethnic affirmation growth only model $[\Delta-2 \operatorname{LL}(5)=$ $40.822, p<.001]$ and associated with good fit $\left[\chi^{2}(27)=56.293, p=.008 ; \mathrm{CFI}=.969\right.$; $\mathrm{RMSEA}=.060 ; \mathrm{SRMR}=.051]$.

Parameter estimates for ethnic and American identity affirmation intercept and slope across site are presented in Table 18. With regards to average change in caregivers' ethnic identity, there were significant differences across site $\left[\bar{x}_{d i f}=-.381, p=.032\right]$ with caregivers from Los Angeles showing significant average decline $\left[\bar{x}_{\text {Slope }}=-.471, p<\right.$ .001]. Moreover, and consistent with Model 5, significant differences emerged across site in caregivers' American identity affirmation at baseline $\left[\bar{x}_{d i f}=3.283, p<.001\right]$ with caregivers from Miami scoring higher. Findings regarding the relationship between ethnic and American identity affirmation was consistent with those found in Model 6 (see Table 13).

Differences across Nationality. Towards evaluation, nationality was included in all growth models as a time-invariant predictor. Although the sample was fairly diverse (over 16 different nations), it was predominately composed of Cubans (30\%) and Mexicans (38\%). As such, all other nationalities (e.g., Nicaraguan, Honduran, Argentinian, etc.) were collapsed into one group and compared to Cubans and Mexicans. 
Nationality was dummy coded and analysis proceeded first with Cubans as the reference group and then participants from all other nationalities.

Model 1 b - Adolescents' Ethnic Identity Affirmation. Once again, analysis began by evaluating the intercept model against a linear growth curve model with nationality as a time-invariant predictor. As shown in Table 16, analysis found the linear growth curve model was significantly different than the intercept-only model $[\Delta-2 \operatorname{LL}(5)=12.482, p=$ .029]. However, parameter estimates revealed no significant differences between Cubans, Mexicans, or adolescents' from all other nationalities or significant growth over time (see Table 18).

Model 2b-Adolescents' American Identity Affirmation. As shown in Table 16, the linear growth curve model with nationality as a time-invariant predictor provided significantly better fit than an intercept-only model and was indicative of good fit $\left[\chi^{2}(9)=\right.$ $5.826, p=.757 ; \mathrm{CFI}=1.000 ; \mathrm{RMSEA}<.001 ; \mathrm{SRMR}=.019]$. Parameter estimates for intercept and slope across nationality are presented in Table 18. Analysis revealed recently immigrated Cuban adolescents' had a significantly higher average level of American identity resolution at Time 1 than Mexicans $\left[\bar{x}_{d i f}=-4.012, p<.001\right]$ and participants from other nationalities $\left[\bar{x}_{d i f}=-2.638, p<.001\right]$. The difference between Mexican adolescents and participants of all other nationalities was found to be approaching significance $\left[\bar{x}_{d i f}=-1.374, p=.070\right]$. Moreover, while there were no significant differences in the average change in American identity affirmation over time, the average growth for Cubans was found to be non-significant $(p=.202)$ while average growth for both Mexicans $\left[\bar{x}_{\text {Slope }}=.637, p=.001\right]$ and participants from other 
nationalities $\left[\bar{x}_{\text {Slope }}=.432, p=.043\right]$ were found to be significantly different from zero and positive.

Model 3b-Adolescents' Ethnic and American Identity Affirmation. Next, nationality was added as a time-invariant predictor on an intercept-only model of adolescents' ethnic and American identity affirmation. As was seen in Model 3a, while a dual process model was associated the best fit, it was indicative of mediocre fit $\left[\chi^{2}(30)=\right.$ 84.081, $p<.001 ; \mathrm{CFI}=.890 ; \mathrm{RMSEA}=.077 ; \mathrm{SRMR}=.056]$. As such, the final model included ethnic identity affirmation as at time-varying predictor. This model was indicative of goodness-of-fit $\left[\chi^{2}(21)=17.571, p=.656 ; \mathrm{CFI}=1.000 ; \mathrm{RMSEA}<.001\right.$; $\mathrm{SRMR}=.027]$. Parameter estimates for intercept and slope across nationality are presented in Table 16.

Even after controlling for ethnic identity, Cuban adolescents had a significantly higher average level of American identity affirmation at Time 1 than Mexicans $\left[\bar{x}_{d i f}=-\right.$ $3.880, p<.001]$ and participants from all other nationalities $\left[\bar{x}_{d i f}=-2.585, p<.001\right]$. Also consistent with Model 2b, after controlling for ethnic identity there was still no significant differences in the average change in American identity affirmation over time. While there was no statistical difference, there were note able differences in the average growth of American identity. More specifically, after controlling for ethnic identity, average change in American identity for Cubans adolescents approached significance [ $\left.\bar{x}_{\text {Slope }}=.419, p=.057\right]$ while average change in American identity for participants from all other nationalities was found to no longer be statistically significant $\left[\bar{x}_{\text {Slope }}=.352, p=\right.$ .101]. With regards to the relationship between American and ethnic identity affirmation, 
analysis once more found significant relationships at Time 2, Time 3 , and Time 4 that parallel the effects found in Model 3.

Model 4b-Caregivers' Ethnic Identity Affirmation. With regards to caregivers' ethnic identity, the linear growth curve model with nationality as a time-invariant predictor was indicative of good fit $\left[\chi^{2}(9)=8.209, p=.513\right.$; CFI $=1.000$; RMSEA $<$ $.001 ; \mathrm{SRMR}=.045]$ and an improvement of the intercept-only model $[\Delta-2 \mathrm{LL}(5)=$ $37.024, p<.001]$. Analysis revealed no significant difference in caregivers' average ethnic identity affirmation at baseline. Regarding change in ethnic identity affirmation over time, Cuban caregivers had a higher average change than Mexican Caregivers $\left[\bar{x}_{d i f}\right.$ $=.543, p=.001]$ and those from all other nationalities $\left[\bar{x}_{d i f}=.558, p=.002\right]$. More specifically, while on average there was a significant decrease in ethnic identity affirmation for both Mexicans [ $\left.\bar{x}_{\text {Slope }}=-.435, p<.001\right]$ and caregivers' from 'Other' nationalities $\left[\bar{x}_{\text {Slope }}=-.450, p=.001\right]$, there was no significant average change for Cubans' $\left[\bar{x}_{\text {Slope }}=.108, p=.442\right]$.

Model 5b-Caregivers' American Identity Affirmation. While model fit for the intercept model with nationality as a time-invariant predictor was indicative of good fit $\left[\chi^{2}(14)=28.590, p=.012 ; \mathrm{CFI}=.989 ; \mathrm{RMSEA}=.062 ; \mathrm{SRMR}=.043\right]$, fit estimates significantly improved with addition of a linear growth parameter $[\Delta-2 \operatorname{LL}(5)=26.726, p$ $<.001]$. However, while no significant differences emerged across nationality, model estimates of average change over time was only significant for Cuban caregivers $\left[\bar{x}_{\text {Slope }}=\right.$ $.176, p=.011]$ with Mexican and participants from all other nationalities exhibiting a non-significant negative trend. Analysis did however revealed significant difference 
across nationality in caregivers' average American identity affirmation at baseline. More specifically, Cuban caregivers' average score at baseline was significantly higher than Mexicans $\left[\bar{x}_{d i f}=-3.804, p<.001\right]$ and participants from all other nationalities $\left[\bar{x}_{d i f}=\right.$ $1.465, p=.018]$. In addition, the average level of American identity affirmation for Mexican participants was $2.399(p=.005)$ less than those from all other nationalities. All model parameters are presented in Table 18.

Model 6b-Caregivers' Ethnic and American Identity Affirmation. Finally, as was done in previous joint processes models, analysis began with an intercept-only model for caregivers' ethnic and American identity affirmation with nationality as a time-variant predictor. Consistent with previous models, the intercept-only model was associated with poor to mediocre fit $\left[\chi^{2}(43)=132.176, p<.001 ; \mathrm{CFI}=.909 ; \mathrm{RMSEA}=.083 ; \mathrm{SRMR}=\right.$ .111]. Building on this model, a linear growth parameter for ethnic affirmation was included, leading to an acceptable fitting model $\left[\chi^{2}(37)=93.105, p<.001 ;\right.$ CFI $=.943$; RMSEA $=.071 ;$ SRMR $=.051]$. As was seen in previous evaluation, upon including a growth parameter for caregivers' American identity, a linear dependency was detected for change in caregivers' ethnic identity affirmation. As shown in Table 17, the final model with the constraining the covariance between slope and intercept for caregivers' Ethnic identity affirmation to zero, was indicative of good fit $\left[\chi^{2}(31)=56.708, p=.003\right.$; CFI $=$ $.974 ;$ RMSEA $=.052 ;$ SRMR $=.044]$

Parameter estimates are presented in Table 18. Significant differences emerged across caregivers' ethnic identity and their American identity affirmation at Time 1. As found in Model 4b, while caregivers from Mexico and all Other nationalities were decreasing in their ethnic identity, no significant change was found for Cubans. 
Additionally, caregivers of Cubans descent had significantly higher American identity affirmation at Time 1 than Mexicans $\left[\bar{x}_{d i f}=4.128, p<.00^{`}\right]$ and those from all Other nationalities $\left[\bar{x}_{d i f}=1.449, p=.09\right]$. Mexicans also had significantly lower American

affirmation than those from all Other nationalities at Time $1\left[\bar{x}_{d i f}=2.679, p<.001\right]$. Once more, findings regarding the relationship between ethnic and American identity affirmation was consistent with those found in Model 6 (see Table 13).

\section{Discussion}

While the literature on ethnic identity derives, in part, its theoretical perspective from a developmental model, there have been only a handful of longitudinal studies (limited to adolescents) examining the trajectory of ethnic identity development (UmañaTaylor, 2011). Moreover, to date, the trajectory of American identity in adolescents or adults has yet to be examined within in a longitudinal study in isolation. The goal of Study 2 was to address this important gap in the literature on cultural identity. Specifically, Study 2 used Latent Growth Curve Modeling (LGCM) in order to evaluate the developmental trend of recently immigrated Hispanic adolescents' and their caregivers' ethnic and American identity affirmation separately.

\section{Developmental Trajectory of Recently Immigrated Hispanic Adolescents'}

Ethnic and American Identity Development. Contrary to Study 2's hypothesis, no significant growth in recently immigrated Hispanic adolescents' ethnic identity affirmation was found. However, results indicated a significant difference in the overall trend of adolescents' ethnic identity affirmation across site. More specifically, adolescents' ethnic affirmation in Los Angeles was found to increase while those in 
Miami decreased over time. Moreover, although this difference non-significant across nationality, a similar pattern was found. While none of these growth parameters were found to be significant, findings may point to theoretically meaningful difference that should be further examined. Additionally, and consistent with previous baseline evaluations (Schwartz et al., 2012b), there were significant differences in baseline levels of recently immigrated Hispanic adolescents' ethnic identity affirmation. More specifically, adolescent from Miami had higher levels of ethnic identity affirmation than those in Los Angeles at Time 1. However, no significant differences were found across nationality. As such, baseline differences in adolescents' ethnic affirmation may be attributed solely to differences across context not yet examined.

While various factors may contribute to these differences, these findings may be a result of the favorable social positions held by Hispanics in Miami (Stepick, Grenier, Castro, \& Dunn, 2003; Stepick et al., 2011). Given that studies found levels of discrimination and perceived negative contexts of reception are significantly lower in Miami than in Los Angeles (Schwartz et al., 2013c), adolescents' immigrating to Miami may initially feel more welcomed and be encouraged to retain their heritage as a result. Baseline differences between sites may therefore reflect differences in adolescents' perception of positive context of reception (Schwartz et al., 2013c) or differences across other contextual variables (i.e., social-economic status). However, as originally discussed by Phinney (1989), ethnicity is a highly salient topic in the US as a result of the socialeconomic disparities, discrimination, and marginalization faced by minority groups. Decreases in adolescents' ethnic affirmation in Miami and for Cubans, who represent the majority of the general population in Miami, may therefore reflect a decrease in the 
relative salience of adolescents' ethnic identity as they explore other domains of their sense of self. Positive change in ethnic affirmation for participants in Los Angeles and/or of Mexican and Other national descent would be consistent with previous longitudinal studies (French et al., 2011; Umaña-Taylor et al., 2009).

With regards to American identity affirmation, and consistent with Schwartz and colleagues (2013a) study on acculturation, the results revealed significant increase in American affirmation over time even after controlling for ethnic affirmation. These findings were also consistent across site and nationality, although growth parameter for Cubans was found to be non-significant. Should this finding be duplicated, it may indicate that adolescents settling in an ethnic enclave, particularly a welcoming one, may lead to a lack of need to ever adapt to the US culture. Significant differences in American identity affirmation were however found at Time 1. More specifically, adolescents in Miami and those of Cuban descent were respectively found to have higher levels of American affirmation than their counterparts, even after controlling for ethnic affirmation. These findings are consistent with Study 2's hypothesis as well as previous evaluations of the COPAL dataset (Schwartz et al., 2012b) and may either be reflective of the large variability across nationality (e.g., exposure to U.S. culture, motivations for immigrating, etc.), differences across context (e.g., differences in perception of negative and positive receiving context), or both. Unfortunately, given underrepresentation of Hispanic subgroups it was not possible to delineate the contributions between context and nationality by examining whether these differences across groups persist within each context. 
As a whole, results of LGCM for adolescents' ethnic and American identity affirmation provide further evidence for general trends towards a bicultural identity (Schwartz et al., 2013a). More specifically, while some differences were found across receiving context and nationality, on average, recently immigrated Hispanic adolescents are developing their American identity (i.e., developing a sense of belonging and commitment towards the United States and being an American) while retaining their heritage culture

\section{Developmental Trajectory of Recently Immigrated Hispanic Caregivers'}

Ethnic and American Identity Development. Contrary to Study 2's original hypothesis, results indicated significant decreases in caregivers' ethnic identity affirmation. However, this decline ethnic identity affirmation was predominately limited to caregivers in Los Angeles or of Mexican and all other national descent. Given the fact recently immigrated Hispanic caregivers are more likely to encounter hostility and discrimination (Schwartz et al., 2013c), differences across groups may result from how these groups are received and perceived within the United States. As previously specified, while in Miami Hispanics enjoy the majority of the political and economic power positions (Stepick, Grenier, Castro, \& Dunn, 2003), caregivers in Los Angeles are met with ambivalence (HayesBautista, 2004) and a perceived negative context of reception (Schwartz et al., 2013c).

Over and above context, it is important to note that while immigrating Cubans are aided by the "wet foot, dry foot" law that allows them to stay legally in the United States and part of the majority in Miami (Stepick \& Stepick, 2002), other Hispanic groups are likely faced with greater discrimination and greater barriers, particularly for 
undocumented immigrants who are not eligible for government benefits or employment in the formal economy.

In the Neo-Eriksonian identity literature, an identity crisis is likely to occur when an individual encounters circumstances in which they lacks enough of a sense of identity (identity deficit) or are made aware of incompatibilities in their sense of self (identity conflict; Baumeister, Shapiro, \& Tice, 1985). Similarly, the social identity perspective has posited that experiences that invalidate one's status as a group member can pose a threat to one's personal identity (Branscombe, Ellemers, Spears, \& Doosje, 1999). For caregivers who face discrimination, the need to contend with views that portray them inaccurately or stereotypically may launch them in (re)exploring their sense of self and identity - likely resulting in temporary distress and a decrease in their commitment and affirmation towards their heritage culture. This developmental task may be intensified as individuals who previously identified with their country, are grouped together in the United States under a large heterogonous cluster labeled Latino/a and/or Hispanic.

Consistent with Study 2's original hypothesis, general growth curve models revealed no significant change in caregivers' American identity affirmation even after account for their ethnic identity affirmation. As previously stated, given the current study was conducted in two large ethnic enclaves, it is likely caregivers can avoid ever having to learn how to speak English or having to adapt to the U.S. Culture (Schwartz, Pantin, Sullivan, Prado, \& Szapocznik, 2006). Moreover, while differences across site and nationality were not detected, it is important to note that reasons behind lack of change in caregivers' American identity affirmation may vary across context and group. More specifically, while the favorable social position of Cubans in Miami and the fact they 
represent the majority of the population may allow Cuban caregivers to avoid having to adapt to the U.S. culture, for caregivers in Los Angeles and other groups, identification with the United States may mark them as target for discrimination and feeling rejected (Schwartz et al., 2013c). Additionally, it is worth noting that significant differences in caregivers' American identity did emerge at Time 1, with Cubans scoring significantly higher than the other groups.

Relationship between Ethnic and American Identity Development. The current study not only further delineating the change in adolescents' and caregivers' cultural identity but was also able to further evaluate the relationship between ethnic and American identity development. More specifically, including ethnic affirmation as a time-varying predictor allowed Model 3 to examine correlation between these two processes at each time point. Results not only indicated a significant positive relationship, which provide further evidence for Schwartz et al. (2012a) conceptualization of the relationship ethnic and American identity, but found a general strengthening of the relationship between these two processes over time. Although a note of caution should be taken in interpreting the results of caregivers' dual-process model, findings after constraining the covariance between intercept and slope for ethnic affirmation' to zero, found a significant and high correlation between change in caregivers' ethnic and American identity affirmation calling to question whether caregivers are able to distinguish between ethnic and American identity.

First-hand accounts by assessment specialist reported confusion behind how to answer questions surrounding their "American identity". It is possible that for recently immigrated adults, the processes underlying ethnic and American are one in the same, 
representing a general exploration of the meaning behind their 'ethnicity', 'nationality', and their place in the United States as a minority. As was stated in Study 1, future studies should employ cognitive interviews in order to ensure participants are understanding items regarding their ethnic and American identity and distinguishing between these processes over time. Over and above evaluating the cognitive processes behind caregivers' responses to both of these measures, it is important to note that additional and/or unique processes not measured by the MEIM/AIM may be playing a role in the high correlation between ethnic and American identity affirmation. Through the use of open-ended questions, it may be possible to get a better understanding of cultural identity development for recently Hispanic immigrated caregivers.

Conclusions. It is by conducting longitudinal studies that researchers can begin to map the course of cultural identity development and evaluate antecedents as well as contextual variables that that lead to more versus less successful cultural identity development (Schwartz, 2005). Moreover, the current study served as a step forward in obtaining a better understanding of the complexity behind cultural identity for immigrating groups. The fact that several differences emerged across participants' receiving context and their nationality, emphasizing the need for studies to not only contextualized their findings within the receiving context of the study, but examine within group differences. The next study will seek extend this developmental systemic perspective to cultural identity development and evaluate dyadic models of ethnic and American identity affirmation. 


\section{STUDY 3 - ADOLESCENTS' AND CAREGIVERS' CULTURAL IDENTITY INTERACTION}

\section{Analytic Overview}

In order to evaluate the relationship between growth in adolescents' and their caregivers' ethnic and American identity affirmation, analysis proceeded by including three additional growth curve models. Specifically, Study 3 proceeded to examine the relationship between a) growth in adolescents' and their caregivers' ethnic identity affirmation, b) growth in adolescents' and their caregivers' American identity affirmation, and c) growth in both adolescents' and their caregivers' ethnic and American identity affirmation. All analysis was conducted in Mplus 5.0 using a sandwich estimator (Kauermann \& Carroll, 2001) to adjust the standard errors and account for nesting of participants within data collection sites (specific schools).

\section{Dyadic Latent Growth Curve Models}

Model 1 - Adolescents' and Caregivers' Ethnic Identity Affirmation. As was done in dual-process models in Study 2, analysis began with an intercept-only model and built from there. More specifically, given Study 2 found a significant decline in caregivers' ethnic identity affirmation, but not adolescents', analysis proceeded by including a growth parameter for caregivers' ethnic identity affirmation. As shown in Table 19, results found a significant improvement in model fit estimates $[\Delta-2 \operatorname{LL}(4)=$ 29.826, $p<.001]$. Next, a growth parameter was included for adolescents' ethnic affirmation. The final model was indicative of both improved fit $[\Delta-2 \operatorname{LL}(9)=42.914, p<$ $.001]$ and good fit $\left[\chi^{2}(22)=26.348, p=.237 ; \mathrm{CFI}=.983 ;\right.$ RMSEA $=.027 ; \mathrm{SRMR}=$ $.069]$. 
Growth parameters (i.e., intercept and slope) for both caregivers' and adolescents' ethnic identity affirmation were similar to those found in Study 2 (see Table 20). More specifically, while there was no significant change over time in adolescents' ethnic affirmation $\left[\bar{x}_{\text {Slope }}=.024, p=.877\right]$, a significant negative change was detected for caregivers $\left[\bar{x}_{\text {Slope }}=-.248, p=.044\right]$. Moreover, while results indicated significant variance around the slope parameter for adolescents' $[S D=1.157, p=.002]$, no significant variance was found around caregivers' ethnic affirmation growth parameter $[S D=.580, p=.002]$. As presented in Table 21, marginally significant covariance was once again detected between caregivers' ethnic affirmation at Time 1 and change over time $[\psi(r)=0.607(.474), p=.071]$. Regarding relationships between adolescents" and their caregivers', analysis found a marginally significant and positive relationship between slope parameters [ $\psi(r)=0.311(.463), p=.057]$. Moreover, a marginally significant and positive relationship was found between adolescents' ethnic affirmation at Time 1 and change in caregivers' ethnic identity affirmation. Specifically, for higher levels of adolescents' ethnic affirmation at baseline, there was significantly greater changer in caregivers' ethnic affirmation over time $[\psi(r)=-.650(-.332), p=.092]$.

Model 2 - Adolescents' and Caregivers' American Identity Affirmation. As was done in Model 1, built upon a null intercept-only model. Given significant positive change was found in Study 2 for adolescents' American identity affirmation, a growth parameter for adolescents' American affirmation was included first. This model was not only an improvement over the intercept-only model $[\Delta-2 \mathrm{LL}(4)=32.852, p<.001]$ but indicative of acceptable to good fit $\left[\chi^{2}(27)=37.593, p=.084\right.$; CFI $=.984$; RMSEA $=$ 
.038 ; SRMR $=.035]$. Building upon this model, a growth parameter was added to model change in caregivers' American affirmation. This model was associated with a significant improvement $[\Delta-2 \operatorname{LL}(9)=59.782, p<.001]$ but indicative of good fit $\left[\chi^{2}(22)=15.328, p\right.$ $=.848 ; \mathrm{CFI}=1.000 ; \mathrm{RMSEA}<.001 ; \mathrm{SRMR}=.035]$.

As detailed in Table 22, and consistent with Study 2, results indicated a significant increase in adolescents' American affirmation over time $\left[\bar{x}_{\text {Slope }}=.465, p=\right.$ $.006]$ with a significant variance around this slope $[S D=1.360, p<.001]$. Moreover, while results once again found no significant change in caregivers' American affirmation over time, a significant variance was once more found around this slope $[S D=1.281, p<$ .001]. Additionally, a negative covariance was found between growth and intercept parameters for both adolescents $[\psi(r)=-2.586(.418), p=.007]$ and their caregivers $[\psi$ $(r)=-1.867(-.369), p=.093] .=$ Regarding the dyadic relationships, results indicated a significant and positive covariance between adolescents' and caregivers' baseline scores [ $\psi(r)=7.344(.388), p=.001]$. Additionally, a marginally significant relationship was found between caregivers' American affirmation at Time 1 and adolescents' change over time $[\psi(r)=-1.501(-.266), p=.086]$. Thus, the higher caregivers' American identity at Time 1, the more negative adolescents' American affirmation trajectory is over time.

\section{Model 3 - Adolescents' and Caregivers' Ethnic and American Identity}

Affirmation. Next, Model 1 and Model 2 were coalesced in order to examine concurrent relationships between adolescents' and caregivers' analysis. As before, the model began with an intercept model for all four processes to serve as a null comparison model. Building on this model, and in order to account for the potential method effect associated with same-reporter, residual correlations at each time point where included between 
adolescents' and their' caregivers' ethnic and American affirmation respectively (i.e., Adolescent Ethnic Affirmation Time 1 with Adolescent American Affirmation Time; Caregiver Ethnic Affirmation Time 2 with Caregiver American Affirmation Time 2, etc.). As shown in Table 19, this model was associated with a significant change in mode fit $[\Delta-2 \operatorname{LL}(38)=117.436, p<.001]$. Next, given results from Study 2, growth parameters for caregivers' ethnic and adolescents' American affirmation were included. While this model was indicative of good fit $\left[\chi^{2}(101)=152.929, p=.007 ; \mathrm{CFI}=.952 ; \mathrm{RMSEA}=\right.$ $.044 ; \mathrm{SRMR}=.056]$, a linear dependency emerged between variables resulting in a correlation greater than 1 between change in ethnic and baseline scores $[\psi(r)=$ $.862(1.285), p<.001]$. Given previous results indicated a non-significant variance in caregivers' ethnic affirmation, and results from this model indicated both a nonsignificant change over time $\left[\bar{x}_{\text {Slope }}=-.619, p=.175\right]$ and a non-significant variance around this slope, $[S D=.401, p=.492]$, the growth parameter for caregivers' ethnic affirmation was dropped from the model. The final model was indicative of good fit $\left[\chi^{2}(93)=150.261, p=.002 ; \mathrm{CFI}=.947 ; \mathrm{RMSEA}=.048 ; \mathrm{SRMR}=.081\right]$.

\section{Estimates of Growth in Caregivers' and Adolescents' Cultural Identity}

Affirmation. Growth parameter estimates are presented in Table 24. Consistent with previous models, results indicated significant and positive growth in adolescents' American affirmation $\left[\bar{x}_{\text {Slope }}=.465, p=.004\right]$ with significant variance around this slope $[S D=1.370]$. Additionally, a significant covariance was found between adolescents' American affirmation at Time 1 and later growth $[\psi(r)=-2.564(-.408), p=.006]$. More specifically, adolescents' with higher American affirmation at Time 1 will have lower (or 
negative) change over time. No significant slope parameters was found for adolescents' ethnic $\left[\bar{x}_{\text {Slope }}=.038, p=.808\right]$ or caregivers' American identity affirmation $\left[\bar{x}_{\text {Slope }}=.052\right.$, $p=.622]$. Results did however reveal significant variation around these respective slopes.

Covariance Between Growth Parameters Within Caregivers' and Adolescents'

Cultural Identity Affirmation. Within this model it was also possible to examine the relationship between ethnic and American affirmation for adolescents' and their caregivers' respectively. As shown in Table 25, results found two significant covariances across cultural identity affirmation. More specifically, results indicated a positive covariance between adolescents' ethnic and American affirmation at Time $1[\psi(r)=$ 4.197(.276), $p=.050]$. Similarly, a significant and positive covariance was also detected between caregivers' ethnic and American affirmation at Time $1[\psi(r)=2.409(.254), p<$ $.001]$.

\section{Covariance Across Growth Parameters Within Caregivers' and Adolescents'}

Cultural Identity Affirmation. Finally, and as presented in Table 26, several significant relationships were found between caregivers' and adolescents' cultural affirmation. With regards to caregivers' American affirmation, results indicated a significant and positive relationship between change in caregivers' American affirmation and adolescents' ethnic affirmation $[\psi(r)=.450(.353), p=.023]$. Moreover, results found a significant and positive relationship between caregivers' and adolescents' American affirmation at Time $1[\psi(r)=7.521(.401), p<.001]$. Similarly, caregivers' ethnic identity affirmation at Time 1 was also positively and significantly related with adolescents' American affirmation at Time $1[\psi(r)=1.902(.179), p=.013]$. Results did however find a negative covariance between caregivers' ethnic affirmation at Time 1 and change in adolescents' 
American affirmation over time $[\psi(r)=-796(-.250), p=.039]$. Thus, the higher caregivers' ethnic affirmation at baseline, the lower the change in adolescents' American affirmation would be over time.

Over and above these relationships, as shown in Table 26, several marginally significant relationships were detected as well. More specifically, caregivers' American affirmation was marginally and negatively related with both change in adolescents' ethnic $[\psi(r)=-1.105(-.234), p=.078]$ and American affirmation over time $[\psi(r)=-$ 1.538(-.274), $p=.073]$. Additionally, a positive relationship was found between caregivers' American affirmation and adolescents' ethnic affirmation at Time $1[\psi(r)=$ $2.459(.181), p=.056]$. Finally, results found adolescents' ethnic $[\psi(r)=-1.020(-.278), p$ $=.080]$ and American affirmation $[\psi(r)=-.923(-.823), p=.080]$ at Time 1 were negatively related with change in caregivers' American affirmation over time. Thus, higher levels in adolescents' ethnic or American affirmation at Time 1 were associated with greater decline in caregivers' American affirmation over time.

\section{Assessing for Differences Across Site and Nationality}

Analytic Overview. As was done in Study 2, analysis proceeded to determine if there were significant differences across receiving context and nationality. Unlike Study 2 , analysis proceeded through the use of multigroup modeling. In doing so, it was possible to examine whether differences emerged across average growth and intercept parameters, variance around these slopes and intercepts, and whether differences emerged in the direction and strength of the relationship between caregivers' and adolescents' baseline scores and change over time. To do this, analysis began with an unconstrained model (all paths free to vary across groups) which was then compared to a constrained 
model. Models were compared against each other using the likelihood ratio test in order to evaluate for significant differences.

Differences across Receiving Contexts. Regarding receiving context, analysis began with a fully unconstrained model including slope and intercept parameter for caregivers' and adolescents' ethnic and American affirmation. However, as occurred previously, a linear dependency emerged between covariance surrounding caregivers' ethnic affirmation. Given the fact variance around caregivers' ethnic affirmation was non-significant in both Miami and Los Angeles, the growth parameter was removed from the model. The final unconstrained model was associated with acceptable to good fit $\left[\chi^{2}(194)=299.090, p=.012 ; \mathrm{CFI}=.902 ; \mathrm{RMSEA}=.064 ; \mathrm{SRMR}=.090\right]$. This model was then compared to a fully constrained model where means and variances for growth parameters as well as covariances were set to be equal across Miami and Los Angeles. Model comparison revealed a significant difference between these two models $[\Delta$ $2 \mathrm{LL}(35)=93.564, p<.012]$. As was done in Study 1 , analysis proceeded to examine which paths varied across site by constraining one path at a time, using the likelihood ratio test in order to evaluate for significant differences.

As shown in Table 27, invariance tests across site revealed six significant differences. However, these differences were centered on growth parameters. Consistent with Study 2, results indicated significant differences regarding baseline scores for adolescents' ethnic affirmation and both adolescents' and caregivers' American affirmation. In all cases, growth parameters were found to be higher for participants in Miami than in Los Angeles. Additionally, a significant difference was found in the change of adolescents' ethnic affirmation over time. As was found in Study 2, Miami 
adolescents' were associated with a non-significant decline $\left[\bar{x}_{\text {Slope }}=-.247, p=.163\right]$ while those in Los Angeles had a marginally significant growth over time $\left[\bar{x}_{\text {Slope }}=.309, p\right.$ $=.099]$. Finally, by employing a multi-group model it was possible to examine whether differences emerged in the variance around these growth parameters. Results indicated higher variability in Los Angeles adolescents' ethnic and American affirmation.

Differences across Nationality. Finally, analysis proceeded to evaluate the Model 3 for differences across nationality (i.e., Cubans, Mexicans, and 'Other'). Follow the procedures outlined above, analysis began with a fully unconstrained model. This model was not only indicative of poor fit $\left[\chi^{2}(269)=433.232, p<.001 ; \mathrm{CFI}=.845\right.$; RMSEA $=.083 ;$ SRMR $=.098$ ] but indicative of correlations greater than 1 and potential linear dependency across groups. For Mexicans and Cubans, the model warned against a potential linear dependency as a result of correlations greater than 1 surrounding change in adolescents' and their caregivers' ethnic affirmation, both indicative of non-significant variance. For participants from all other nationalities, the correlations greater than 1 emerged between caregivers' American slope and intercept. As was the case with Cubans and Mexicans ethnic affirmation, for caregivers of other nationality, there was no significant variance around the average slope. Constraining each of the variance around these slopes to zero for their respective groups would not only make it difficult to develop a constrained model that would allow for evaluation of group differences across the remaining estimated parameters, but also limited the relationships between caregivers' and adolescents' cultural identity processes that could be examined. Given the 
complexity of the model, and the low sample size within each cell, no further attempt was made to derive a model examining for differences across nationality.

\section{Discussion}

Within a Developmental Systems framework (Lerner \& Castellino, 2002), identity emerges from multi-linear and bi-directional relationships across multiple structurally and functionally integrated levels of organization. Despite contemporary theories of human development and this dynamic conceptualization of identity, few studies have taken on a systemic approach and examined the parent $<$ - $>$ child identity systems (Koepke \& Denissen, 2012). Given the relative salience ethnic and American identity is hypothesized to have for both recently immigrated adolescents and their caregivers' (Phinney, 1989), examining this identity system offers a unique opportunity to evaluate what is likely to be concurrent identity development in both adolescents' and their caregivers'. Towards this end, Study 3 sought to examine the whether significant relationships emerged between adolescents' and their caregivers' ethnic and American identity processes, placing cultural identity development within the dyadic context it emerges out of.

\section{Relationship between Adolescents' and their Caregivers' Ethnic and}

American Identity Development. As specified in Hypothesis 3A, Study 3 predicted positive relationships between adolescents' and their caregivers' ethnic affirmation respectively. Consistently, results from Model 1 provided preliminary support for this hypothesis, detecting a marginally significant positive relationship between change in adolescents' and their caregivers' ethnic identity affirmation. Unfortunately, given the lack of variance around caregivers' ethnic affirmation, it was not possible to further 
explore this relationship. Thus, whether the relationship between change in adolescents' and their caregivers' ethnic affirmation is still present even after controlling for American affirmation and differences across site and nationality remains an empirical question. Despite this limitation, results from Model 1 were in line with research highlighting the role caregivers' have in promoting the retention of adolescents' ethnic affirmation (Portes \& Rumbaut, 2006; Schwartz, Zamboanga, Rodriguez, \& Wang, 2007; Umaña-Taylor, Bhanot, \& Shin, 2006; Umaña-Taylor, Zeiders, Updegraff, \& Kimberly, 2013). It should be noted however that results in both Model 1 and 3 revealed no relationship between adolescents' and their caregivers' ethnic affirmation at Time 1. To a certain extent, covariance between baseline score represent the level of shared experiences that adolescents' and their caregivers' have had prior to the study in determining what their ethnicity means to them. While previous studies have found adolescents' are to a certain extent insulated from negative aspects of their local context (Schwartz et al., 2013c), for caregivers' who must interact across various context as they settle into the United States, the likelihood of encountering hostility and discrimination is higher (Schwartz et al., 2013c). As previously specified, ethnicity becomes a more salient identity domain as a result of perceived discrimination and marginalization faced by minority groups (Phinney, 1989). Thus, lack of significant relationship between adolescents' and their caregivers' ethnic affirmation baseline scores may reflect differences in the context adolescents and caregivers spend their time in the receiving culture. Additionally, for caregivers' who have had a more extensive and vivid memory of their lives prior to migration (Portes \& Rumbaut, 2006), it is possible their sense of pride and belonging to their ethnic group is determined by experiences they have had in 
their own childhood while adolescents' are still exploring and participating in key experiences that will come to shape their pride and sense and belonging to their heritage culture.

As previously specified, research has highlighted the role adolescents have in transmitting American values and culture (Padilla, 2006), as such, Study 3 hypothesized a significant and positive relationship between change in adolescents' and their caregivers' American affirmation. Consistently, results from Model 2 indicated a positive relationships between change in adolescents' and their caregivers' American affirmation over time. However, although still positive, after controlling for ethnic affirmation, no significant relationship was found between change in adolescents' and their caregivers' American affirmation. Results may indicate the strength of this relationship varies as a result of adolescents' ethnic affirmation and/or caregivers' ethnic affirmation. Research has found that adolescents' with higher ethnic affirmation have a stronger family orientation (Sabogal, Marin, Otero-Sabogal, Marin, \& Perez-Stable, 1987) and parentchild relationship (Schwartz et al., 2013a). Therefore, adolescents' with higher ethnic affirmation may be better suited towards assisting in the emergence of caregivers' American affirmation. Consistently, Study 3 found a positive relationship between baseline scores and change in adolescents' ethnic affirmation and caregivers' American affirmation respectively. Future studies should examine whether the relationship between change in adolescents' and their caregivers' American affirmation varies as a function of adolescents' ethnic affirmation and/or family communication and parent relationship.

Although results from Model 3 found no significant relationship between change in adolescents' and their caregivers' American affirmation, results did indicate a 
significant positive relationship between adolescents' and their caregivers' American affirmation at Time 1. While this findings may be a consequence of the shared exposure both adolescents' and their caregivers' have had to the United States culture (e.g., movies music, shows, etc.) (Arnett, 2000) before entering to the United States it may also be a product of adolescent-driven socialization prior to participation in the study. Results may indicate that adolescent-driven socialization, may unravel more slowly. Given the fact caregivers' living in ethnic enclaves may not feel the need to adapt to the United States (Schwartz et al., 2006), adolescents' may run into resistance in transmitting what they learned about the United States to their caregivers (Morales \& Hanson, 2005). As previously specified, caregivers have had significantly more exposure to their countries of origins, and as such, may be find the process of developing a sense of belonging towards a foreign land the most difficulty (Schwartz et al., 2006). Moreover, contrary to Study 3's hypothesis, results indicated a positive relationship between adolescents' American and caregivers' ethnic affirmation at Time 1. Findings may reflect parents' adherence to familismo or a cultural value which emphasizes trust between family members, loyalty to the family, and a general orientation to the family (Sabogal, Marín, Otero-Sabogal, \& Marín, 1987). For many immigrants, the United States is viewed as the "land of opportunity" (Hirschman, 2001). As such, caregivers' who embrace familismo may feel it is their obligation to also encourage their children to become more American so they may be more apt to succeed and capitalize on opportunities that were not available for them in their country of origin.

Finally, while Model 3 did find significant negative relationships between adolescents' and their caregivers' ethnic and American affirmation intercept and slope 
parameters, it is worth pointing out the potential confound in interpreting these findings. As specified by Little (2013), negative correlations between intercepts and slopes in Latent Growth Curve Models are very common with close-ended Likert-type scales. This largely a result of both floor and ceiling effects associated with measurement. For caregivers' and adolescents' who report 5 at baseline, they have no choice but to report less ethnic or American affirmation at a later time point. The reverse would be the case for those scoring 1. Given the fact these negative relationships between slope and intercept where all marginally significant, largely counter intuitive, and present only among those variables that shared a high positive correlation between intercepts, these relationships were dismissed from interpretation.

\section{Developmental Trajectory of Recently Immigrated Hispanic Adolescents'} and their Caregivers' Ethnic and American Identity Development. Over and above examining the relationship between adolescents' and their caregivers' ethnic and American affirmation, Study 3 also found significant change in adolescents' American and caregivers' ethnic affirmation (although no variance was found around this slope) after controlling for ethnic and American affirmation respectively. Moreover, invariance tests across site revealed once again significant differences in growth parameters means. More specifically, and consistent with Study 2, adolescents' ethnic and American affirmation and caregivers' American affirmation was higher for those participants in Miami than in Los Angeles. Additionally, results indicated once again that adolescents' while there was no significant change in Miami adolescents' ethnic affirmation, for those in Los Angeles, ethnic affirmation increased over time. While the theoretical implication of these results were discussed in Study 2, it is important to note that the use of multi- 
group modeling also revealed significant difference in the variability in adolescent's ethnic and American baseline scores.

Conclusion. As a whole, the findings of Study 3 provides preliminary evidence of the importance for examining identity development within a systemic lens. In doing so, Study 3 served as a step forward in evaluating how caregivers and their children are two inter-related identity systems (Koepke \& Denissen, 2012) that directly (and indirectly) affect each other. While it is critical for future studies to further examine these relationship, it is clear that identity "emerging in relationships, [and] developing as a dynamic, self-organizing system"' (Bosma \& Kunnen, 2001, p. 5). 


\section{GENERAL DISCUSSION}

\section{Summary}

As a result of heavy health disparities, several scholars (e.g., Case \& Robinson, 2003) and the US Surgeon General (Thompson, 2001) have called for more prevention research focused on ethnic minority groups, in particular Hispanics who are estimated to account for one-third of the entire U.S. population by 2050 (Ennis et al. 2011). The current dissertation sought to address several pervasive gaps in the literature (i.e., need for psychometric evaluation, longitudinal studies, a more systemic approach, to examine cultural identity development in adults, evaluate differences across receiving context, and examine within-group differences) on a key predictor and index of psychosocial adjustment among Hispanic adolescents and adults, ethnic and American identity (Schwartz et al., 2010).

In Study 1 of the current dissertation, the first evidence of longitudinal psychometric validity for the Multi-Group Ethnic Identity Measure (MEIM, Phinney 1992, Roberts et al., 1999) and the American Identity Measure (AIM; Schwartz et al., 2012a) was obtained. In doing so, Study 1 provided additional support for the theoretical parallelism between ethnic and American identity, generalizability for these measurement tools, and ensured mean change over time could be attributed to change in the true score of the construct (Brown, 2006). However, as noted in the discussion, several modifications were required in order to achieve acceptable model fit. Future studies should further examine the items of both the MEIM and the AIM to ensure participants understand the question in the way intended by the researcher (Collins, 2003). 
In Study 2, the current dissertation evaluated longitudinal change in adolescents' and their caregivers' ethnic and American identity. Consistent with the literature on biculturalism, results indicated recently immigrated Hispanic adolescents retain their heritage culture while acquiring a sense of belonging towards the United States. It should be noted however, results did indicate a non-significant negative trend in Miami/Cuban adolescents' ethnic affirmation. While results may be indicate a loss of saliency as a result of being part of the majority group, future studies should examine whether this trend intensifies past Time 4. In addition, as highlighted by Umaña-Taylor (2011), the vast majority of cultural identity research has focused on adolescents and emerging adults with little to no attention given to adults. Study 2 addressed this pervasive gap and found significant decreases in recently immigrated Hispanic caregivers' ethnic affirmation. While these findings were primarily limited to participants from Los Angeles, future studies should further examine this negative trend in order to determine if it represents a true decline in ones sense of belonging to their ethnic group or a change in the content of what their ethnicity means. Given the role ethnic identity has a protective barrier against the effects of discrimination and marginalization (Umaña-Taylor, 2011), future studies should examine the psychosocial outcome associated with declining ethnic identity in adult samples of recently immigrated Hispanics. Additionally, Study 2 highlight specific differences across receiving context and within group. In doing so, Study 2 represented a step forward in obtaining a better understanding of the complexity behind cultural identity for immigrating groups, emphasizing the need for studies to not only contextualized their findings within the receiving context of the study, but examine within group differences. 
Finally, Study 3 sought to examine the relationship between adolescents' and their caregivers' ethnic and American identity. Consistent with Erikson's (1969) conceptualization of identity emerging at the intersection between the individual and the society/culture and Developmental Systems Theory (Lerner \& Castellino, 2002), Study 3 provides preliminary evidence for cultural identity as a bidirectional and interactive process (Kuczynski, 2003). Future studies should further explore this process to delineate adolescents' and caregivers' contribution to cultural identity development.

\section{Implications for Intervention}

Over and above the intellectual merits of the current dissertation, the present findings have important implications for prevention interventions targeting recently immigrated Hispanic adolescents' and their caregivers'. While the results indicated a general trend in adolescents' towards a bicultural identity, results from both Study 2 and Study 3 consistently indicated, although non-significant, a negative trend in Miami adolescents' ethnic affirmation. Moreover, findings from these studies raised special concern over caregivers' cultural identity trajectory, particularly those in Los Angeles who were found to be associated with significant decline in ethnic affirmation over time. While future studies should further examine these findings (i.e., evaluate the relationship between decline in either of these group ethnic affirmation and psychosocial functioning), results may indicate Miami/Cuban adolescents and caregivers in Los Angeles are particularly vulnerable and in need of participation in treatment and/or prevention programs focused on cultural identity and/or acculturation.

That being said, research developing, implementing, and evaluating cultural identity focused intervention has been relatively scarce and predominately focused on 
ethnic identity. Findings have however suggested that individuals' ethnic identity is amenable to interventions (Gurin \& Nagda, 2006). For example, in Belgrave and colleagues' (2004) work with the Sisters of Nia, a cultural program for African American girls, ethnic identity was targeted by focusing on adolescents' knowledge of Afrocentric culture, customs, and values. Results indicated participants in the intervention were associated with significantly higher change in ethnic identity than those in the control comparison. Similarly, the program YES! (Thomas, Davidson, \& McAdoo, 2008) targeted ethnic identity exploration by focusing on adolescent African American girls' knowledge and awareness of cultural values, history and racism. With regards to programs developed for working with Hispanics, Marlot and colleagues (2010) is among the few programs focused on targeting ethnic identity as the primary outcome among Mexican American high school students (Malott, Paone, Humphreys, \& Martinez, 2010). Similar to results from the Sisters of Nia and Yes!, qualitative analysis indicated participants felt greater identification with their Mexican heritage and felt more proud to be Mexican than before the intervention began. Finally, a recent study by Syed and colleagues (2011) suggested that the mere act of participating in ethnicity-related research study prompted individuals to think more deeply about their ethnic identity.

Despite these positive findings, these ethnic-identity focused programs have been met with several limitations. To begin with, empirical evaluation of these programs has been limited to small samples and have failed to examine treatment maintenance. Moreover, these programs have focused solely on retention and promotion of adolescents' ethnic identity and not taken into account their American identity. In addition, the modality of these programs have been limited to group work led by trained 
facilitators (Syed, 2011). Whether a group intervention modality may serve as the best structure for cultural identity-focused interventions with Hispanics, who come from a predominately collectivist culture, is an empirical question (Schwartz, Montgomery, \& Briones, 2006). As argued by Santisteban, Muir-Malcolm, Mitrani, and Szapocznik (2002), and consistent with the findings from Study 3, family-based interventions may be most appropriate for individuals from primarily collectivist groups. Consistently, within the acculturation literature, two prevention programs have been developed for adolescents and their caregivers, the Bicultural Effectiveness Training (Szapocznik et al. 1986) and the Entre Dos Mundos (Between Two Worlds; Smokowski and Bacallao 2011) program. While findings have supported the efficacy of the Bicultural Effectiveness Training, both of these programs have primarily focused on cultural practices, not cultural identification. As a whole, results from Study 2 and 3 emphasize the need to extend either these family-based acculturation-prevention programs to target adolescents' and their caregivers' identification or develop and implement new cultural identityfocused interventions addressing these limitations.

\section{Limitations}

While the findings of these three studies advance the literature on cultural identity, it is important they be interpreted in light of several limitations. To begin with, the level of generalizability of the current findings cannot be assessed given the specific sample. More specifically, whether these findings can be generalized to all immigrants let alone all immigrating Hispanics is questionable, given the unique contexts the data was collected from. The fact both Study 2 and Study 3 found strong significant differences across site further emphasizes that generalization of such findings should be done so with 
a note of caution. Future studies should examine general trends in ethnic and American identity formation in less densely Hispanic communities. Moreover, the current sample was drawn from Hispanic families who had been in the United States for less than 5 years and limited to those that could be reached and committed to stay in South Florida and Southern California for the duration of the study. Thus, findings may not be generalized to poor and undocumented immigrants who are likely more transient and shift from various context of receptions.

Over and above these general limitations, it is important to note Study specific limitations that future studies can further address. For both Study 1 and Study 2, while significant differences were found across site and nationality, as a result of uneven distribution of Hispanic sub-groups, it was not possible to examine differences between nationalities within each context. More specifically, while nearly all Cubans where situated in Miami, nearly all Mexicans where collected from Los Angeles. For example, while Study 2 found significant growth in Cubans caregivers' American affirmation over time, it is likely that findings would differed for Cubans in a context where they are not the majority. Additionally, in both Study 2 and Study 3, analysis proceeded by grouping several different nationalities into an "Other" classification while ignoring potentially theoretically meaningful difference across these groups. Although the current dissertation marks a step forward in examining within-group differences, future studies should ensure equal representation across groups in order to truly examine similarities and differences in the development of cultural identity and adaptation to the United States.

It is important to note the lack of inclusion of several variables. More specifically, Study 2 and 3 did not take into account contextual factors that may moderate or even 
mask significant findings. More specifically, adolescents' or caregivers' gender, family income, and years in the United States were not examined as potential predictors of growth in Study 2 and Study 3. Finally, while Study 3 found significant relationships between recently immigrated Hispanic adolescents' and their caregivers' ethnic and American affirmation, it is important to note the limitations associated Latent Growth Curve Modeling (LGCM). More specifically, while LGCM is better equipped for examining change over time, it is not possible to delineate the order of these relationships. As such, future studies should employ cross-lagged panel models in order to evaluate whether significant relationships in Study 3 where adolescent-driven, parentdriven, or both.

\section{Conclusion}

Despite these limitations, the current dissertation represents a step forward in addressing the current gaps in the cultural identity literature. By examining ethnic and American in recently immigrated Hispanic adolescents' and their caregivers', employing a longitudinal and multi-site methodology, and evaluating identity within a system embedded within a context, the current study provides a truly developmental account of cultural identity development and provides a foundation for further evaluations. 


\section{REFERENCES}

Adams, G. R., Munro, B., Doherty-Poirer, M., Munro, G., Petersen, A. R., \& Edwards, J. (2001). Diffuse-avoidant, normative, and informational identity styles: Using identity theory to predict maladjustment. Identity, 1(4), 307-320.

Arnett, J. J. (1999). Adolescent storm and stress, reconsidered. American Psychologist, $54,317-326$.

Arnett, J. J. (2002). The psychology of globalization. American Psychologist, 57, 774783.

Ashmore, R. D., Deaux, K., \& McLaughlin-Volpe, T. (2004). An organizing framework for collective identity: Articulation and significance of multidimensionality.

Psychological Bulletin, 130, 80-114

Baltes, P. B., Lindenberger, U., \& Staudinger, U. M. (2006). Lifespan theory in developmental psychology. In R. M. Lerner, W. Damon, \& R. M. Lerner (Eds.), Theoretical models of human development (6th ed.). Handbook of Child Psychology, Vol. 1 Hoboken, NJ: Wiley.

Baltes, P. B., Reese, H. W., \& Nesselroade, J. R. (1977). Life-span developmental psychology: Introduction to research methods. Monterey, CA: Brooks/Cole.

Beatty, P. C., \& Willis, G. B. (2007). Research Synthesis: The practice of Cognitive Interviewing. Public Opinion Quarterly, 71(2), 287-311.

Belgrave, F.Z., Reed, M. C., Plybon, L. E., Butler, D. S., Allison, K. W., \& Davis, T. (2004). An evaluation of Sisters of Nia: A cultural program for African American girls. Journal of Black Psychology, 30, 329-343.

Berman, S. L., Kurtines, W. M., Silverman, W. K., \& Serafini, L. T. (1996). The impact of exposure to crime and violence on urban youth. American Journal of Orthopsychiatry, $66(3), 329-336$

Berry, J. W. (1980). Acculturation as varieties of adaptation. In A. M. Padilla (Ed.), Acculturation: Theory, models, and some new findings (9-25). Boulder, CO: Westview Press.

Berry, J. W. (1997). Immigration, acculturation, and adaptation. Applied Psychology: An International Review, 46, 5-34.

Bollen, K., \& Long, S. (1993). Testing structural equation models. Newbury Park: Sage.

Bosma, H. A., \& Kunnen, E. S. (2001).Determinants and mechanisms in ego identity development: A review and synthesis. Developmental Review, 21, 39-66. 
Bracey, J. R., Bámaca-Gómez, M. Y., \& Umaña-Taylor, A. J. (2004). Examining ethnic identity and self-esteem among biracial and monoracial adolescents. Journal of Youth and Adolescence, 33, 123-132.

Brandtstädter, J. (1999). The self in action and development: cultural, biosocial, and ontogenetic bases of intentional self-development. In J. Brandtstädter, \& R. M. Lerner (Eds.), Action and self-development: Theory and research through the life-span (pp. 3765). Thousand Oaks, CA: Sage.

Brandtstädter, J. (2006). Action perspectives on human development. In R. M. Lerner, W. Damon, \& R. M. Lerner (Eds.), Theoretical models of human development (6th ed.). Handbook of child psychology, Vol. 1 Hoboken, NJ: Wiley

Branscombe, N. R., Ellemers, N., Spears, R., \& Doosje, B. (1999). The context and content of social identity threat. In N. Ellemers, R. Spears, \& B. Doosje (Eds.), Social identity: Context, commitment, content (pp. 35-58). Oxford, UK: Wiley-Blackwell.

Brook, J. S., Duan, T., Brook, D. W., Ning, Y. (2007). Pathways to nicotine dependence in African American and Puerto Rican youth adults. American Journal on Addictions, 16, 450-456.

Brook, J. S., Whiteman, M., Balka, E. B., Win, P. T., \& Gursen, M. D. (1998). Drug use among Puerto Ricans: Ethic identity as a protective factor. Hispanic Journal of Behavioral Sciences, 20, 241-254.

Brown, T. A. (2006). Confirmatory factor analysis for applied research. New York: The Guildford Press.

Case, M. H., \& Robinson, W. L. (2003). Interventions with ethnic minority populations: The legacy and promise of community psychology. In G. Bernal, J. E. Trimble, A. K. Burlew, \& F. T. L. Leong (Eds.), Handbook of racial and ethnic minority psychology (pp. 573-590). Thousand Oaks, CA: Sage.

Centers for Disease Control and Prevention. (2004). HIV/AIDS Surveillance Report: Vol. 15. Cases of HIV infection and AIDS in the United States, 2003. Atlanta, GA: Department of Health \& Human Services.

Cheung, G. W., \& Rensvold, R. B. (2002). Evaluating goodness-of-fit indexes for testing measurement invariance. Structural Equation Modeling, 9, 233-255.

Cislo, A. (2008). Ethnic Identity and Self-Esteem: Contrasting Cuban and Nicaraguan Young Adults. Hispanic Journal of Behavioral Sciences, 30(2), 230-250

Collins, D. (2003). Pretesting survey instruments: An overview of cognitive methods. Quality of Life Research, 12, 229-238. 
Côté, J. E., \& Allahar, A. L. (1994).Generation on hold: Coming of age in the late twentieth century. Toronto: Stoddart.

Côté, J. E., \& Levine, C. G. (2002). Identity formation, agency, and culture. Mahwah, NJ: Erlbaum.

Crocetti, E., Meeus, W. H. J., Ritchie, R. A., Meca, A., \& Schwartz, S. J. (2014).

Adolescent identity: The key to unraveling associations between family relationships and problem behaviors? In L. M. Scheier \& W. B. Hansen (Eds.), Parenting and teen drug use. New York: Oxford University Press.

Dahlberg, L. L. (1998). Youth violence in the United States: Major trends, risk factors, and prevention approaches. American Journal of Preventive Medicine, 14(4), 259-272.

Davey, A., \& Savla, J. (2010). Statistical power analysis with missing data: A structural equation modeling approach. New York, NY: Routledge

Devos, T., \& Banaji, M. R. (2005). American = White? Journal of Personality and Social Psychology, 88, 447-466.

Eichas, K., Meca, A., Montgomery, M., \& Kurtines, W. M. (in press). Identity and Positive Youth Development: Advances in Developmental Intervention Science. In McLean, K. \& Syed, M. (Eds.), The Oxford Handbook of Identity Development, New York: Oxford University Press, Inc..

Elder, G. H. (1998). The life course and human development. In R. M. Lerner (Ed.), Handbook of child psychology, Vol. 1: Theoretical models of human development. New York: John Wiley.

Ennis, S. R., Ríos-Vargas, M., \& Albert, N. G. (2011). The Hispanic population: 2010. 2010 Census Briefs. Washington, DC: U. S. Census Bureau.

Erikson, E. H. (1950). Childhood and society. New York: Norton.

Erikson, E. H. (1968). Identity: Youth and crisis. New York: Norton.

Erikson, E. H. (1969). Gandhi's truth: On the origins of militant nonviolence. New York: Norton.

Fernández-Kelly, P., \& Curran, S. (2001). Nicaraguans: Voices lost, voices found. In R. G. Rumbaut \& A. Portes (Eds.), Ethnicities: Children of immigrants in America (pp. 127-156). Berkeley, CA: University of California Press.

French, S. E., Kim, T. E., \& Pillado, O. (2006). Ethnic identity, social group membership, and youth violence. In N. G. Guerra \& E. P. Smith (Eds.), Preventing youth violence in a multicultural society (pp. 47-73). Washington, DC: American Psychological Association. 
French, S. E., Seidman, E., Allen, L., \& Aber, J. L. (2006). The development of ethnic identity during adolescence. Developmental Psychology, 42, 1-10.

Gee, G. C., Spencer, M., Chen, J., Yip, T., \& Takeuchi, D. T. (2007). The association between self-reported racial discrimination and 12-month DSM-IV mental disorders among Asian Americans nationwide. Social Science \& Medicine, 64, 1984-1996.

Gestsdóttir, S. \& Lerner, R. M. (2007). Intentional self-regulation and positive youth development in early adolescence: Findings from the 4-H study of positive youth development. Developmental Psychology, 43(2), 508-521.

Gestsdóttir, S. \& Lerner, R. M. (2008). Positive development in adolescence: The development and role of intentional self-regulation. Human Development, 51, 202-224.

Gong, L. (2007). Ethnic identity and identification with the majority group: Relations with national identity and self-esteem. International Journal of Intercultural Relations, $31,503-523$.

Goossens, L. (2001). Global versus domain-specific statuses in identity research: A comparison of two self-report measures. Journal of Adolescences, 24, 681-699.

Greene, J. P., \& Forster, G. (2003). Public high school graduation and college readiness rates in the United States. New York: Manhattan Institute for Policy Research.

Grotevant, H. D. (1987). Toward a process model of identity formation. Journal of Adolescent Research, 2, 203-222.

Gurin, P., \& Nagda, B. A. (2006). Getting to the what, how, and why of diversity on campus. Educational Researcher, 35, 20-24.

Halgunseth, L. C., Ispa, J. M., \& Rudy, D., (2006). Parental control in Latino families: an integrated review of the literature. Child Development, 77, 1282-1297.

Hayes-Bautista, D. (2004). La Nueva California: Latinos in the Golden State. Berkeley: University of California Press.

Hirschman, C. (2001). The educational enrollment of immigrant youth: A test of the segmented assimilation hypothesis. Demography, 38, 317- 336.

Johnston, L. D., O’Malley, P. M., Bachman, J. G., \& Schulenberg, J. E. (2006). Monitoring the future: National results on adolescent drug use-Overview of key findings 2005. Bethesda, MD: National Institute on Drug Abuse.

Jones, R. M., \& Hartmann, B. R. (1988). Ego identity: Developmental differences and experimental substance use among adolescents. Journal of Adolescence, 11, 347-360. 
Kauermann, G., \& Carroll, R. J. (2001). A note on the efficiency of sandwich covariance matrix estimation. Journal of the American Statistical Association, 96, 1387-1396.

Kerpelman, J. L., Pittman, J. F., \& Lamke, L. K. (1997). Toward a microprocess perspective on adolescent identity development: An identity control theory approach. Journal of Adolescent Research, 12, 325-346

Koepke, S., \& Denissen, J. A. (2012). Dynamics of identity development and separationindividuation in parent-child relationships during adolescence and emerging adulthood A conceptual integration. Developmental Review, 32(1), 67-88.

Kosterman, R., \& Feshbach, S. (1989). Toward a measure of patriotic and nationalistic attitudes. Political Psychology, 10, 257-274

Kroger, J. (2007). Identity: The balance between self and other. London: Routledge.

Kroger, J., \& Marcia, J. E. (2011). The identity statuses: Origins, meanings, and interpretations. In S. J. Schwartz, K. Luyckx, \& V. L. Vignoles (Eds.), Handbook of identity theory and research (pp. 31-53). New York: Springer.

Lei, M., \& Lomax, R. G. (2005). The effect of varying degrees of nonnormality in structural equation modeling. Structural Equation Modeling, 12, 1-27.

Lerner, R. M. (1982). Children and adolescents as producers of their own development. Developmental Review, 2, 342-370.

Lerner, R. M. (1984). On the nature of human plasticity. New York: Cambridge University Press. Lerner,

Lerner, R. M. (2004). Liberty: Thriving and civic engagement among American youth. Thousand Oaks, CA: Sage.

Lerner, R. M. (2005). Promoting Positive Youth Development: Theoretical and Empirical Bases. White paper: Workshop on the Science of Adolescent Health \& Development, $\mathrm{NRC/Institute} \mathrm{of} \mathrm{Medicine.} \mathrm{Washington,} \mathrm{D.C.:} \mathrm{National} \mathrm{Academies} \mathrm{of} \mathrm{Science.}$

Lerner, R. M., \& Busch-Rossnagel, N. A. (Eds.). (1981). Individuals as producers of their development: A life-span perspective. New York: Academic Press.

Lerner, R. M., \& Castellino, D. R. (2002). Contemporary Developmental Theory and Adolescence: Developmental Systems and Applied Developmental Science. The Journal of Adolescent Health, 31(6), 122-135.

Lerner, R. M., Lerner, J. V., Bowers, E. P., Lewin-Bizan, S., Gestsdóttir, S., \& Urban, J. B. (2011). Self-regulation processes and thriving in childhood and adolescence: A view of the issues. In R. M. Lerner, J. V. Lerner, E. P. Bowers, S. Lewin-Bizan, S. Gestsdóttir, 
\& J. B. Urban (Eds.), Thriving in childhood and adolescence: The role of self-regulation processes. New Directions for Child and Adolescent Development, 133, 1-9.

Lerner, R. M., \& Walls, T. (1999). Revisiting individuals as producers of their development: from dynamic interactionism to developmental systems. In J. Brandtstädter, \& R. M. Lerner (Eds.), Action and self-development: Theory and research through the life-span (pp. 3-36). Thousand Oaks, CA: Sage.

Little, T. D. (2013). Longitudinal structural equation modeling. New York: Guilford Press.

Luyckx, K., Goossens, E., Van Damme, C., \& Moons, P. (2011).Identity formation in adolescents with congenital cardiac disease: A forgotten issue in the transition to adulthood. Cardiology in the Young, 21, 411-420.

Marcia, J. E. (1966). Development and validation of ego-identity status. Journal of Personality and Social Psychology, 3, 551-558.

Marcia, J. E. (1980). Identity in adolescence. In J. Adelson (Ed.), Handbook of Adolescent psychology (159-187). New York: Wiley.

Marcia, J. E. (1988). Common processes underlying ego identity, cognitive/moral development, and individuation. Self, ego, and identity: Integrative approaches, 211, 225 .

Malott, K. M., Paone, T., Humphreys, K., \& Martinez, T. (2010). Use of group counseling to address ethnic identity development: Application with adolescents of Mexican descent. Professional School Counseling, 13, 257-268.

Marsiglia, F. F., Kulis, S., \& Hect, M. L. (2001). Ethnic labels and ethnic identity as predictors of drug use among middle school students in the southwest. Journal of Research on Adolescences, 11, 21-48.

Marsiglia, F. F., Kulis, S., Hect, M. L., \& Sills, S. (2004). Ethnicity and Ethnic identity as predictors of drug norms and drug use among preadolescents in the US southwest. Substance Use and Misuse, 39, 1061-1094.

Martinez, R., \& Dukes, R. L. (1991). Ethnic and gender differences in self-esteem. Youth and Society, 22, 318-338.

Massey, D. S., Rugh, J. S., \& Pren, K. A. (2010). The geography of undocumented Mexican migration. Mexican Studies, 26, 129-152.

Meade, A. W., Johnson, E. C., \& Braddy, P. W. (2008). Power and sensitivity of alternative fit indices in tests of measurement invariance. Journal of Applied Psychology, 93, 568-592. 
Montgomery, M. J., Kurtines, W. M., Ferrer-Wreder, L., Berman, S. L., Lorente, C. C., Briones, E., Silverman, W., Ritchie, R., \& Eichas, K. (2008). A Developmental Intervention Science (DIS) outreach research approach to promoting youth development: Theoretical, methodological, and meta-theoretical challenges. Journal of Adolescent Research, 23(3), 268-290.

Morales, A., \& Hanson,W. E. (2005). Language brokering: An integrative review of the literature. Hispanic Journal of Behavioral Sciences, 27, 471-503.

Mossakowski, K. N. (2003). Coping with perceived discrimination: Does ethnic identity protect mental health? Journal of Health and Social Behavior, 44, 318-331.

Motel, S., \& Pattern, E. (2013). Statistical portrait of Hispanics in the United States, 2011. Pew Research Hispanic Center.

Muthén, L. K. (2002, October 30). Variances of growth factors. Mplus Discussion. Retrieved January $15^{\text {th }}, 2014$, from

http://www.statmodel2.com/discussion/messages/14/228.html?1378745081

Muthén, L. K., \& Muthén, B. O. (2010). Mplus user's guide. 6th ed. Los Angeles: Muthén \& Muthén.

Overton, W. F. (2006). Developmental psychology: Philosophy, concepts, methodology. In R. M. Lerner (Ed.) Theoretical models of human development.Volume 1 of the Handbook of child psychology (pp. 18-88), (6th ed.), Editor-in-Chief: William Damon; Richard M. Lerner. New York: Wiley.

Padilla, A. M. (2006). Bicultural Social Development. Hispanic Journal of Behavioral Sciences, 28, 467-497.

Pahl, K., \& Way, N. (2006). Longitudinal trajectories of ethnic identity among urban Black and Latino adolescents. Child Development, 77, 1403-1415.

Passmore, N. L., Fogarty, G. J., Bourke, C. J., \& Baker-Evans, S. F. (2005). Parental bonding and identity style as correlates of self-esteem among adult adoptees and nonadoptees. Family Relations, 54, 523-534.

Pastorino, E., Dunham, R. M., Kidwell, J. S., Bacho, R. A., \& Lamborn, S. D. (1997). Domain-specific gender comparisons in identity development among college youth: Ideology and relationships. Adolescence, 32, 559-577.

Pegg, P. O., \& Plybon, L. E. (2005). Toward the theoretical measurement of ethnic identity. Journal of Early Adolescence, 25(2), 250-265.

Phinney, J. S. (1989). Stages of ethnic identity development in minority group adolescents. Journal of Early Adolescence, 9, 34-49. 
Phinney, J. S. (1992). The multigroup ethnic identity measure: A new scale for use with diverse groups. Journal of Early Adolescence, 9, 156-176.

Phinney, J. S. (1993).A three-stage model of ethnic identity development in adolescence. In M. E. Bernal \& G. P. Knight (Eds.), Ethnic identity: Formation and transmission among Hispanics and other minorities (pp. 61-79). New York: State University of New York Press.

Phinney, J. S. (1996). Understanding ethnic diversity: The role of ethnic identity. American Behavioral Scientist, 40, 143-152.

Phinney, J. S., Cantu, C. L., \& Kurtz, D. A. (1997). Ethnic and American identity as predictors of self-esteem among African American, Latino, and White adolescents. Journal of Youth and Adolescence, 26, 165-185.

Phinney, J. S., \& Ong, A. D. (2007). Conceptualization and measurement of ethnic identity: Current status and future directions. Journal of Counseling Psychology, 54, 271281.

Phinney, J. S., \& Rosenthal, D. A. (1992). Ethnic identity in adolescence: Process, context, and outcome. In G. R. Adams, T.P. Gullota, \& R. Montemayor (Eds.), Adolescent identity formation (pp. 145-172). Newbury Park, CA: Sage.

Plybon, L. E. (2001). Ethnic identity by any other name: A longitudinal analysis of the measurement of ethnic identity in an urban African American early adolescent sample. Unpublished doctoral dissertation, Virginia Commonwealth University, Richmond.

Ponterotto, J. G., Gretchen, D., Utsey, S. O., Stracuzzi, T., \& Saya, R., Jr. (2003). The Multigroup Ethnic Identity Measure (MEIM): Psychometric review and further validity testing. Educational and Psychological Measurement, 63, 502-515.

Portes, A., \& Rumbaut, R. G. (2001). Legacies: The story of the immigrant second generation. Berkeley and Los Angeles: University of California Press.

Portes, A., \& Rumbaut, R. G. (2006). Immigrant America: A portrait (3rd ed.). Berkeley: University of California Press. Raffaelli,

Portes, A., \& Stepick, A. (1994). City on the edge: The transformation of Miami. Berkeley, CA: University of California Press.

Prado, G., Szapocznik, J., Maldonado-Molina, M. M., Schwartz, S. J., \& Pantin, H. (2008). Drug use/abuse prevalence, etiology, prevention, and treatment in Hispanic adolescents: A cultural perspective. Journal of Drug Issues, 22, 5-36.

Reese, L.E., Vera, E.M., \& Paikoff, R.L. (1998). Ethnic identity development of urban, African American children. Journal of Black Psychology, 24, 289-304. 
Ritchie, R. A., Meca, A., Madrazo, V. L., Schwartz, S. J., Hardy, S. A., Zamboanga, B. L., Weisskirch, R. S., Kim, S. Y., \& Whitbourne, S. K. (2013). Identity Dimensions and Related Processes in Emerging Adulthood: Helpful or Harmful? Journal of Clinical Psychology, 69(4), 415-432.

Roberts, R. E., Phinney, J. S., Masse, L. C., Chen, Y. R., Roberts, C. R., \& Romero, A. (1999). The structure of ethnic identity in young adolescents from diverse ethnocultural groups. Journal of Early Adolescence, 19, 301-322.

Roccas, S., Klar, Y., \& Liviatan, I. (2006). The paradox of group-based guilt: Models of national identification, conflict vehemence, and reactions to the in-group's moral violations. Journal of Personality and Social Personality, 91, 698-711.

Romero, A. J., \& Roberts, R. E. (2003). The impact of multiple dimensions of ethnic identity on discrimination and adolescents' self-esteem. Journal of Applied Social Psychology, 33, 2288-2305.

Roth, J. L., \& Brooks-Gunn, J. (2003). What is a youth development program? Identification and defining principles. In F. Jacobs, D.Wertlieb, \& R. M. Lerner (Eds.), Enhancing the life chances of youth and families: Public service systems and public policy perspectives. Handbook of applied developmental science: Promoting positive child, adolescent, and family development through research, policies, and programs, Vol. 2 (pp. 197-223). Thousand Oaks, CA: Sage.

Sabogal, E. (2005). Viviendo en la sombra: The immigration of Peruvian professionals to South Florida. Latino Studies, 3, 113-131.

Sabogal, F., Marin, G., Otero-Sabogal, R., Marin, B. V., \& Perez-Stable, E. (1987). Hispanic familism and acculturation: What changes and what doesn't? Hispanic Journal of Behavioral Sciences, 9, 397-412

Santisteban, D. A., Muir-Malcolm, J. A., Mitrani, V. B., \& Szapocznik, J. (2002). Integrating the study of ethnic culture and family psychology intervention science. In H.A. Liddle, R.F. Levant, D.A. Santisteban \& J.H. Bray (Eds). Family psychology: Science-based interventions (pp. 331-352). Washington, DC: American Psychological Association.

Scales,P. C., Benson,P. L., Leffert, N.,\& Blyth, D. A. (2000).Thecontribution of developmental assets to the prediction of thriving among adolescents. Applied Developmental Science, 4, 27-46.

Schatz, R. T., Staub, E., \& Lavine, H. (2003). On the varieties of national attachment: Blind versus constructive patriotism. Political Psychology, 20, 151-174.

Schildkraut, D. J. (2003). American identity and attitudes toward official-English policies. Political Psychology, 24, 469-499. 
Schildkraut, D. J. (2005). Press one for English: Language policy, public opinion, and American identity. Princeton, NJ: Princeton University Press.

Schildkraut, D. J. (2007). Defining American identity in the 21 st century: How much "there"' is there? Journal of Politics, 69, 597-615.

Schwartz, S. J. (2001). The evolution of Eriksonian and neo-Eriksonian identity theory and research: A review and integration. Identity: An International Journal of Theory and Research, 1, 7-58.

Schwartz, S. J. (2005). A new identity for identity research: Recommendations for expanding and refocusing the identity literature. Journal of Adolescent Research, 20, 293-308.

Schwartz, S. J., Beyers, W., Luyckx, K., Soenens, B., Zamboanga, B. L., Forthun, L. F., ... Waterman, A. S. (2011a). Examining the light and dark sides of emerging adults' identity: A study of identity status differences in positive and negative psychosocial functioning. Journal of Youth and Adolescence, 40, 839-859.

Schwartz, S. J., Des Rosiers, S., Huang, S., Zamboanga, B. L., Unger, J. B., Knight, G. P., Pantin, H., \& Szapocznik, J. (2013a). Developmental trajectories of acculturation in Hispanic adolescents: Associations with family functioning and adolescent risk behavior. Child Development, 84(4), 1355-1372.

Schwartz, S. J., Montgomery, M. J., \& Briones, E. (2006). The role of identity in acculturation among immigrant people: Theoretical propositions, empirical questions, and applied recommendations. Human Development, 49(1), 1-30.

Schwartz, S. J., Pantin, H., Prado, G., Sullivan, S., \& Szapocznik, J. (2006). Nativity and years in the receiving culture as markers of acculturation in ethnic enclaves. Journal of Cross-Cultural Psychology, 37, 345-353.

Schwartz, S. J., Park, Irene J. K., Huynh, Q., Zamboanga, B. L., Umaña-Taylor, A. J., Lee, R. M., Rodriguez, L., Kim, S. Y., Whitbourne, S. K., Castillo, L. G., Weisskirch, R. S., Vazsonyi, A. T., Williams, M. K., \& Agocha, V. B. (2012a). The American Identity Measure: Development and Validation across Ethnic Group and Immigrant Generation. Identity, 12(2), 93-128.

Schwartz, S. J., Unger, J. B., Des Rosiers, S. E., Huang, S., Baezconde-Garbanati, L., Lorenzo-Blanco, E., Villamar, J. A., Soto, D. W., Pattarroyo, M., \& Szapocznik, J. (2012b). Substance use and sexual behavior among recent Hispanic immigrant adolescents: Effects of parent-adolescent differential acculturation and communication. Drug and Alcohol Dependence, 125, 1, S26-S34

Schwartz, S. J., Unger, J. B., Des Rosiers, S. E., Lorenzo-Blanco, E. I., Zamboanga, B. L., Huang, S., Baezconde-Garbanati, L., Villamar, J. A., Soto, D. W., Pattarroyo, M., \& 
Szapocznik, J. (2013b). Domains of acculturation and their effects on substance use and sexual behavior in Hispanic recent immigrant adolescents. Prevention Science.

Schwartz, S. J., Unger, J. B., Lorenzo-Blanco, E., Des Rosiers, S. E., Villamar, J. A., Soto, D. W., Pattarroyo, M., Baezconde-Garbanati, L., \& Szapocznik, J. (2013c). Perceived context of reception among recent Hispanic immigrants: Conceptualization, instrument development, and preliminary validation. Cultural Diversity and Ethnic Minority Psychology.

Schwartz, S. J., Unger, J. B., Zamboanga, B. L., \& Szapocznik, J. (2010). Rethinking the concept of acculturation: implications for theory and research. The American Psychologist, 65(4), 237-251.

Schwartz, S. J., Vignoles, V. L., Brown, R., \& Zagefka, H. (in press). The identity dynamics of acculturation and multiculturalism: Situating acculturation in context. In V. Benet-Martínez \& Y.-Y. Hong (Eds.), Oxford handbook of multicultural identity. Oxford, England: Oxford University Press.

Schwartz, S. J., Weisskirch, R. S., Zamboanga, B. L., Castillo, L. G., Ham, L. S., Huynh, Q.-L., Park, I. J. K., Donovan, R., Kim, S. Y., Vernon, M., Davis. M. J., \& Cano, M. A. (2011b). Dimensions of acculturation: Associations with health risk behaviors among college students from immigrant families. Journal of Counseling Psychology, 58, 27-41.

Schwartz, S. J., Zamboanga, B. L., \& Jarvis, L. H. (2007a). Ethnic identity and acculturation in Hispanic early adolescents: Mediated relationships to academic grades, prosocial behaviors, and externalizing symptoms. Cultural Diversity and Ethnic Minority Psychology, 13, 364-373.

Schwartz, S. J., Zamboanga, B. L., Luyckx, K., Meca, A., \& Ritchie, R. A. (2013). Identity in emerging adulthood: Reviewing the field and looking forward. Emerging Adulthood, 1(2), 96-113.

Schwartz, S. J., Zamboanga, B. L., Rodriguez, L., \& Wang, S. C. (2007b). The structure of cultural identity in an ethnically diverse sample of emerging adults. Basic and Applied Social Psychology, 29, 159-173.

Skorikov, V. B. (2007). Continuity in adolescent career preparation and its effects on adjustment. Journal of Vocational Behavior, 70, 8-24.

Smart, J. \& Smart, D. (1995). Acculturative Stress of Hispanics: Loss and Challenge. Journal of Counseling \& Development, 73(4), 390-396.

Smith, E. P., Walker, K., Fields, L., Brookins, C. C., \& Seay, R. C. (1999). Ethnic identity and its relationship to self-esteem, perceived efficacy, and prosocial attitudes in early adolescence. Journal of Adolescence, 22, 867-880. 
Smokowski, P. R., \& Bacallao, M. L. (2011). Becoming bicultural: Risk, resilience, and Latino youth. New York, NY: New York University Press.

Spencer, M. S., Icard, L. D., Harachi, T. W., Catalano, R. F., \& Oxford, M. (2000). Ethnic identity among monoracial and multiracial early adolescents. Journal of Early Adolescence, 20, 365-387.

Spinner-Halev, J., \& Theiss-Moore, E. (2003). National identity and self-esteem. Perspectives on Politics, 1, 515-532.

Stepick, A., Grenier, G., Castro, M., \& Dunn, M. (2003). This land is our land: Immigrants and power in Miami. Berkeley, CA: University of California Press.

Stepick, A. \& Stepick, C.D. (2002). Power and identity: Miami Cubans. In: SuárezOrozco, M.M., Páez, M.M. (Eds.), Latinos: Remaking America. Harvard University Press, Cambridge, MA, pp. 75-92

Stepick, A., Dutton Stepick, C., \& Vanderkooy, P. (2011). Becoming American. In S. J. Schwartz, K. Luyckx, \& V. L. Vignoles (Eds.), Handbook of identity theory and research (pp. 831-857). New York, NY: Springer.

Stepick, A., Stepick, C., \& Labissiere, Y. (2008). South Florida's immigrant youth and civic engagement: Major engagement, minor differences. Applied Developmental Science, 12(2), 57-6.

Stierlin, H. (1974). Separating parents and adolescents. New York: Quadrangle. Van

Supple, A. J., Ghazarian, S. R., Frabutt, J. M., Plunkett, S. W., \& Sands, T. (2006). Contextual influences on Latino adolescent ethnic identity and academic outcomes. Child Development, 77, 1427-1433.

Syed, M., Azmitia, M., \& Phinney, J. S. (2007). Stability and change in ethnic identity among Latino emerging adults in two contexts. Identity: An International Journal of Theory and Research, 7, 155-178.

Syed, M., Juan, M. J. D., \& Juang, L. P. (2011): Might the survey be the intervention? Participating in ethnicity-related research as a consciousness-raising experience. Identity: An International Journal of Theory and Research, 11(4), 289-310.

Szapocznik, J. \& Kurtines, W. M. (1993). Family psychology and cultural diver- sity: opportunities for theory, research and application. American Psychology, 48, 400-407.

Szapocznik, J., Rio, A., Perez-Vidal, A., Kurtines, W. M., Hervis, O., \& Santisteban, D. (1986). Bicultural Effectiveness Training (BET): An Experimental Test of an Intervention Modality for Families Experiencing Intergenerational/Intercultural Conflict. Hispanic Journal of Behavioral Sciences, 8(4), 303-330. 
Tajfel, H. (1981). Human groups and social categories. New York: Cambridge University Press.

Tajfel, H., \& Turner, J. C. (1986). An integrative theory of intergroup conflict. In W. G. Austin \& S. Worchel (Eds.), The social psychology of intergroup relations (pp. 33-48). Monterey, CA: Brooks/Cole.

Telzer, E. H. (2010). Expanding the acculturation gap-distress model: an integrative review of research. Human Development, 53, 313-340.

Theiss-Morse, E. (2009). Who counts as American? New York, NY: Cambridge University Press.

Thomas, O., Davidson, W., \& McAdoo, H. (2008). An evaluation study of the Young Empowered Sisters (YES!) Program: Promoting cultural assets among African American adolescent girls through a culturally relevant school-based intervention. Journal of Black Psychology, 34, 281-308.

Thompson, T. G. (2001). Culture, race, and ethnicity: A supplement to mental health: A report of the Surgeon General. Washington, DC: Department of Health and Human Services.

Turner, C. F., Ku, L., Rogers, S. M., Lindberg, L. B., Pleck, J. H., \& Sonsenstein, L. H. (1998). Adolescent sexual behavior, drug use, and violence: Increased reporting with computer survey technology. Science, 280, 867-873.

Umaña-Taylor, A. J. (2004). Ethnic identity and self-esteem: Examining the role of social context. Journal of Adolescence, 27, 139-146.

Umaña-Taylor, A. J. (2011). Ethnic identity. In S. J. Schwartz, K. Luyckx, \& V. L. Vignoles (Eds.), Handbook of identity theory and research (pp. 755-773). New York, NY: Springer.

Umaña-Taylor, A. J., Bhanot, R., \& Shin, N. (2006). Ethnic identity formation during adolescence: The critical role of families. Journal of Family Issues, 27, 390-414.

Umaña-Taylor, A. J., Diversi, M., \& Fine, M. A. (2002). Ethnic identity and self-esteem among Latino adolescents: Making distinction among the Latino populations. Journal of Adolescent Research, 17, 303-327.

Umaña-Taylor, A. J., \& Shin, N. (2007). An examination of ethnic identity scale with diverse populations: Exploring variation by ethnicity and geography. Cultural Diversity and Ethnic Minority Psychology, 13, 178-186.

Umaña-Taylor, A. J., \& Updegraff, K. (2007). Latino adolescents' mental health: Exploring the role of discrimination, ethnic identity, accultura- tion, and self-esteem. Journal of Adolescence, 30, 549-567. 
Umana-Taylor, A. J., Vargas-Chanes, D., Garcia, C. D., \& Gonzales-Backen, M. (2009). A longitudinal examination of Latino adolescents' ethnic identity, coping with discrimination and self-esteem. Journal of Early Adolescence, 28, 16-50.

Umaña-Taylor, A. J., Yazedjian, A., \& Bámaca-Gómez, M. Y. (2004). Developing the ethnic identity scale using Eriksonian and social identity perspectives. Identity: An International Journal of Theory and Research, 4, 9-38.

Umaña-Taylor, A. J., Zeiders, K. H., \& Updegraff, K. A. (2013). Family ethnic socialization and ethnic identity: A family-driven, youth-driven, or reciprocal process? Journal of Family Psychology, 27, 137-146.

U.S. Census Bureau. (2011). The 2010 statistical abstract. Retrieved from www/census.gov/compendia/statab/cats/population.html

Utsey, S. O., Chae, M. H., Brown, C. F., \& Kelly, D. (2002). Effect of ethnic group membership on ethnic identity, race-related stress, and quality of life. Cultural Diversity and Ethnic Minority Psychology, 8, 366-377.

Vignoles, V. L., Schwartz, S. J., \& Luyckx, K. (2011). Introduction: Toward an integrative model of identity. In S. J. Schwartz, K. Luyckx, \& V. L. Vignoles (Eds.). Handbook of identity theory and research (pp. 1-27). New York: Springer.

Waterman, A. S. (1999). Identity, the identity statuses, and identity status development: A contemporary statement. Developmental Review, 19, 591-621.

Waterman, A. S. (2007). Doing well: The relationship of identity status to three conceptions of well-being. Identity: An International Journal of Theory and Research, 7, 289-307.

Widaman, K. F., \& Thompson, J. S. (2003). On specifying the null model for incremental fit indices in structural equation modeling. Psychological Methods, 8, 16-37.

Willis, G.B. (2005). Cognitive Interviewing: A Tool for Improving Questionnaire Design. Thousand Oaks, CA: Sage Publications.

Wilson, D. K., Rodriguez, J. R., \& Taylor, W. C. (1997). Health-promoting and healthcompromising behaviors among minority adolescents. Washington, DC: American Psychological Association.

Worrell, F. C. (2000). A validity study of scores on the Multigroup Ethnic Identity Measure based on a sample of academically talented adolescents. Educational and Psychological Measurement, 60, 439-447.

Yancey, A., Aneshensel, C., \& Driscoll, A. (2003). The assessment of ethnic identity in a diverse urban youth population. Journal of Black Psychology, 27, 190-208. 
Zamboanga, B. L., Raffaelli, M., \& Horton, N. J. (2006). Acculturation status and heavy alcohol use among Mexican American college students: An investigation of the moderating role of gender. Addictive Behaviors, 31, 2188-2198.

Zamboanga, B. L., Schwartz, S. J., Jarvis, L. H., \& Van Tyne, K. (2009). Acculturation and substance use among Hispanic early adolescents: Investigating the mediating roles of acculturative stress and self-esteem. Journal of Primary Prevention, 30, 315-333 


\section{TABLES}

Table 1

Item Description for the Multigroup Ethnic Identity Measure (MEIM) and the American Identity Measure (AIM)

\begin{tabular}{cl}
\hline Item Number & Item Wording \\
\hline Exploration & I have spent time trying to find out about my ethnic group/the \\
Item 1 & United States, such as its history, traditions, and customs. \\
Item 2 & $\begin{array}{l}\text { I am active in organizations or social groups that include mostly } \\
\text { members of my own ethnic group/Americans. }\end{array}$ \\
Item 4 & $\begin{array}{l}\text { I think a lot about how my life will be affected by my ethnic } \\
\text { group membership/being American. }\end{array}$ \\
Item 8 & $\begin{array}{l}\text { In order to learn more about my ethnic background/being } \\
\text { American, I have often talked to other people about my ethnic } \\
\text { group/the Untied States. }\end{array}$ \\
Item 10 & $\begin{array}{l}\text { I participate in cultural practices of my own group/the United } \\
\text { States, such as special food, music, or customs. }\end{array}$ \\
Affirmation/Commitment \\
Item 3 & $\begin{array}{l}\text { I have a clear sense of my ethnic background and what it/the } \\
\text { United States and what being American means to me. }\end{array}$ \\
Item 5 & $\begin{array}{l}\text { I am happy that I am a member of the group I belong to/an } \\
\text { American. }\end{array}$ \\
Item 6 & $\begin{array}{l}\text { I have a strong sense of belonging to my own ethnic group/the } \\
\text { United States. }\end{array}$ \\
Item 7 & $\begin{array}{l}\text { I understand pretty well what my ethnic group } \\
\text { membership/being American means to me. }\end{array}$ \\
Item 9 & $\begin{array}{l}\text { I have a lot of pride in my ethnic group/the United States. } \\
\text { I feel a strong attachment towards my own ethnic group/the } \\
\text { United States. }\end{array}$ \\
$\begin{array}{l}\text { I feel good about my cultural or ethnic background/being } \\
\text { American. }\end{array}$ \\
\end{tabular}


Table 2

Model Comparison for the Multigroup Ethnic Identity Measure (MEIM)

\begin{tabular}{|c|c|c|c|c|c|c|c|c|c|c|}
\hline & \multicolumn{4}{|c|}{ Two-Factor Model } & \multicolumn{3}{|c|}{ One-Factor Model } & \multicolumn{3}{|c|}{ Difference Tests } \\
\hline & $\chi^{2}(53)$ & CFI & $\begin{array}{c}\text { RMSEA } \\
\text { (90\% C.I.) } \\
\end{array}$ & SRMR & $\chi^{2}(54)$ & CFI & $\begin{array}{c}\text { RMSEA } \\
(90 \% \text { C.I. }) \\
\end{array}$ & $\Delta \mathrm{CFI}$ & $\triangle \mathrm{RMSEA}$ & $\Delta \chi^{2}(1)$ \\
\hline \multicolumn{11}{|c|}{ Adolescents } \\
\hline Time 1 & $127.609^{*}$ & .929 & $.068(.053-.084)$ & .050 & $160.355^{*}$ & .898 & $.081(.067-.095)$ & .031 & .013 & $32.746^{*}$ \\
\hline Time 2 & $110.671^{*}$ & .947 & $.063(.046-.079)$ & .044 & $178.505^{*}$ & .886 & $.091(.077-.106)$ & .061 & .028 & $67.834^{*}$ \\
\hline Time 3 & $105.863^{*}$ & .937 & $.063(.045-.080)$ & .049 & $158.339^{*}$ & .876 & $.087(.072-.103)$ & .061 & .024 & $52.476^{*}$ \\
\hline Time 4 & $145.334^{*}$ & .874 & $.084(.068-.100)$ & .063 & $159.587^{*}$ & .856 & $.089(.073-.105)$ & .018 & .005 & $14.253^{*}$ \\
\hline \multicolumn{11}{|c|}{ Caregivers } \\
\hline Time 1 & $216.487^{*}$ & .846 & $.101(.088-.116)$ & .060 & $239.369^{*}$ & .825 & $.107(.093-.121)$ & .021 & .006 & $22.881^{*}$ \\
\hline Mod. & $160.889^{*}$ & .896 & $.085(.070-.100)$ & .053 & & & & & & \\
\hline Time 2 & $225.381^{*}$ & .843 & $.108(.094-.123)$ & .067 & $269.423^{*}$ & .803 & $.120(.106-.134)$ & .040 & .012 & $44.042^{*}$ \\
\hline Mod. & $169.271^{*}$ & .892 & $.091(.076-.107)$ & .062 & & & & & & \\
\hline Time 3 & $167.783^{*}$ & .893 & $.092(.076-.108)$ & .057 & $261.397^{*}$ & .807 & $.122(.108-.137)$ & .086 & .030 & $93.614^{*}$ \\
\hline Mod. & $144.472^{*}$ & .913 & $.084(.068-.101)$ & .057 & & & & & & \\
\hline Time 4 & $113.219^{*}$ & .946 & $.067(.050-.084)$ & .048 & $135.239^{*}$ & .927 & $.077(.061-.093)$ & .019 & .010 & $22.020^{*}$ \\
\hline
\end{tabular}


Table 3

Model Comparison for the American Identity Measure (AIM)

\begin{tabular}{|c|c|c|c|c|c|c|c|c|c|c|}
\hline & \multicolumn{4}{|c|}{ Two-Factor Model } & \multicolumn{3}{|c|}{ One-Factor Model } & \multicolumn{3}{|c|}{ Difference Tests } \\
\hline & $\chi^{2}(53)$ & CFI & $\begin{array}{c}\text { RMSEA } \\
(90 \% \text { C.I. }) \\
\end{array}$ & SRMR & $\chi^{2}(51)$ & CFI & $\begin{array}{c}\text { RMSEA } \\
(90 \% \text { C.I. }) \\
\end{array}$ & $\Delta \mathrm{CFI}$ & $\triangle \mathrm{RMSEA}$ & $\Delta \chi^{2}(1)$ \\
\hline \multicolumn{11}{|c|}{ Adolescents } \\
\hline Time 1 & $194.496^{*}$ & .896 & $.094(.080-.109)$ & .051 & $209.748^{*}$ & .922 & $.098(.084-.112)$ & .011 & .004 & $43.733^{*}$ \\
\hline Mod. & 143.922 & .931 & $.078(.063-.093)$ & .045 & & & & & & \\
\hline Time 2 & $161.953^{*}$ & .918 & $.086(.071-.101)$ & .058 & $186.242^{*}$ & .899 & $.094(.079-.109)$ & .017 & .008 & $24.289^{*}$ \\
\hline Mod. & 148.733 & .927 & $.083(.068-.099)$ & .056 & & & & & & \\
\hline Time 3 & $132.298^{*}$ & .925 & $.077(.060-.093)$ & .053 & $157.561^{*}$ & .902 & $.087(.071-.103)$ & .023 & .010 & $25.263^{*}$ \\
\hline Time 4 & $90.237^{*}$ & .946 & $.054(.034-.073)$ & .050 & $123.543^{*}$ & .900 & $.073(.056-.090)$ & .046 & .019 & $33.306^{*}$ \\
\hline \multicolumn{11}{|c|}{ Caregivers } \\
\hline Time 1 & $167.884^{*}$ & .92 & $.078(.063-.093)$ & .053 & $209.748^{*}$ & .922 & $.086(.079-.108)$ & .015 & .008 & $22.692^{*}$ \\
\hline Mod. & $142.262^{*}$ & .936 & $.077(.062-.092)$ & .05 & & & & & & \\
\hline Time 2 & $173.761^{*}$ & .899 & $.090(.074-.105)$ & .057 & $186.242^{*}$ & .899 & $.092(.079-.109)$ & .007 & .002 & $10.213^{*}$ \\
\hline Mod. & $161.98^{*}$ & .907 & .089 (.076-.107) & .055 & & & & & & \\
\hline Time 3 & $145.367^{*}$ & .901 & $.082(.065-.098)$ & .059 & $157.561^{*}$ & .902 & $.086(.071-.103)$ & .013 & .004 & $12.755^{*}$ \\
\hline Mod. & $136.221^{*}$ & .908 & $.080(.065-.097)$ & .058 & & & & & & \\
\hline Time 4 & $173.574^{*}$ & .888 & $.092(.076-.108)$ & .06 & $123.543^{*}$ & .900 & $.098(.086-.117)$ & .017 & .006 & $19.720^{*}$ \\
\hline Mod. & $157.288^{*}$ & .901 & $.091(.075-.108)$ & .058 & & & & & & \\
\hline
\end{tabular}


Table 4

Longitudinal Invariance for the Multigroup Ethnic Identity Measure (MEIM)

\begin{tabular}{|c|c|c|c|c|c|c|c|c|}
\hline & CFI & $\Delta \mathrm{CFI}$ & $\begin{array}{l}\text { RMSEA } \\
(90 \% \text { C.I. })\end{array}$ & $\triangle \mathrm{RMSEA}$ & SRMR & $\chi^{2}(\mathrm{df})$ & $\Delta \chi^{2}(\Delta \mathrm{df})$ & $p$-Value \\
\hline \multicolumn{9}{|l|}{ Adolescents } \\
\hline Configural Invariance & .895 & & $\begin{array}{c}.059 \\
(.052-.067)\end{array}$ & & .059 & $482.220(234)^{*}$ & & \\
\hline $\begin{array}{l}\text { Configural Invariance } \\
\text { with Covariates }\end{array}$ & .902 & .007 & $\begin{array}{c}.057 \\
(.050-.065)\end{array}$ & .002 & .059 & $463.471(233)^{*}$ & $18.753(1)$ & $<.001$ \\
\hline $\begin{array}{l}\text { Weak Factorial } \\
\text { Invariance }\end{array}$ & .901 & .001 & $\begin{array}{c}.057 \\
(.049-.064)\end{array}$ & $<.001$ & .064 & $477.185(243)^{*}$ & $13.714(10)$ & .186 \\
\hline $\begin{array}{l}\text { Strong Factorial } \\
\text { Invariance }\end{array}$ & .899 & .002 & $\begin{array}{c}.056 \\
(.048-.063)\end{array}$ & .001 & .065 & $490.371(253)^{*}$ & $13.186(10)$ & .213 \\
\hline \multicolumn{9}{|l|}{ Caregiver } \\
\hline $\begin{array}{c}\text { Configural Invariance } \\
\text { with Covariates }\end{array}$ & .931 & & $\begin{array}{c}.051 \\
(.043-.059)\end{array}$ & $<.001$ & .053 & $414.348(232)^{*}$ & & \\
\hline $\begin{array}{l}\text { Weak Factorial } \\
\text { Invariance }\end{array}$ & .929 & .002 & $\begin{array}{c}.051 \\
(.043-.059)\end{array}$ & $<.001$ & .059 & $429.938(242)^{*}$ & $15.590(10)$ & .112 \\
\hline $\begin{array}{l}\text { Strong Factorial } \\
\text { Invariance }\end{array}$ & .926 & .003 & $\begin{array}{c}.051 \\
(.043-.058)\end{array}$ & $<.001$ & .061 & $445.919(252)^{*}$ & $15.981(10)$ & .100 \\
\hline
\end{tabular}


Table 5

Longitudinal Invariance for the American Identity Measure (AIM)

\begin{tabular}{|c|c|c|c|c|c|c|c|c|}
\hline & CFI & $\Delta \mathrm{CFI}$ & $\begin{array}{l}\text { RMSEA } \\
(90 \% \text { C.I. })\end{array}$ & $\triangle \mathrm{RMSEA}$ & SRMR & $\chi^{2}(\mathrm{df})$ & $\Delta \chi^{2}(\Delta \mathrm{df})$ & $p$-Value \\
\hline \multicolumn{9}{|l|}{ Adolescents } \\
\hline Configural Invariance & .913 & & $\begin{array}{c}.053 \\
(.046-.061)\end{array}$ & & .051 & $434.861(234)^{*}$ & & \\
\hline $\begin{array}{l}\text { Weak Factorial } \\
\text { Invariance }\end{array}$ & .910 & .003 & $\begin{array}{c}.053 \\
(.045-.061)\end{array}$ & $<.001$ & .059 & $450.361(244)^{*}$ & $15.00-8(10)$ & .115 \\
\hline $\begin{array}{l}\text { Strong Factorial } \\
\text { Invariance }\end{array}$ & .895 & .015 & $\begin{array}{c}.056 \\
(.049-.063)\end{array}$ & .002 & .062 & $494.372(254)^{*}$ & $44.911(10)$ & $<.001$ \\
\hline \multicolumn{9}{|l|}{ Caregiver } \\
\hline Configural Invariance & .909 & & $\begin{array}{c}.059 \\
(.050-.065)\end{array}$ & & .053 & $482.216(235)^{*}$ & & \\
\hline $\begin{array}{l}\text { Weak Factorial } \\
\text { Invariance }\end{array}$ & .910 & .001 & $\begin{array}{c}.057 \\
(.050-.065)\end{array}$ & .002 & .056 & $487.072(245)^{*}$ & $4.856(10)$ & .900 \\
\hline $\begin{array}{l}\text { Strong Factorial } \\
\text { Invariance }\end{array}$ & .905 & .005 & $\begin{array}{c}.058 \\
(.051-.065)\end{array}$ & .001 & .057 & $512.644(255)^{*}$ & $25.572(10)$ & .004 \\
\hline
\end{tabular}


Table 6

Descriptive Statistics for Study Variables

\begin{tabular}{lccc}
\hline Variable Name & Mean (SD) & Skewness & Kurtosis \\
\hline Adolescent & & & \\
Ethnic Affirmation 1 & $19.775(4.965)$ & -0.560 & 1.117 \\
Ethnic Affirmation 2 & $19.752(5.289)$ & -0.557 & 0.858 \\
Ethnic Affirmation 3 & $19.839(5.268)$ & -0.421 & 0.356 \\
Ethnic Affirmation 4 & $19.776(5.008)$ & -0.158 & 0.029 \\
American Affirmation 1 & $16.520(5.754)$ & -0.497 & 0.314 \\
American Affirmation 2 & $16.784(6.210)$ & -0.087 & 0.291 \\
American Affirmation 3 & $17.883(5.978)$ & -0.492 & 0.309 \\
American Affirmation 4 & $17.897(5.455)$ & -0.294 & 0.285 \\
& & & \\
Caregiver & & & \\
Ethnic Affirmation 1 & $20.944(3.328)$ & -0.118 & 1.482 \\
Ethnic Affirmation 2 & $20.657(3.475)$ & -0.264 & 0.915 \\
Ethnic Affirmation 3 & $20.172(3.839)$ & -0.584 & 1.804 \\
Ethnic Affirmation 4 & $20.036(4.075)$ & -0.408 & 0.646 \\
American Affirmation 1 & $17.792(4.970)$ & -0.411 & 0.287 \\
American Affirmation 2 & $18.031(5.038)$ & -0.197 & -0.152 \\
American Affirmation 3 & $17.792(4.914)$ & -0.258 & 0.142 \\
American Affirmation 4 & $17.996(4.929)$ & -0.711 & 1.353 \\
\hline
\end{tabular}


Table 7

Evaluation of Latent Growth Curve Models for Recently Immigrated Hispanic Adolescents' Cultural Identity

\begin{tabular}{|c|c|c|c|c|c|c|c|}
\hline & \multicolumn{4}{|c|}{ Model Fit } & \multicolumn{3}{|c|}{ Model Comparison } \\
\hline & $\chi^{2}(\mathrm{df})$ & CFI & RMSEA & SRMR & $-2 \mathrm{LL}(\mathrm{df})$ & $\Delta-2 \mathrm{LL}(\mathrm{df})$ & p-value \\
\hline \multicolumn{8}{|l|}{ Ethnic Affirmation } \\
\hline Intercept & $14.400(8)$ & 0.919 & 0.052 & 0.099 & $6452.926(6)$ & & \\
\hline Linear Change & $9.828(5)$ & 0.939 & 0.057 & 0.087 & $6443.632(9)$ & $9.294(3)$ & .026 \\
\hline \multicolumn{8}{|l|}{ American Affirmation } \\
\hline Intercept Model & $26.403(8)^{*}$ & 0.906 & 0.087 & 0.085 & $6608.464(6)$ & & \\
\hline Linear Change & $4.718(5)$ & 1.000 & $<.001$ & 0.025 & $6579.172(9)$ & $29.292(3)$ & $<.001$ \\
\hline Quadratic Change & $1.676(1)$ & 0.997 & 0.047 & 0.015 & $6574.866(13)$ & $4.306(4)$ & .366 \\
\hline \multicolumn{8}{|c|}{ Ethnic \& American Affirmation } \\
\hline Intercept Model & $109.151(31)^{*}$ & 0.795 & 0.091 & 0.085 & $13037.508(13)$ & & \\
\hline $\begin{array}{l}\text { Linear Change in American } \\
\text { Affirmation }\end{array}$ & $82.696(27)^{*}$ & 0.854 & 0.083 & 0.073 & $13002.830(17)$ & $34.678(4)$ & $<.001$ \\
\hline Dual Process Model & $74.769(22)^{*}$ & 0.861 & 0.089 & 0.089 & $12981.122(22)$ & $21.708(5)$ & $<.001$ \\
\hline Time-Varying Model & $15.838(17)$ & 1.000 & $<.001$ & .032 & $12922.596(27)$ & - & - \\
\hline
\end{tabular}


Table 8

Evaluation of Latent Growth Curve Models for Recently Immigrated Hispanic Caregivers' Cultural Identity

\begin{tabular}{|c|c|c|c|c|c|c|c|}
\hline & \multicolumn{4}{|c|}{ Model Fit } & \multicolumn{3}{|c|}{ Model Comparison } \\
\hline & $\chi^{2}(\mathrm{df})$ & CFI & RMSEA & SRMR & $-2 \mathrm{LL}(\mathrm{df})$ & $\Delta-2 \mathrm{LL}(\mathrm{df})$ & $p$-value \\
\hline \multicolumn{8}{|l|}{ Ethnic Affirmation } \\
\hline Intercept Model & $27.678(8)^{*}$ & 0.858 & 0.096 & 0.204 & $4867.956(6)$ & & \\
\hline Linear Change & $3.944(5)$ & 1.000 & $<.001$ & 0.068 & $4838.436(9)$ & $29.520(3)$ & $<.001$ \\
\hline Quadratic Change & $0.405(1)^{*}$ & 1.000 & $<0.001$ & 0.006 & $4835.202(13)$ & $3.234(4)$ & .519 \\
\hline \multicolumn{8}{|l|}{ American Affirmation } \\
\hline Intercept Model & $21.514(8)^{*}$ & 0.986 & 0.080 & 0.055 & $5202.422(6)$ & & \\
\hline Linear Change & $4.736(5)$ & 1.000 & $<.001$ & 0.056 & $5176.944(9)$ & $25.478(3)$ & $<.001$ \\
\hline Quadratic Change & $2.478(1)$ & 0.998 & 0.074 & 0.014 & $5172.396(13)$ & $4.552(4)$ & .336 \\
\hline \multicolumn{8}{|c|}{ Ethnic \& American Affirmation } \\
\hline Intercept Model & $117.479(31)^{*}$ & 0.894 & 0.102 & 0.0130 & $10049.449(13)$ & & \\
\hline $\begin{array}{l}\text { Linear Change in Ethnic } \\
\text { Affirmation }\end{array}$ & $97.007(27)^{*}$ & 0.849 & 0.098 & 0.068 & $10018.736(17)$ & $30.706(4)$ & $<.001$ \\
\hline Dual Process Model & $60.725(22)^{*}$ & 0.941 & 0.080 & 0.064 & $9972.266(22)$ & $46.470(5)$ & $<.001$ \\
\hline $\begin{array}{l}\text { Modified Dual Process } \\
\text { Model }\end{array}$ & $60.558(23)^{*}$ & 0.940 & 0.080 & 0.067 & $9972.144(21)$ & $44.592(4)^{1}$ & $<.001$ \\
\hline
\end{tabular}

Note: ${ }^{*} p<.050$

${ }^{1}$ This model was evaluated against the linear change in caregivers' Ethnic identity affirmation 
Table 9

Growth Parameters for Recently Immigrated Hispanic Adolescents' and their Caregivers' Ethnic and American Affirmation Separately

\begin{tabular}{lcccc}
\hline & \multicolumn{2}{c}{ Adolescents } & \multicolumn{2}{c}{ Caregivers } \\
\hline Ethnic Affirmation & & & & \\
Mean & & & & \\
$\quad$ Intercept & 19.757 & $<.001$ & 20.954 & $<.001$ \\
Slope & 0.010 & 0.942 & -0.250 & .046 \\
Variance & & & & \\
Intercept & 11.502 & .001 & 3.352 & $<.001$ \\
Slope & 1.270 & .033 & 0.354 & .147 \\
Covariance $(r)$ & -1.269 & .322 & 0.580 & .093 \\
& $(-.332)$ & & $(.532)$ & \\
American Affirmation & & & & \\
Mean & & & & \\
Intercept & 16.499 & $<.001$ & 17.668 & $<.001$ \\
Slope & 0.480 & .001 & -0.002 & .985 \\
Variance & & & & \\
Intercept & 20.328 & $<.001$ & 17.374 & $<.001$ \\
Slope & 1.733 & .001 & 1.506 & .005 \\
Covariance $(r)$ & -2.533 & .004 & -1.911 & .092 \\
& $(-.427)$ & & $(-.374)$ & \\
\hline
\end{tabular}


Table 10

Growth in Recently Immigrated Hispanic Adolescents' American Affirmation with Ethnic Affirmation as a Time Varying Predictor

\begin{tabular}{ccc}
\hline Parameter & Estimate & $p$-value \\
\hline Mean & & $<.001$ \\
$\quad$ Intercept & 16.500 & $<.001$ \\
Slope & 0.492 & \\
& & $<.001$ \\
Variance & 19.608 & $<.001$ \\
Intercept & 1.682 & .005 \\
Slope & & \\
Covariance $(r)$ & -2.603 & \\
& $(-.431)$ & .032
\end{tabular}


Table 11

Relationship among Recently Immigrated Hispanic Adolescents' American and Ethnic Affirmation

\begin{tabular}{cccc}
\hline Variables & Predictor & Estimate (Std) & $p$-value \\
\hline American (Time 1) & Ethnic (Time 1) & $0.106(.092)$ & .164 \\
American (Time 2) & Ethnic (Time 2) & $0.251(.215)$ & .003 \\
American (Time 3) & Ethnic (Time 3) & $0.386(.345)$ & $<.001$ \\
American (Time 4) & Ethnic (Time 4) & $0.371(.336)$ & $<.001$ \\
\hline
\end{tabular}

Note: Ethnic Identity was centered according to the Grand Mean 
Table 12

Growth in Recently Immigrated Hispanic Caregivers' Ethnic and American Affirmation

\begin{tabular}{|c|c|c|c|c|}
\hline & \multicolumn{2}{|c|}{ Ethnic Affirmation } & \multicolumn{2}{|c|}{ Adolescent Affirmation } \\
\hline & Estimate & $p$-value & Estimate & $p$-value \\
\hline \multicolumn{5}{|l|}{ Mean } \\
\hline Intercept & 20.964 & $<.001$ & 17.673 & $<.001$ \\
\hline Slope & -0.259 & .038 & -.004 & .965 \\
\hline \multicolumn{5}{|l|}{ Variance } \\
\hline Intercept & 4.590 & $<.001$ & 16.914 & $<.001$ \\
\hline Slope & 0.541 & .018 & 1.425 & .007 \\
\hline Covariance $(r)$ & -- & -- & $\begin{array}{l}-1.715 \\
(-.349)\end{array}$ & .123 \\
\hline
\end{tabular}


Table 13

Relationship among Recently Immigrated Hispanic Caregivers' Ethnic and American Affirmation

\begin{tabular}{llcc}
\hline & & $\begin{array}{c}\text { Covariance } \\
(r)\end{array}$ & $p$-value \\
\hline American Intercept & Ethnic Intercept & 4.122 & $<.001$ \\
& & $(.468)$ & .051 \\
& Ethnic Slope & -0.997 & .044 \\
American Slope & Ethnic Intercept & $-.330)$ & \\
& & -0.881 & $<.001$ \\
& Ethnic Slope & $(-.344)$ & \\
& & $(.820)$ & \\
\hline
\end{tabular}


Table 14

Evaluation of Latent Growth Curve Models for Recently Immigrated Hispanic Adolescents' Ethnic and American Affirmation by Site

\begin{tabular}{|c|c|c|c|c|c|c|c|}
\hline & \multicolumn{4}{|c|}{ Model Fit } & \multicolumn{3}{|c|}{ Model Comparison } \\
\hline & $\chi^{2}(\mathrm{df})$ & CFI & RMSEA & SRMR & $-2 \mathrm{LL}(\mathrm{df})$ & $\Delta-2 \mathrm{LL}(\mathrm{df})$ & p-value \\
\hline \multicolumn{8}{|l|}{ Ethnic Affirmation } \\
\hline Intercept Model & $21.548(11)^{*}$ & 0.907 & 0.056 & 0.087 & $6889.900(7)$ & & \\
\hline Linear Change & $10.574(7)$ & 0.968 & 0.041 & 0.073 & $6875.850(11)$ & $14.050(4)$ & .007 \\
\hline \multicolumn{8}{|l|}{ American Affirmation } \\
\hline Intercept Model & $31.006(11)^{*}$ & 0.921 & 0.078 & 0.075 & $7029.460(7)$ & & \\
\hline Linear Change & $6.399(7)$ & 1.000 & $<.001$ & 0.025 & $7000.560(11)$ & $28.900(4)$ & $<.001$ \\
\hline \multicolumn{8}{|l|}{ Ethnic \& American Affirmation } \\
\hline Intercept Model & $123.252(37)^{*}$ & 0.803 & 0.088 & 0.080 & $13458.214(15)$ & & \\
\hline $\begin{array}{l}\text { Linear Change in American } \\
\text { Affirmation }\end{array}$ & $94.628(32)^{*}$ & 0.857 & 0.081 & 0.068 & $13423.758(20)$ & $34.456(5)$ & $<.001$ \\
\hline Dual Process Model & $78.482(26)^{*}$ & 0.880 & 0.082 & 0.060 & $13397.128(26)$ & $26.630(6)$ & $<.001$ \\
\hline Time-Varying Model & $16.314(19)$ & 1.000 & $<.001$ & 0.027 & $13337.642(33)$ & $59.486(7)$ & $<.001$ \\
\hline
\end{tabular}


Table 15

Evaluation of Latent Growth Curve Models for Recently Immigrated Hispanic Caregivers' Ethnic and American Affirmation by Site

\begin{tabular}{|c|c|c|c|c|c|c|c|}
\hline & \multicolumn{4}{|c|}{ Model Fit } & \multicolumn{3}{|c|}{ Model Comparison } \\
\hline & $\chi^{2}(\mathrm{df})$ & CFI & RMSEA & SRMR & $-2 \mathrm{LL}(\mathrm{df})$ & $\Delta-2 \mathrm{LL}(\mathrm{df})$ & p-value \\
\hline \multicolumn{8}{|l|}{ Ethnic Affirmation } \\
\hline Intercept Model & $39.739(11)^{*}$ & 0.834 & 0.099 & 0.176 & $5256.364(7)$ & & \\
\hline Linear Change & $10.474(7)$ & 0.980 & 0.043 & 0.060 & $5223.420(11)$ & $32.944(4)$ & $<.001$ \\
\hline \multicolumn{8}{|l|}{ American Affirmation } \\
\hline Intercept Model & $25.363(11)^{*}$ & 0.994 & 0.070 & 0.050 & $5537.054(7)$ & & \\
\hline Linear Change & $5.703(7)$ & 1.000 & $<.001$ & 0.042 & $5510.588(11)$ & $26.466(4)$ & $<.001$ \\
\hline \multicolumn{8}{|c|}{ Ethnic \& American Affirmation } \\
\hline Intercept Model & $123.034(37)^{*}$ & 0.910 & 0.088 & 0.199 & $11807.188(15)$ & & \\
\hline $\begin{array}{l}\text { Linear Change in Ethnic } \\
\text { Affirmation }\end{array}$ & $87.573(32)^{*}$ & 0.942 & 0.076 & 0.059 & $11764.832(20)$ & $42.356(5)$ & $<.001$ \\
\hline Dual Process Model & $55.182(26)^{*}$ & 0.974 & 0.061 & 0.050 & $11722.927(26)$ & $41.860(5)$ & $<.001$ \\
\hline $\begin{array}{l}\text { Modified Dual Process } \\
\text { Model }\end{array}$ & $56.293(27)^{*}$ & 0.969 & 0.060 & 0.051 & $11724.010(25)$ & $40.822(5)^{1}$ & $<.001$ \\
\hline
\end{tabular}

Note: ${ }^{*} p<.050$

${ }^{1}$ This model was evaluated against the linear change in caregivers' Ethnic identity affirmation 
Table 16

Evaluation of Latent Growth Curve Models for Recently Immigrated Hispanic Adolescents' Ethnic and American Affirmation by Nationality

\begin{tabular}{|c|c|c|c|c|c|c|c|}
\hline & \multicolumn{4}{|c|}{ Model Fit } & \multicolumn{3}{|c|}{ Model Comparison } \\
\hline & $\chi^{2}(\mathrm{df})$ & CFI & RMSEA & SRMR & $-2 \mathrm{LL}(\mathrm{df})$ & $\Delta-2 \mathrm{LL}(\mathrm{df})$ & $p$-value \\
\hline \multicolumn{8}{|l|}{ Ethnic Affirmation } \\
\hline Intercept Model & $22.996(14)$ & 0.931 & 0.046 & 0.073 & $7158.204(8)$ & & \\
\hline Linear Change & $14.438(9)$ & 0.958 & 0.045 & 0.065 & $7145.722(13)$ & $12.482(5)$ & .029 \\
\hline \multicolumn{8}{|l|}{ American Affirmation } \\
\hline Intercept Model & $33.981(14)^{*}$ & 0.944 & 0.069 & 0.064 & $7282.000(8)$ & & \\
\hline Linear Change & $5.826(9)$ & 1.000 & $<.001$ & 0.019 & $7252.156(13)$ & $29.844(5)$ & $<.001$ \\
\hline \multicolumn{8}{|l|}{ Ethnic \& American Affirmation } \\
\hline Intercept Model & $129.430(43)^{*}$ & 0.831 & 0.082 & 0.072 & $13705.698(17)$ & & \\
\hline $\begin{array}{l}\text { Linear Change in American } \\
\text { Affirmation }\end{array}$ & $97.544(37)^{*}$ & 0.881 & 0.074 & 0.062 & $13670.700(23)$ & $34.998(6)$ & $<.001$ \\
\hline Dual Process Model & $84.081(30)^{*}$ & 0.890 & 0.077 & 0.056 & $13645.034(30)$ & $25.666(7)$ & $<.001$ \\
\hline Time-Varying Model & $17.571(21)$ & 1.000 & $<.001$ & 0.027 & $13584.082(39)$ & $60.952(9)$ & $<.001$ \\
\hline
\end{tabular}
Note: ${ }^{*} p<.050$ 
Table 17

Evaluation of Latent Growth Curve Models for Recently Immigrated Hispanic Caregivers' Ethnic and American Affirmation by Nationality

\begin{tabular}{|c|c|c|c|c|c|c|c|}
\hline & \multicolumn{4}{|c|}{ Model Fit } & \multicolumn{3}{|c|}{ Model Comparison } \\
\hline & $\chi^{2}(\mathrm{df})$ & CFI & RMSEA & SRMR & $-2 \mathrm{LL}(\mathrm{df})$ & $\Delta-2 \mathrm{LL}(\mathrm{df})$ & p-value \\
\hline \multicolumn{8}{|l|}{ Ethnic Affirmation } \\
\hline Intercept Model & $47.438(14)^{*}$ & 0.840 & 0.094 & 0.155 & $5491.080(8)$ & & \\
\hline Linear Change & $8.209(9)$ & 1.000 & $<.001$ & 0.045 & $5454.056(13)$ & $37.024(5)$ & $<.001$ \\
\hline \multicolumn{8}{|l|}{ American Affirmation } \\
\hline Intercept Model & $28.590(14)^{*}$ & 0.989 & 0.062 & 0.043 & $5774.188(8)$ & & \\
\hline Linear Change & $5.998(9)$ & 1.000 & $<.001$ & 0.038 & $5747.462(13)$ & $26.726(5)$ & $<.001$ \\
\hline \multicolumn{8}{|l|}{ Ethnic \& American Affirmation } \\
\hline Intercept Model & $132.176(43)^{*}$ & 0.909 & 0.083 & 0.111 & $12073.706(17)$ & & \\
\hline $\begin{array}{l}\text { Linear Change in American } \\
\text { Affirmation }\end{array}$ & $93.105(37)^{*}$ & 0.934 & 0.071 & 0.051 & $12031.082(23)$ & $42.624(6)$ & $<.001$ \\
\hline Dual Process Model & $55.871(30)^{*}$ & 0.974 & 0.053 & 0.043 & $11988.668(30)$ & $42.414(6)$ & $<.001$ \\
\hline $\begin{array}{l}\text { Modified Dual Process } \\
\text { Model }\end{array}$ & $56.708(31)^{*}$ & .969 & .060 & .051 & $11989.392(29)$ & $41.690(5)^{1}$ & $<.001$ \\
\hline
\end{tabular}

Note: ${ }^{*} p<.050$

${ }^{1}$ This model was evaluated against the linear change in caregivers' Ethnic identity affirmation 
Table 18

General Ethnic and American Affirmation Growth Parameters

\begin{tabular}{|c|c|c|c|c|c|}
\hline & \multicolumn{3}{|c|}{ Site } & \multicolumn{2}{|c|}{ Nationality } \\
\hline & Miami & $\begin{array}{c}\text { Los } \\
\text { Angeles }\end{array}$ & Cuban & Mexican & Other \\
\hline \multicolumn{6}{|l|}{ Adolescent } \\
\hline \multicolumn{6}{|c|}{ Ethnic Affirmation } \\
\hline Intercept & $20.347_{a}^{*}$ & $19.146_{b}^{*}$ & $20.006_{a}^{*}$ & $19.286_{a}^{*}$ & $20.075_{a}^{*}$ \\
\hline Slope & $-0.224_{b}$ & $0.267_{a}$ & $-0.272_{a}$ & $0.182_{a}$ & $0.121_{a}$ \\
\hline \multicolumn{6}{|c|}{ American Affirmation } \\
\hline Intercept & $17.676_{a}^{*}$ & $15.294_{b}^{*}$ & $18.847_{a}^{*}$ & $14.835_{b}^{*}$ & $16.209_{b}^{*}$ \\
\hline Slope & $0.383_{a}^{\dagger}$ & $0.567_{a}^{*}$ & $0.297 \mathrm{a}$ & $0.637_{a}^{*}$ & $0.432_{a}^{*}$ \\
\hline \multicolumn{6}{|c|}{ American \& Ethnic } \\
\hline Intercept & $17.595_{a}^{*}$ & $15.380_{b}^{*}$ & $18.782_{a}^{*}$ & $14.894_{b}^{*}$ & $16.197_{b}^{*}$ \\
\hline Slope & $0.440_{a}^{*}$ & $0.532_{a}^{*}$ & $0.419_{\mathrm{a}}$ & $0.637_{a}^{*}$ & $0.352_{a}^{*}$ \\
\hline \multicolumn{6}{|l|}{ Caregiver } \\
\hline \multicolumn{6}{|c|}{ Ethnic Affirmation } \\
\hline Intercept & $20.868_{a}^{*}$ & $20.037_{a}^{*}$ & $20.988_{a}^{*}$ & $20.654_{a}^{*}$ & $21.318_{a}^{*}$ \\
\hline Slope & $-0.088_{a}$ & $-0.424_{a}^{*}$ & $0.108_{\mathrm{a}}$ & $-0.435_{b}^{*}$ & $-0.450_{b}^{*}$ \\
\hline \multicolumn{6}{|c|}{ American Affirmation } \\
\hline Intercept & $19.247_{a}^{*}$ & $16.133_{b}^{*}$ & $19.603_{a}^{*}$ & $15.799_{c}^{*}$ & $18.138_{b}^{*}$ \\
\hline Slope & $0.130_{\mathrm{a}}$ & $-0.175_{a}$ & $0.176_{a}^{*}$ & $-0.206_{a}$ & $-0.007_{a}$ \\
\hline \multicolumn{6}{|c|}{ Ethnic \& American } \\
\hline \multicolumn{6}{|c|}{ Ethnic Affirmation } \\
\hline Intercept & $20.845_{a}^{*}$ & $21.004_{a}^{*}$ & $21.053_{a}^{*}$ & $20.576_{a}^{*}$ & $21.229_{a}^{*}$ \\
\hline Slope & $-0.090_{a}$ & $-0.471_{b}^{*}$ & $0.049_{\mathrm{a}}$ & $-0.477_{b}^{*}$ & $-0.385_{b}^{*}$ \\
\hline \multicolumn{6}{|c|}{ American Affirmation } \\
\hline Intercept & $19.486_{a}^{*}$ & $16.204_{b}^{*}$ & $19.886_{a}^{*}$ & $15.758_{c}^{*}$ & $18.437_{b}^{*}$ \\
\hline Slope & $0.108_{a}$ & $-0.177_{a}$ & $0.040_{\mathrm{a}}$ & $-0.183_{a}$ & $0.069_{a}$ \\
\hline
\end{tabular}


Table 19

Model Fit for Concurrent Latent Growth Curve Models of Recently Immigrated Hispanic Adolescents and their Caregivers' Ethnic and American Affirmation

\begin{tabular}{|c|c|c|c|c|c|c|c|}
\hline & \multicolumn{4}{|c|}{ Model Fit } & \multicolumn{3}{|c|}{ Model Comparison } \\
\hline & $\chi^{2}(\mathrm{df})$ & CFI & RMSEA & SRMR & $-2 \mathrm{LL}(\mathrm{df})$ & $\Delta-2 \mathrm{LL}(\mathrm{df})$ & $p$-value \\
\hline \multicolumn{8}{|l|}{ Model 1: Ethnic Affirmation } \\
\hline Intercept Model & $61.187(31)^{*}$ & 0.882 & 0.060 & 0.134 & $10618.158(13)$ & & \\
\hline Caregiver Growth Only & $35.875(27)$ & 0.965 & 0.035 & 0.076 & $10588.330(17)$ & $29.826(4)$ & $<.001$ \\
\hline Dual Process & $26.348(22)$ & 0.983 & 0.027 & 0.069 & $10575.244(22)$ & $42.914(9)$ & $<.001$ \\
\hline \multicolumn{8}{|l|}{ Model 2: American Affirmation } \\
\hline Intercept Model & $61.524(31)^{*}$ & 0.953 & 0.061 & 0.066 & $11075.210(13)$ & & \\
\hline Adolescent Growth Only & $37.593(27)$ & 0.984 & 0.038 & 0.037 & $11042.358(17)$ & $32.852(4)$ & $<.001$ \\
\hline Dual Process & $15.328(22)$ & 1.000 & $<.001$ & 0.035 & $11015.428(22)$ & $59.782(9)$ & $<.001$ \\
\hline \multicolumn{8}{|l|}{ Model 3: Ethnic and American } \\
\hline \multicolumn{8}{|l|}{ Affirmation } \\
\hline Intercept Model & $314.832(122)^{*}$ & 0.822 & 0.077 & 0.093 & $21650.98(30)$ & & \\
\hline Intercept Model-Modified & $213.360(114)^{*}$ & 0.908 & 0.057 & 0.089 & $21533.542(38)$ & $117.436(8)$ & $<.001$ \\
\hline Dual Process & $152.828(101)^{*}$ & 0.952 & 0.044 & 0.056 & $21462.768(51)$ & $70.774(13)$ & $<.001$ \\
\hline Triple Process & $213.36(93)^{*}$ & 0.947 & 0.048 & 0.081 & $21457.404(59)$ & $76.138(21)^{1}$ & $<.001$ \\
\hline
\end{tabular}

Note: ${ }^{*} p<.050$

${ }^{1}$ This model was evaluated against the modified intercept model. 
Table 20

Model 1 - Concurrent Growth Parameters for Recently Immigrated Hispanic Adolescents' and their Caregivers' Ethnic Affirmation

\begin{tabular}{lcccc}
\hline & \multicolumn{2}{c}{ Adolescents } & \multicolumn{2}{c}{ Caregivers } \\
\hline Mean & Estimate & $p$-value & Estimate & $p$-value \\
$\quad$ Intercept & 19.791 & $<.001$ & 20.954 & $<.001$ \\
$\quad$ Slope & 0.024 & .877 & -0.248 & .044 \\
Variance & & & & \\
$\quad$ Intercept & 11.361 & .002 & 3.319 & .001 \\
$\quad$ Slope & 1.338 & .033 & 0.337 & .150 \\
& & & & .071 \\
Covariance $(r)$ & -1.393 & .327 & 0.607 & \\
& $(-.357)$ & & $(.574)$ & \\
\hline
\end{tabular}


Table 21

Model 1 - Relationship Among Adolescents' and their Caregivers' Ethnic Affirmation Growth Parameter

\begin{tabular}{lcccc}
\hline \multicolumn{5}{c}{ Adolescents } \\
\hline & \multicolumn{2}{c}{ Intercept } & \multicolumn{2}{c}{ Slope } \\
\hline Estimate & (Std.) & $p$-value & $\begin{array}{c}\text { Estimate } \\
(\text { Std. })\end{array}$ & $p$-value \\
\hline Caregivers & & & & \\
Intercept & 1.003 & .164 & -0.355 & .327 \\
Slope & $(.163)$ & & $(-.168)$ & \\
& -0.650 & .092 & 0.311 & .057 \\
\hline
\end{tabular}


Table 22

Model 2 - Concurrent Growth Parameters for Recently Immigrated Hispanic Adolescents' and their Caregivers' American Affirmation

\begin{tabular}{lcccc}
\hline & \multicolumn{2}{c}{ Adolescents } & \multicolumn{2}{c}{ Caregivers } \\
\hline Mean & Estimate & $p$-value & Estimate & $p$-value \\
$\quad$ Intercept & 16.645 & $<.001$ & 17.671 & $<.001$ \\
$\quad$ Slope & 0.465 & .006 & -.005 & .957 \\
Variance & & & & \\
$\quad$ Intercept & 20.728 & $<.001$ & 17.289 & $<.001$ \\
$\quad$ Slope & 1.849 & $<.001$ & 1.484 & $<.001$ \\
& & & & .093 \\
Covariance $(r)$ & -2.586 & .007 & -1.867 & \\
& $(-.418)$ & & $(-.369)$ & \\
\hline
\end{tabular}


Table 23

Model 2 - Relationship Among Adolescents' and their Caregivers' American Affirmation Growth Parameter

\begin{tabular}{ccccc}
\hline \multicolumn{5}{c}{ Adolescents } \\
\hline & \multicolumn{2}{c}{ Intercept } & \multicolumn{2}{c}{ Slope } \\
\hline Caregivers & $($ Std. $)$ & $p$-value & $\begin{array}{c}\text { Estimate } \\
(\text { Std. })\end{array}$ & $p$-value \\
Intercept & 7.344 & .001 & -1.501 & \\
Slope & $(.388)$ & & $(-.266)$ & .086 \\
& -0.709 & .218 & .173 & .001 \\
\hline
\end{tabular}


Table 24

Model 3 - Concurrent Growth Parameters for Recently Immigrated Hispanic Adolescents' and their Caregivers' American Affirmation

\begin{tabular}{lcccc}
\hline & \multicolumn{2}{c}{ Adolescents } & \multicolumn{2}{c}{ Caregivers } \\
\hline & Estimate & $p$-value & Estimate & $p$-value \\
\hline Ethnic Affirmation & & & & \\
Mean & & & & \\
$\quad$ Intercept & 19.779 & $<.001$ & 20.615 & $<.001$ \\
Slope & 0.038 & .808 & -- & -- \\
Variance & & & & \\
Intercept & 11.042 & .002 & 5.392 & $<.001$ \\
Slope & 1.338 & .021 & -- & -- \\
Covariance $(r)$ & -1.309 & .341 & -- & -- \\
& $(-.341)$ & & & \\
American Affirmation & & & & \\
Mean & & & & \\
Intercept & 16.648 & $<.001$ & 17.599 & $<.001$ \\
Slope & 0.465 & .004 & 0.052 & .622 \\
Variance & & & & \\
Intercept & 21.005 & $<.001$ & 16.722 & $<.001$ \\
Slope & 1.877 & $<.001$ & 1.216 & .002 \\
Covariance $(r)$ & -2.564 & .006 & -1.577 & .115 \\
& $(-.408)$ & & $(-.350)$ & \\
\hline
\end{tabular}


Table 25

Model 3 - Relationship Between Cultural Affirmation Within Caregivers and Adolescents

\begin{tabular}{llcccc}
\hline \multicolumn{2}{l}{ Ethnic Affirmation } & \multicolumn{3}{c}{ American Affirmation } \\
\hline & & $\begin{array}{c}\text { Estimate } \\
(\mathrm{Std})\end{array}$ & $p$-Value & $\begin{array}{c}\text { Estimate } \\
(\mathrm{Std})\end{array}$ & $p$-Value \\
\hline \multirow{3}{*}{ Adolescents } & Slope & $\begin{array}{c}0.476 \\
(.301)\end{array}$ & .202 & $\begin{array}{c}-0.979 \\
(-.185)\end{array}$ & .218 \\
& Intercept & $\begin{array}{l}0.010 \\
(.002)\end{array}$ & .991 & $\begin{array}{l}4.197 \\
(.276)\end{array}$ & .050 \\
Caregivers & Intercept & $\begin{array}{l}0.054 \\
(.021)\end{array}$ & .854 & $\begin{array}{l}2.409 \\
(.254)\end{array}$ & .001 \\
& & & & & \\
\hline
\end{tabular}


Table 26

Model 3 - Relationship Between Cultural Affirmation Across Caregivers and Adolescents Adolescents' Cultural Affirmation

\begin{tabular}{|c|c|c|c|c|c|c|c|c|c|}
\hline & & \multicolumn{4}{|c|}{ Ethnic Affirmation } & \multicolumn{4}{|c|}{ American Affirmation } \\
\hline & & \multicolumn{2}{|c|}{ Slope } & \multicolumn{2}{|c|}{ Intercept } & \multicolumn{2}{|c|}{ Slope } & \multicolumn{2}{|c|}{ Intercept } \\
\hline Caregivers' Cultural & firmation & $\begin{array}{c}\text { Estimate } \\
\text { (Std) }\end{array}$ & $p$-Value & $\begin{array}{l}\text { Estimate } \\
(\mathrm{Std})\end{array}$ & $p$-Value & $\begin{array}{c}\text { Estimate } \\
\text { (Std) }\end{array}$ & $p$-Value & $\begin{array}{c}\text { Estimate } \\
(\mathrm{Std})\end{array}$ & $p$-Value \\
\hline \multirow{2}{*}{ American Affirmation } & Slope & $\begin{array}{c}.450 \\
(.353)\end{array}$ & .023 & $\begin{array}{l}-1.020 \\
(-.278)\end{array}$ & .080 & $\begin{array}{c}.207 \\
(.137)\end{array}$ & .340 & $\begin{array}{l}-0.823 \\
(-.163)\end{array}$ & .080 \\
\hline & Intercept & $\begin{array}{l}-1.105 \\
(-.234)\end{array}$ & .078 & $\begin{array}{l}2.459 \\
(.181)\end{array}$ & .056 & $\begin{array}{l}-1.538 \\
(-.274)\end{array}$ & .073 & $\begin{array}{l}7.521 \\
(.401)\end{array}$ & .001 \\
\hline Ethnic Affirmation & Intercept & $\begin{array}{l}0.057 \\
(.021)\end{array}$ & .849 & $\begin{array}{l}0.175 \\
(.023)\end{array}$ & .697 & $\begin{array}{l}-0.796 \\
(-.250)\end{array}$ & .039 & $\begin{array}{l}1.902 \\
(.179)\end{array}$ & .013 \\
\hline
\end{tabular}


Table 27

Model 3 - Invariant Paths Across Site

\begin{tabular}{|c|c|c|c|c|c|c|}
\hline \multirow{2}{*}{ Growth Parameter } & \multirow{2}{*}{$\Delta-2 \operatorname{LL}(1)$} & \multirow{2}{*}{$p$-Value } & \multicolumn{2}{|c|}{ Miami } & \multicolumn{2}{|c|}{ Los Angeles } \\
\hline & & & Estimate & $p$-Value & Estimate & $p$-Value \\
\hline \multicolumn{7}{|l|}{ Means } \\
\hline $\begin{array}{l}\text { Caregivers' American } \\
\text { Affirmation Intercept }\end{array}$ & 31.836 & $<.001$ & 19.296 & $<.001$ & 15.901 & $<.001$ \\
\hline $\begin{array}{l}\text { Adolescents' American } \\
\text { Affirmation Intercept }\end{array}$ & 13.014 & $<.001$ & 17.790 & $<.001$ & 15.527 & $<.001$ \\
\hline $\begin{array}{l}\text { Adolescents' Ethnic } \\
\text { Affirmation Intercept }\end{array}$ & 7.140 & .007 & 20.529 & $<.001$ & 19.047 & $<.001$ \\
\hline $\begin{array}{l}\text { Adolescents' Ethnic } \\
\text { Affirmation Slope }\end{array}$ & 5.724 & .016 & -0.247 & .163 & 0.309 & .099 \\
\hline $\begin{array}{l}\text { Variance } \\
\text { Adolescents' American } \\
\text { Affirmation Intercept }\end{array}$ & 4.106 & .043 & 18.202 & $<.001$ & 21.951 & $<.001$ \\
\hline $\begin{array}{l}\text { Adolescents' Ethnic } \\
\text { Affirmation Intercept }\end{array}$ & 3.170 & .075 & 1.393 & .023 & 12.884 & $<.001$ \\
\hline
\end{tabular}


VITA

\section{ALAN MECA}

$2006-2010$

B.A., Psychology with Honors

Florida International University

Miami, FL.

$2010-2012$

M.S., Psychology

Florida International University

Miami, FL.

$2012-2014$

Doctoral Candidate, Psychology

Florida International University, Miami, FL.

\section{PUBLICATIONS AND PRESENTATIONS}

Meca, A., Quintana, S., Eichas, K., Maximin, B. M., Ritchie, R. A., Madrazo, V. L., Harari, G. M., \& Kurtines, W. M. (in press). The Miami Adult Development Project: An identity intervention for emerging adults. Identity: An International Journal of Theory of Research.

Eichas, K., Meca, A., Montgomery, M., \& Kurtines, W.M. (in press). Identity and Positive Youth Development: Advances in Developmental Intervention Science. In McLean, K. \& Syed, M. (Eds.), The Oxford Handbook of Identity Development, New York: Oxford University Press, Inc.

Meca, A., Eichas, K., Quintana, S., Maximin, B., Madrazo, V., Ritchie, R., \& Kurtines, W. M.(2014, March). Preliminary Evaluation of the Adult Development Project: An Identity Intervention for Emerging Adults. Will be presented at the 15th annual meeting of the Society for Research in Adolescents (SRA), Austin, TX.

Crocetti, E., Meeus, W. H. J., Ritchie, R. A., Meca, A., \& Schwartz, S. J. (2014).

Adolescent identity: The key to unraveling associations between family relationships and problem behaviors? In L. M. Scheier \& W. B. Hansen (Eds.), Parenting and teen drug use. New York: Oxford University Press.

Dezutter, J., Waterman, A. S., Schwartz, S. J., Luyckx, K., Beyers, W., Meca, A., Kim, S. Y., Whitbourne, S. K., Zamboanga, B. L., Lee, R. M., Hardy, S. A., Forthun, L. F., Ritchie, R. A., Weisskirch, R. S., Brown, E. J., \& Caraway, S. J. (2014). Meaning in life in emerging adulthood: A person-oriented approach. Journal of Personality, 82(1), 57-68.

Schwartz, S. J., Zamboanga, B. L., Luyckx, K., Meca, A., \& Ritchie, R. A. (2013). Identity in emerging adulthood: Reviewing the field and looking forward. Emerging Adulthood, 1(2), 96-113. 
Ritchie, R. A., Meca, A., Madrazo, V. L., Schwartz, S. J., Hardy, S. A., Zamboanga, B. L., Weisskirch, R. S., Kim, S. Y., Whitbourne, S. K., Ham, L. S., \& Lee, R. M. (2013). Identity dimensions and related processes in emerging adulthood: Helpful or harmful? Journal of Clinical Psychology, 69(4), 415-432.

Meca, A. (2012, February). Positive Youth Development: Control and Responsibility as a Mediator of Change. Presentation made at the 2nd Annual Graduate Student Scholarly Forum at Florida International University, Miami, FL.

Rinaldi, R. L., Meca, A., Eichas, K., Kurtines, W. K., Albrecht, R. E., \& Goodletty, S. (2012). The development of a qualitative extension for the Personally Expressive Activities Questionnaire (PEAQ-QE): A construct validation study. Identity: An International Journal of Theory and Research, 12(4), 320-344.

Schwartz, S. J., Zamboanga, B. L., Meca, A., \& Ritchie, R. A. (2012). Identity around the world: An overview. New Directions for Child and Adolescent Development, 1(2), 96113.

Meca, A., Ritchie, R., Eichas, K., Albrecht, R., Rinaldi, R., Goodletty, S., \& Kurtines, W. M. (2011, February). The Relationship between Identity Distress and Identity Conflict Resolution in the Miami Youth Development Project. Poster presented at the 18th annual meeting of the Society for Research on Identity Formation (SRIF), Daytona Beach, FL.

Meca, A., Rinaldi, R., Eichas, K., Kasian, E., \& Kurtines, W. (2010, March). A Longitudinal Investigation of the Effects of Participation in the Changing Lives Program on Control and Responsibility Over Life Change Goals. Poster presented at the 17th annual meeting of the Society for Research on Identity Formation (SRIF), Philadelphia, PA.

Meca, A., Eichas, K., Rinaldi, R., Ritchie, R., Garcia, A., Madrazo, V., Kkasian, E., O’Dowd, B., Quintana, S., \& Kurtines, W. (2010, March). Positive Youth Development: Promoting Control and Responsibility for Life Challenges. Poster presented at the 17th annual meeting of the Society for Research on Identity Formation (SRIF), Philadelphia, PA. 